University of Louisville

ThinkIR: The University of Louisville's Institutional Repository

Electronic Theses and Dissertations

8-2010

\title{
Synthesis and characterization of ceria nanomaterials.
}

Nitzia Cheong $\mathrm{Ng}$

University of Louisville

Follow this and additional works at: https://ir.library.louisville.edu/etd

\section{Recommended Citation}

$\mathrm{Ng}$, Nitzia Cheong, "Synthesis and characterization of ceria nanomaterials." (2010). Electronic Theses and Dissertations. Paper 1054.

https://doi.org/10.18297/etd/1054

This Master's Thesis is brought to you for free and open access by ThinkIR: The University of Louisville's Institutional Repository. It has been accepted for inclusion in Electronic Theses and Dissertations by an authorized administrator of ThinkIR: The University of Louisville's Institutional Repository. This title appears here courtesy of the author, who has retained all other copyrights. For more information, please contact thinkir@louisville.edu. 


\title{
SYNTHESIS AND CHARACTERIZATION OF CERIA NANOMATERIALS
}

\author{
By \\ Nitzia Cheong $\mathrm{Ng}$ \\ B.S., University of Louisville, May 2009
}

\begin{abstract}
A Thesis
Submitted to the Faculty of the

University of Louisville

J. B. Speed School of Engineering

as Partial Fulfillment of the Requirements

for the Professional Degree

MASTER OF ENGINEERING

Department of Chemical Engineering
\end{abstract}

August 2010 


\title{
SYNTHESIS AND CHARACTERIZATION OF CERIA NANOMATERIALS
}

\author{
Submitted by: \\ Nitzia Cheong Ng \\ A Thesis Approved On \\ Date
}

by the Following Reading and Examination Committee:

Dr. Xiao-An Fu, Thesis Advisor

Dr. James C. Watters

Dr. Gamini Sumanasekera 


\section{ACKNOWLEDGEMENTS}

The author is grateful for the support, knowledge, and patience of Dr. Xiao-An Fu, Thesis Advisor.

The author thanks Jacek Jasinski and Rodica McCoy for their help in characterization.

The author appreciates Dr. James Watters for participating in the defense committee.

The author appreciates Dr. Gamini Sumanasekera for participating in the defense committee.

The author also thanks Surender Venna, Chinmay Deshmane and Dr. Moises Carreon for their help and knowledge in BET and Dr. Kyung Kang and Dr. Martin O'Toole for the centrifugation instrument.

The author is gratified to Dr. Michael Tseng from the Medical School for his knowledge and support. 


\begin{abstract}
Cerium dioxide or ceria, $\mathrm{CeO}_{2}$, has been widely used in industry as catalyst for automotive exhaust controls, chemical mechanical polishing (CMP) slurries, and high temperature fuel cells because of its unique metal oxide properties. This well-known rare metal oxide has high thermal stability, electrical conductivity and chemical diffusivity. Proper synthesis method requires knowledge of reaction temperature, concentration, and time effects on the synthesis. In this work, ceria nanomaterials were prepared via the hydrothermal method using a Teflon autoclave. Cerium nitrate solution was used as the source and three different precursors: $\mathrm{NaOH}, \mathrm{H}_{2} \mathrm{O}_{2}$, and $\mathrm{NH}_{4} \mathrm{OH}$ were used as the oxidizing agents. $\mathrm{CeO}_{2}$ nanoplates, nanocubes and nanorods were produced and studied using transmission electron microscopy (TEM), BET specific surface area, X-ray diffraction (XRD) and X-ray photoelectron spectroscopy (XPS).
\end{abstract}

Through characterization, $\mathrm{CeO}_{2}$ nanomaterials showed the presence of mixed valence states $\left(\mathrm{Ce}^{3+}\right.$ and $\left.\mathrm{Ce}^{4+}\right)$ through XPS spectra. Deconvolution was performed to investigate the ratio of $\mathrm{Ce}^{3+} / \mathrm{Ce}^{4+}$ concentration in the synthesized $\mathrm{CeO}_{2}$ nanostructures. Nanocubes showed a higher $\mathrm{Ce}^{3+}$ concentration. $\mathrm{CeO}_{2}$ nanomaterials were found to be mesoporous. Nanoplates synthesized with $\mathrm{H}_{2} \mathrm{O}_{2}$, and $\mathrm{NH}_{4} \mathrm{OH}$ were found with surface areas of $95.11 \mathrm{~m}^{2} / \mathrm{g}$ and $62.07 \mathrm{~m}^{2} / \mathrm{g}$, respectively. Nanorods and nanocubes showed surface areas of $16.77 \mathrm{~m}^{2} / \mathrm{g}$ and $16.55 \mathrm{~m}^{2} / \mathrm{g}$, respectively. The prepared ceria nanoplates, nanocubes and nanorods had crystallite size in the range of 5-25 $\mathrm{nm}$ and pore size range of 7-15 nm. XRD spectra confirmed that the peaks were indexed to the cubic phase of 
$\mathrm{CeO}_{2}$ with fluorite structure and with an average lattice parameter, 5.407 $\AA$. Higher $\mathrm{Ce}^{3+}$ concentration and exposed surface of crystalline planes suggest that nanorods are better catalyst for CO oxidation and oxygen storage capacity (OSC). 
TABLE OF CONTENTS

APPROVAL PAGE $\quad$ ii

ACKNOWLEDGEMENTS

ABSTRACT $\quad$ iv

TABLE OF CONTENTS vi

NOMENCLATURE viii

LIST OF TABLES $\quad$ X

LIST OF FIGURES $\quad$ xi

I. INTRODUCTION

II. BACKGROUND 3

A. Cerium dioxide or Ceria 3

B. Hydrogen Peroxide $\quad 6$

C. Ammonium Hydroxide $\quad 8$

D. Sodium Hydroxide 9

III. EXPERIMENTATION 13

A. Plan of Experimentation $\quad 13$

B. Materials 14

C. Procedure 15

D. Characterization of the Prepared $\mathrm{CeO}_{2} \quad 17$

$\begin{array}{ll}\text { E. Equipment } & 17\end{array}$

IV. RESULTS AND DISCUSSION 20

A. Shape Selective and Mechanism 20

B. TEM analysis $\quad 21$

$\begin{array}{ll}\text { C. BET specific surface area analysis } & 26\end{array}$

D. XPS analysis 31

E. XRD analysis $\quad 37$

$\begin{array}{ll}\text { V. CONCLUSIONS } & 48\end{array}$

VI. RECOMMENDATIONS 49

APPENDIX 1: RAW DATA 50 
APPENDIX 2: DECONVOLUTED XPS SPECTRUM

APPENDIX 3: SAMPLE CALCULATION

REFERENCES

VITA 


\section{NOMENCLATURE}

\begin{tabular}{|c|c|c|}
\hline $\mathrm{NH}_{4} \mathrm{OH}$ & $=$ & Ammonium hydroxide \\
\hline $\mathrm{BE}$ & $=$ & Binding energy \\
\hline BJH & $=$ & Barret-Joyner-Halenda \\
\hline BET & $=$ & Brunaure Emmett Teller \\
\hline $\mathrm{CO}$ & $=$ & Carbon dioxide oxidation \\
\hline $\mathrm{CeO}_{2}$ & $=$ & Ceria or cerium oxide \\
\hline $\mathrm{Ce}\left(\mathrm{NO}_{3}\right)_{3}$ & $=$ & Cerium nitrate \\
\hline $\mathrm{C}_{\mathrm{NaOH}}$ & $=$ & Concentration of sodium hydroxide \\
\hline $\mathrm{d}_{\mathrm{hkl}}$ & $=$ & Crystalline face space at the crystallite indices \\
\hline $\mathrm{D}_{\mathrm{hkl}}$ & $=$ & Crystallite size at the crystallite indices \\
\hline $\mathrm{h}, \mathrm{k}, \mathrm{l}$ & $=$ & Crystallite size indices \\
\hline TG-DTA & $=$ & Differential thermal analysis and thermo-gravimetric analysis \\
\hline$\theta$ & $=$ & Diffraction angle \\
\hline FCC & $=$ & Face-centered-cubic \\
\hline FFT & $=$ & Fast Fourier transform \\
\hline FT-IR & $=$ & Fourier transform infrared \\
\hline $\mathrm{H}_{2} \mathrm{O}_{2}$ & $=$ & Hydrogen peroxide \\
\hline HRTEM & $=$ & High-resolution transmission electron microscopy \\
\hline $\mathrm{n}$ & $=$ & Integer number, usually 1 \\
\hline $\mathrm{A}_{\mathrm{i}}$ & $=$ & Integrated area of peak " $i . "$ \\
\hline$a$ & $=$ & Lattice parameter \\
\hline $\mathrm{B}_{\mathrm{hkl}}$ & $=$ & Measured half-width \\
\hline
\end{tabular}




$\begin{array}{lll}\mathrm{OSC} & = & \text { Oxygen storage capacity } \\ \mathrm{SAED} & = & \text { Selected area electron diffraction } \\ \mathrm{NaOH} & = & \text { Sodium hydroxide } \\ \mathrm{H}_{2}-\mathrm{TPR} & = & \text { Temperature-programmed reduction of hydrogen } \\ \mathrm{TEM} & = & \text { Transmission electron microsope } \\ \lambda & = & \text { Wavelength of the incident X-rays } \\ \mathrm{XPS} & = & \text { X-ray photoelectron spectroscopy } \\ \mathrm{XRD} & = & \text { X-ray diffraction }\end{array}$




\section{LIST OF TABLES}

TABLE II-I CRYSTAL STRUCTURES, SHAPES, AND SIZES OF SEVERAL $\mathrm{CEO}_{2}$ SAMPLES

TABLE III-I SYNTHESIS OF CERIA NANOPLATE WITH HYDROGEN

PEROXIDE PRECURSOR

TABLE III-II SYNTHESIS OF CERIA NANOPLATE WITH

AMMONIUM HYDROXIDE PRECURSOR

TABLE III-III SYNTHESIS OF CERIA NANOROD $\left(\mathrm{C}_{\mathrm{NaOH}}=9 \mathrm{M}\right) \mathrm{WITH}$ SODIUM HYDROXIDE PRECURSOR

TABLE III-IV SYNTHESIS OF CERIA NANOCUBE $\left(\mathrm{C}_{\mathrm{NaOH}}=6 \mathrm{M}\right)$ WITH

TABLE IV-I BET SPECIFIC SURFACE AREA OF DIFFERENT CEO SHAPES $_{2}$ SH $^{2}$

TABLE IV-II PORE SIZE AND PORE VOLUME OF THE

TABLE IV-III XPS BINDING ENERGIES OF INDIVIDUAL PEAKS OF THE CE (3D) SPECTRUM FOR DIFFERENT $\mathrm{CeO}_{2}$ SHAPES

TABLE IV-VI INTEGRATED AREAS OF INDIVIDUAL PEAKS

TABLE IV-V CONCENTRATION OF $\mathrm{Ce}^{3+}$ FOR DIFFERENT SHAPES OF

TABLE IV-VIII BET SPECIFIC SURFACE AREA AND CYRSTALLITE SIZE 44 OF DIFFERENT $\mathrm{CeO}_{2}$ SHAPES

TABLE A1 - 1 EXPERIMENTAL DATA FOR CERIA NANOPLATES BY $\mathrm{H}_{2} \mathrm{O}_{2} \quad 50$

TABLE A1 - 2 EXPERIMENTAL DATA FOR CERIA NANOPLATES BY 50 $\mathrm{NH}_{4} \mathrm{OH}$ NANOCUBES 


\section{LIST OF FIGURES}

FIGURE 2.1 - Number of publications on $\mathrm{CeO} 2$-based materials in catalysis:

$(\boldsymbol{\square})$ open literature, $(\bullet)$ patents (Trovarelli, 1999).

FIGURE 2.2- Number of scientific articles (not patents) published in 1997 on ceria and related materials in different areas of catalysis: 1 (TWC), 2 (flue gas treatment), 3 (oxidation), 4 (treatment of diesel exhaust), 5 (catalyst characterization), 6 (electrocatalysis), 7 (hydrogenation), 8 (others) (Trovarelli, 1999).

FIGURE 2.3 - a) TEM image of $\mathrm{CeO}_{2}$ nanowires, b) HRTEM image of individual 6 $\mathrm{CeO}_{2}$ nanowire (Tang,2005).

FIGURE 2.4 - HRTEM image of $\mathrm{CeO}_{2}$ nanowires (Han, 2005).

FIGURE 2.5 - TEM images of the $\mathrm{CeO} 2$ nanoparticles (a and b), nanorods (c and d) and nanowires (e and f) (Tana, 2009).

FIGURE 2.6 - TEM images of the products obtained by the utilization of varied cerium source: (A) $\left(\mathrm{NH}_{4}\right)_{2} \mathrm{Ce}\left(\mathrm{NO}_{3}\right)_{6}$; (B) $\mathrm{CeCl}_{3} \cdot 7 \mathrm{H}_{2} \mathrm{O}$ (Yang, 2009).

FIGURE 3.1 - Experimental flow chart of synthesis of $\mathrm{CeO}_{2}$ with $\mathrm{H}_{2} \mathrm{O}_{2}$.

FIGURE 3.2 - Vulcan Furnace

FIGURE 3.3 - Hydrothermal Autoclave

FIGURE 3.4 - Transmission Electron Microscope

FIGURE 3.5 - X-ray Photoelectron Spectroscopy

FIGURE 3.6 - X-ray Diffraction

FIGURE 4.1 - TEM and SAED images of $\mathrm{CeO}_{2}$ nanoplates at $220^{\circ} \mathrm{C}$ by $\mathrm{H}_{2} \mathrm{O}_{2}$.

FIGURE 4.2 - TEM, HRTEM and SAED images of $\mathrm{CeO}_{2}$ nanoplatesby $\mathrm{H}_{2} \mathrm{O}_{2}$

FIGURE 4.4- TEM and HRTEM images of $\mathrm{CeO}_{2}$ nanorods with a 
FIGURE 4.5 - TEM and HRTEM images of $\mathrm{CeO}_{2}$ nanocubes with a $\mathrm{C}_{\mathrm{NaOH}}=9 \mathrm{M}$ at $180^{\circ} \mathrm{C}$.

FIGURE 4.6 - TEM and HTERM images of $\mathrm{CeO}_{2}$ nanocubes with a

$\mathrm{C}_{\mathrm{NaOH}}=6 \mathrm{M}$ at $180^{\circ} \mathrm{C}$.

FIGURE 4.7 - Nitrogen adsorption-desorption isotherm pattern as synthesized of $\mathrm{CeO}_{2}$ nanoplates by $\mathrm{H}_{2} \mathrm{O}_{2}$ (a), nanoplates by $\mathrm{NH}_{4} \mathrm{OH}$ (b), nanocubes (c), and nanorods (d), (• adsorption, $\square$ desorption).

FIGURE 4.8 - Plot of the pore volume vs. pore diameter for $\mathrm{CeO}_{2}$ nanoplates by $\mathrm{H}_{2} \mathrm{O}_{2}$, nanoplates by $\mathrm{NH}_{4} \mathrm{OH}$, nanocubes, and nanorods in $\mathrm{BJH}$ adsorption (a) and desorption (b).

FIGURE 4.9 - XPS survey spectra of $\mathrm{CeO}_{2}$ nanoplates by $\mathrm{H}_{2} \mathrm{O}_{2}$ and $\mathrm{NH}_{4} \mathrm{OH}$, nanocubes, and nanorods.

FIGURE 4.10 - XPS spectrum of the six peaks of Ce $3 \mathrm{~d}$ for nanoplates by $\mathrm{H}_{2} \mathrm{O}_{2}$ (a), nanorods (b), nanoplates by $\mathrm{NH}_{4} \mathrm{OH}$ (c), and nanocubes (d).

FIGURE 4.11 - XPS spectrum of the synthesized ceria nanoplates by $\mathrm{H}_{2} \mathrm{O}_{2}$ with the mixed valence state.

FIGURE 4.12 - Deconvoluted XPS Ce (3d) spectrum of ceria nanocubes.

FIGURE 4.13 - XRD of $\mathrm{CeO}_{2}$ nanorods (a), nanoplates by $\mathrm{NH}_{4} \mathrm{OH}$ (b), nanocubes (c), and nanoplates by $\mathrm{H}_{2} \mathrm{O}_{2}(\mathrm{~d})$.

FIGURE 4.14 - XRD patterns of $\mathrm{CeO}_{2}$ nanoplates by $\mathrm{H}_{2} \mathrm{O}_{2}$ calcined at $100^{\circ} \mathrm{C}$ (a) and $400^{\circ} \mathrm{C}$ (b).

FIGURE 4.15 - XRD patterns of $\mathrm{CeO}_{2}$ nanoplates by $\mathrm{NH}_{4} \mathrm{OH}$ calcined at $100^{\circ} \mathrm{C}(\mathrm{a})$ and $600^{\circ} \mathrm{C}(\mathrm{b})$.

FIGURE 4.16 - XRD patterns of $\mathrm{CeO}_{2}$ nanocubes calcined at $100^{\circ} \mathrm{C}$ (a) and 40 $400^{\circ} \mathrm{C}(\mathrm{b})$.

FIGURE 4.17 - XRD patterns of $\mathrm{CeO}_{2}$ nanorods calcined at $100^{\circ} \mathrm{C}$ (a) and $600^{\circ} \mathrm{C}(\mathrm{b})$.

Figure 4.18 - Crystallite size as a function of calcination temperatures for 43 nanoplates by $\mathrm{H}_{2} \mathrm{O}_{2}$ (a), nanocubes (b), nanoplates by $\mathrm{NH}_{4} \mathrm{OH}$ (c), and nanorods (d) 
FIGURE 4.19 - Concentration of $\mathrm{Ce}^{3+}$ as a function of lattice parameter for $\mathrm{CeO}_{2}$ nanocubes (a), nanorods (b), nanoplates by $\mathrm{NH}_{4} \mathrm{OH}$ (c), and nanoplates by $\mathrm{H}_{2} \mathrm{O}_{2}$.

FIGURE A2-1 - $\mathrm{CeO}_{2}$ nanoplates by $\mathrm{H}_{2} \mathrm{O}_{2}$ deconvoluted XPS spectrum

FIGURE A2-2 - $\mathrm{CeO}_{2}$ nanoplates by $\mathrm{NH}_{4} \mathrm{OH}$ deconvoluted XPS spectrum

FIGURE A2-3 - $\mathrm{CeO}_{2}$ nanorods deconvoluted XPS spectrum

FIGURE A2-4 - $\mathrm{CeO}_{2}$ nanocubes deconvoluted XPS spectrum 


\section{INTRODUCTION}

Studies in the morphologies and sizes of cerium dioxide or ceria have attracted the interests of researchers in recent years due to ceria's unique properties that lead to a wide range of applications. Some examples of ceria applications include fast ion conductors, UV blockers, catalyst (Tang, 2005), gas and bio-sensors, cosmetic material, fuel cells, and slurry for chemical mechanical planarization (Seok, 2004). Several synthetic approaches such as electrochemical deposition, microwave-hydrothermal, solvothermal, hydrothermal and others have been developed to form ceria nanomaterials. Of these methods, the hydrothermal method (Mai, 2005) has been considered as one of the most effective and economical routes, because of its single step low-temperature synthesis, superior composition and morphological control, and powder reactivity.

To explore the morphology and properties of ceria, proper synthesis and precursors are required to obtain specific ceria nanostructures. The present work investigates the different shapes of ceria formed by using three different precursors: hydrogen peroxide, ammonium hydroxide, and sodium hydroxide through hydrothermal 
method for 24 hours. The different precursors and reaction parameters such as time, temperature, and concentration influence the size and shape of ceria, forming nanoplates, nanorods, and nanocubes.

In the current project, ceria is synthesized from cerium nitrate and three different precursors mentioned earlier. Once the synthesis was done, the samples were centrifuged, purified by washing several times, and dried. The dried precipitates show the following colors: white for the synthesis with $\mathrm{H}_{2} \mathrm{O}_{2}$, light yellow with $\mathrm{NaOH}$, and medium yellow with $\mathrm{NH}_{4} \mathrm{OH}$. Characterization is performed to understand the morphologies and properties of ceria formed using each precursor. In this work, the samples have been characterized with TEM, X-Ray diffraction, BET specific surface area, and XPS to understand their properties. 


\section{BACKGROUND}

\section{A. Cerium Oxide or Ceria}

Cerium with an atomic number 58 has brought new discoveries in terms of nanomaterials. Cerium is the most abundant of the rare earth elements. As a well-known functional rare earth material, ceria has wide applications in fields such as catalysis, electrochemistry, and optics due to its unique properties (Powell, 1988). In addition, cerium dioxide has been extensively studied and employed in various applications including fast ion conductors, oxygen storage capacitors, catalysts, UV blockers, polishing materials (Tang, 2005), and gas sensor (Yahiro, 1988).

Preparation of ceria powders is by no means a new research subject; however, practical methods are still needed for synthesizing high-quality ultrafine powders with required characteristics in terms of their size, uniformity, morphology, specific surface area, and crystallinity. Numerous techniques have been proposed to synthesize nano-sized $\mathrm{CeO}_{2}$ particles with promising control of properties (Lee, 2004; Zhou, 1995). 
Cerium dioxide has been used in many catalysis applications. Trovarelli (1996 and 2002) reported that $\mathrm{CeO}_{2}$ has been extensively studied and applied in heterogeneous catalysis based on its ability to release and uptake oxygen under operation conditions while preserving the fluorite crystal structure. It has an important role in two of the most important commercial catalytic processes in terms of economic relevance and tonnage: three-way catalysis (TWC) and fluid catalytic cracking (FCC). The importance of $\mathrm{CeO}_{2}$ in catalysis is also exhibited by the number of industrial and academic publications that have appeared on the topic over the last several years as shown in Figure 2.1. In 1997, the number of published ceria topics reveals that approximately $50 \%$ is based on the treatment of emissions from mobile and stationary sources, and that the majority of articles deal with the application of ceria in TWCs and novel technologies for the treatment of emissions from diesel and spark-ignited internal combustion engines as shown in Figure 2.2 (Trovarelli, 1999).

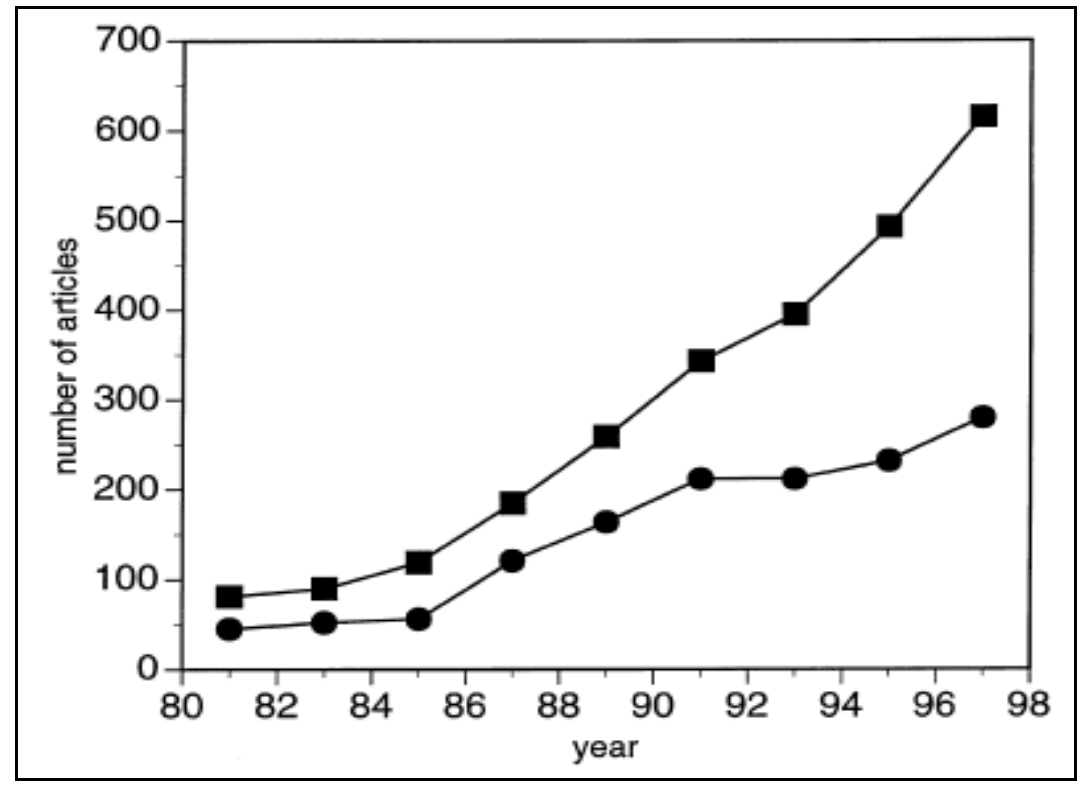

FIGURE 2.1 - Number of publications on $\mathrm{CeO} 2$-based materials in catalysis: ( $\mathbf{(})$ open literature, $(\bullet)$ patents (Trovarelli, 1999). 
This indicates that there are several rising applications or processes for which cerium oxide is currently being actively investigated. Trovarelli mentioned that ceria acts as an oxygen buffer by absorbing and releasing oxygen through a fast $\mathrm{Ce}^{3+} / \mathrm{Ce}^{4+}$ cycle in the TWCs, and simultaneously encouraging the oxidation of $\mathrm{CO}$ to $\mathrm{CO}_{2}$ and involving the participation of the lattice oxygen species.

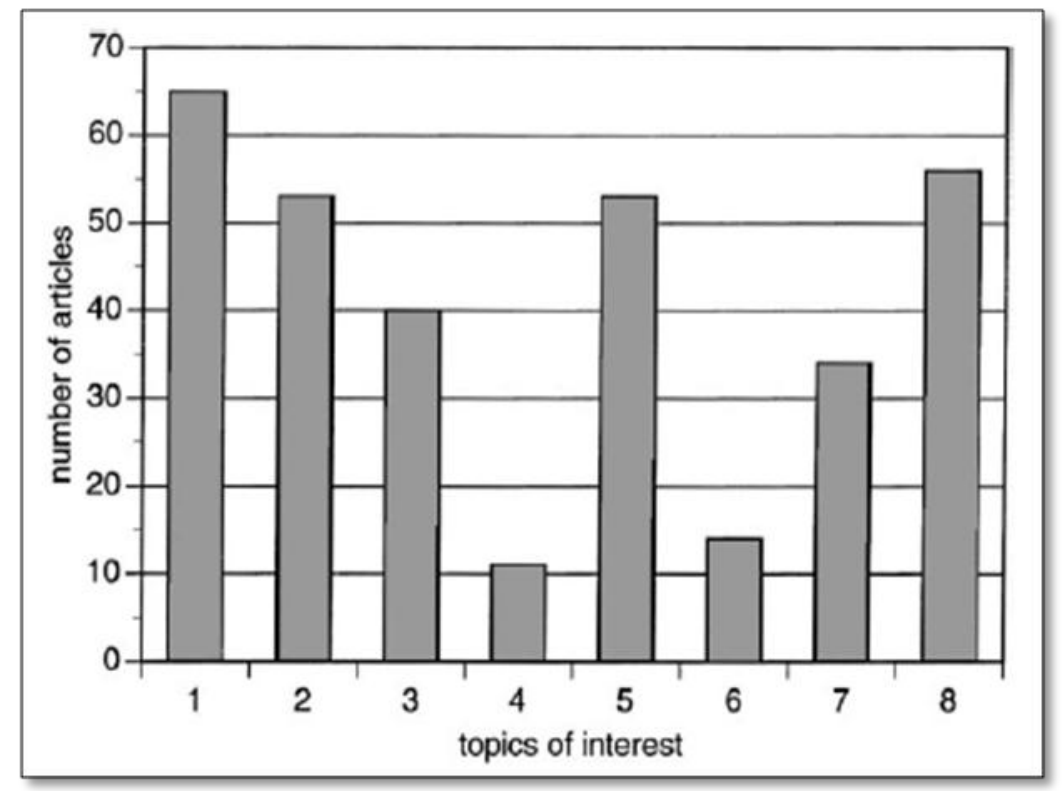

FIGURE 2.2- Number of scientific articles (not patents) published in 1997 on ceria and related materials in different areas of catalysis: 1 (TWC), 2 (flue gas treatment), 3 (oxidation), 4 (treatment of diesel exhaust), 5 (catalyst characterization), 6 (electrocatalysis), 7 (hydrogenation), 8 (others) (Trovarelli, 1999).

Additionally, the unique redox property is usually described by the oxygen storage capacity (OSC), which is largely dependent on the size of ceria particles (Carrettin, 2004; Trovarelli, 1996 and 2002). The morphology also contributes to the redox feature of ceria depending on the exposed ceria crystalline planes (Mai; 2005; Zhou, 2005). Lastly, it was found that $\mathrm{CeO}_{2}$ has potential uses (Trovarelli, 1996) as diesel 
fuels catalyst for a more complete combustion to abate soot formation, and for higherenergy efficiency and energy density of solid-oxide fuel-cell.

\section{B. Hydrogen Peroxide}

The preparation of ceria using hydrogen peroxide as an oxidizer has been a facile method through hydrothermal synthesis. Several methods have been used to synthesize ceria nanowires by cerium nitrate $\left(\mathrm{Ce}\left(\mathrm{NO}_{3}\right)_{3}\right)$ with $\mathrm{H}_{2} \mathrm{O}_{2}$. For example, Figure 2.3 shows a TEM image of $\mathrm{CeO}_{2}$ nanowires by hydrothermal method. The obtained $\mathrm{CeO}_{2}$ nanowires are single crystalline and uniform with diameters of 20-70 nm and lengths up to $40 \mu \mathrm{m}$ (Tang, 2005).

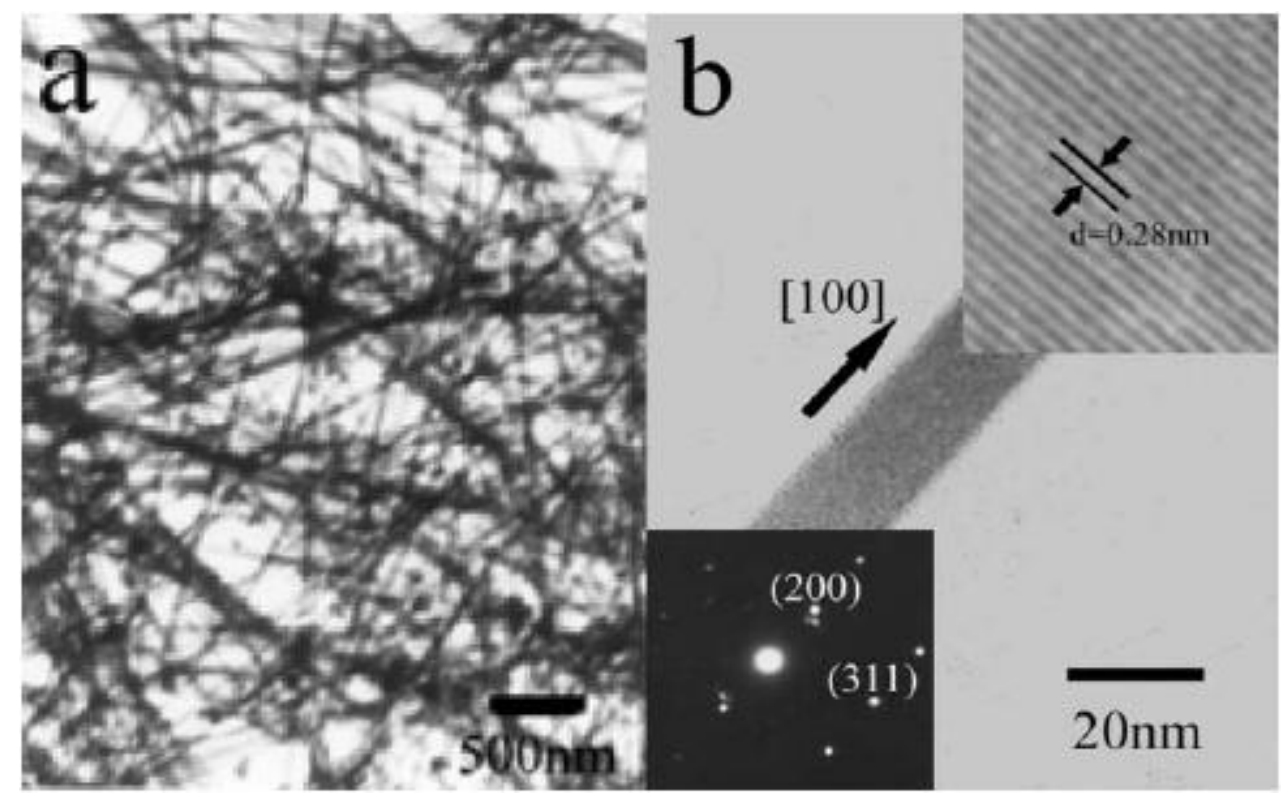

FIGURE 2.3 - a) TEM image of $\mathrm{CeO}_{2}$ nanowires, b) HRTEM image of individual $\mathrm{CeO}_{2}$ nanowire (Tang,2005).

On the other hand, $\mathrm{H}_{2} \mathrm{O}_{2}$ with cerium nitrate can form $\mathrm{CeO}_{2}$ nanoplates as described in Chapter IV. The morphology (Mai, 2005; Zhou, 2005) is mainly composed 
of polyhedron which exposes eight $\left\{\begin{array}{lll}1 & 1 & 1\end{array}\right\}$ or eight $\left\{\begin{array}{lll}1 & 1 & 1\end{array}\right\}$ and six $\left\{\begin{array}{lll}1 & 0 & 0\end{array}\right\}$ plane, but the rod-shaped nanostructures tend to preferentially expose four $\left\{\begin{array}{lll}1 & 1 & 0\end{array}\right\}$ and two $\left\{\begin{array}{lll}1 & 0 & 0\end{array}\right\}$ planes. Therefore, Mai et al. (2005) reported that the oxygen storage is confined mainly on the surface of $\mathrm{CeO}_{2}$ nanoparticles, while the oxygen species both on the surface and in the bulk could participate in the redox cycle in the nanorods, giving a much higher OSC (Mai, 2005). Djuricic et al. (1999) reported that the role of $\mathrm{H}_{2} \mathrm{O}_{2}$ is to make it much easier to change the valence state of cerium ion from $\mathrm{Ce}$ (III) to $\mathrm{Ce}$ (IV). The following reaction takes place in solution:

$$
\mathrm{Ce}^{3+}+\mathrm{H}_{2} \mathrm{O}_{2}+2 \mathrm{H}^{+} \text {(aq.) } \rightarrow \mathrm{Ce}^{4+}+2 \mathrm{H}_{2} \mathrm{O}
$$

To obtain cerium(IV) oxide from $\mathrm{Ce}(\mathrm{III})$ nitrate, $\mathrm{H}_{2} \mathrm{O}_{2}$ is used as an oxidizer, owing to the H-bond interaction with other hydroxyl or hydroperoxyl groups at twodirections. Tang et al. (2005) revealed that $\mathrm{H}_{2} \mathrm{O}_{2}$ was also a template agent. In contrast with most of the other templates, which can generate complicated process and an increase of impurity concentration in the final product, $\mathrm{H}_{2} \mathrm{O}_{2}$ makes the process very simple and does not leave any impurity in the hydrothermal reaction system. The $\mathrm{H}_{2} \mathrm{O}_{2}$-assisted hydrothermal method might offer an opportunity to synthesize other similar nanomaterials and have significant contribution for industrial applications. $\mathrm{CeO}_{2}$ nanoparticles have significant impact in applications such as UV blocking and shielding materials. This is because of their considerably small sizes, high surface areas, and especially the general improvements in the material properties with respect to their micronized or bulk like materials (Mai, 2005). 


\section{Ammonium Hydroxide}

Ceria nanoplates are also formed by using the second precursor ammonium hydroxide. Recently, nanoplates have attracted increasing attention due to two advantages: one is high crystallinity and well-defined chemical composition as well as extremely high anisotropy with an ultrathin thickness (Zhang, 2005) and the other is that they are superior precursors to be used for conversion into other nanostructrures (Tian, 2002), such as nanotubes based on the rolling-up mechanism. Therefore, $\mathrm{CeO}_{2}$ nanoplates are hoped to be synthesized so that they can improve the catalytic performance and also be easy to convert into other useful nanostructures.

Besides producing $\mathrm{CeO}_{2}$ nanoplates, other approaches have successfully formed $\mathrm{CeO}_{2}$ nanoparticles by adding aqueous ammonium hydroxide precipitant into cerium nitrate solution at room temperature and introducing oxygen into the reactor to oxidize $\mathrm{Ce}^{3+}$ to $\mathrm{Ce}^{+}$(Zhou, 2002). Han et al (2005) proved that $\mathrm{CeO}_{2}$ nanowires with a diameter range from 5-30 nm and a length up to several microns shown in Figure 2.4 can be formed by adding aqueous ammonium hydroxide precipitant into cerium nitrate at $70^{\circ} \mathrm{C}$ and then aging at $0{ }^{\circ} \mathrm{C}$ for 1 day. Chen et al. (2004) reported that high-alkaline environments support the oxidation of $\mathrm{Ce}(\mathrm{OH})_{3}$ to hydrated $\mathrm{Ce}$ (IV). Oxidation of $\mathrm{Ce}^{3+}$ to

$\mathrm{Ce}^{4+}$ in solution takes place at high $\mathrm{pH}$, for example, $\mathrm{Ce}^{3+}+\mathrm{H}_{2} \mathrm{O} \rightarrow \mathrm{Ce}(\mathrm{OH})^{3+}+\mathrm{H}^{+}+\mathrm{e}^{-}$ with subsequent hydrolysis to $\mathrm{Ce}(\mathrm{OH})_{4}$ and precipitation. Hydroxyl ions play an important role in this process and strongly affect the upper saturation degree of initial precipitate and oxidation of $\mathrm{Ce}$ (III) to Ce (IV). 


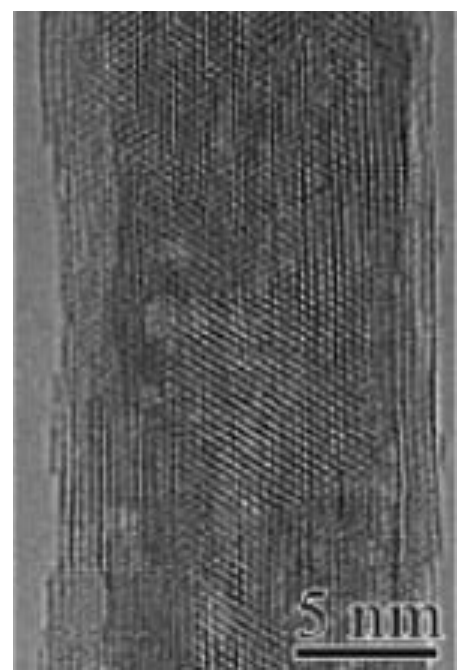

FIGURE 2.4 - HRTEM image of $\mathrm{CeO}_{2}$ nanowires (Han, 2005).

An enhanced catalytic activity was found for $\mathrm{CO}$ oxidation by using $\mathrm{CeO}_{2}$ nanoplates as compared with $\mathrm{CeO}_{2}$ nanotubes and nanorods, and the crystal surfaces (100) of $\mathrm{CeO}_{2}$ nanoplates were considered to play an important role in determining their catalytic oxidation properties. The structural characteristics of $\mathrm{CeO}_{2}$ are believed to affect their performance in catalysis and can be extended to other technological applications (Pan, 2008).

\section{Sodium Hydroxide}

In order to achieve ceria nanorods and nanocubes, sodium hydroxide precursor helps to obtain these morphologies. Cerium nitrate is synthesized with sodium hydroxide to form different crystal structures, shapes and sizes. Table I presents the synthesis factors used to obtain these types of $\mathrm{CeO}_{2}$ morphologies. Mai et al. (2005) found that $\mathrm{CeO}_{2}$ nanorods and nanocubes could be selectively obtained by varying the $\mathrm{NaOH}$ concentration and hydrothermal temperature. For example, $\mathrm{CeO}_{2}$ nanorods were 
yielded at a much higher concentration $\left(\mathrm{C}_{\mathrm{NaOH}}=6-9 \mathrm{~mol} \mathrm{~L}^{-1}\right)$ when hydrothermally treated at $100^{\circ} \mathrm{C}$, while $\mathrm{CeO}_{2}$ nanocubes were formed under the same reactant concentrations but $180^{\circ} \mathrm{C}$. The base concentration and hydrothermal temperature seemed to be the two key factors in the selective formation of $\mathrm{CeO}_{2}$ nanopolyhedra, nanorods, and nanocubes according to Table II-I.

TABLE II-I

CRYSTAL STRUCTURES, SHAPES, AND SIZES OF SEVERAL $\mathrm{CeO}_{2} \mathrm{SAMPLES}$ (MAI, 2005)

\begin{tabular}{|cccccll|}
\hline no. & $C_{\mathrm{Na} \text { OH }}\left(\mathrm{mol} \mathrm{L}^{-1}\right)$ & $T\left({ }^{\circ} \mathrm{C}\right)$ & $t(\mathrm{~h})$ & structure & \multicolumn{1}{c|}{ shape } & \multicolumn{1}{c|}{ size $(\mathrm{nm})$} \\
\hline 1 & 0.01 & 100 & 24 & cubic & polyhedra & $11.5 \pm 1.8$ \\
2 & 0.01 & 180 & 24 & cubic & polyhedra & $9-25$ \\
3 & 1 & 100 & 24 & cubic & polyhedra; rods & \\
4 & 3 & 100 & 24 & cubic & polyhedra; rods & \\
5 & 6 & 100 & 24 & cubic & rods & $(9.6 \pm 1.2) \times(50-200)$ \\
6 & 6 & 140 & 24 & cubic & rods; cubes & \\
7 & 6 & 180 & 24 & cubic & cubes & $36.1 \pm 7.1$ \\
8 & 9 & 100 & 24 & cubic & rods & $(13.3 \pm 2.8) \times(100-400)$ \\
\hline
\end{tabular}

On the other hand, $\mathrm{CeO}_{2}$ nanowires (Tana, 2009) exhibited a much higher OSC than the nanorods despite their comparable specific surface area and similar geometrical configuration. The higher OSC might be due to the differing proportions of exposed $\left(\begin{array}{lll}1 & 1 & 0\end{array}\right)$ and/or $\left(\begin{array}{lll}1 & 0 & 0\end{array}\right)$ planes between the nanorods and the nanowires. Since the OSC on the (1 $\left.\begin{array}{lll}1 & 0\end{array}\right)$ plane is much higher than that on the $\left(\begin{array}{lll}1 & 1 & 0\end{array}\right)$ plane in $\mathrm{CeO}_{2}$, it is most likely that the nanowire exposes relatively more $\left(\begin{array}{lll}1 & 0 & 0\end{array}\right)$ planes on the surface than the nanorod, although both of them preferentially expose the (llll $\left.\begin{array}{lll}1 & 1 & 0\end{array}\right)$ and $\left(\begin{array}{lll}1 & 0 & 0\end{array}\right)$ planes, as shown in Figure 2.5 (c) to (f).

$\mathrm{CeO}_{2}$ nanocubes are formed not only due to the accelerated dissolution/recrystallization, but also due to a transfer step from $\mathrm{Ce}(\mathrm{OH})_{3}$ to $\mathrm{CeO}_{2}$. 
Nanocubes resulted at higher base concentrations as temperature was raised from 100 to $180^{\circ} \mathrm{C}$. It is enclosed by six (100) planes and that $\{100\} /\{110\}$-dominated surface structures are much more reactive for $\mathrm{CO}$ oxidization and make the associated lattice oxygen migration from bulk to surface much easier than the $\{111\}$-dominated one, and the $\{100\}$-dominated one is more active than the $\{110\}$ - dominated one (Madier, 1999).

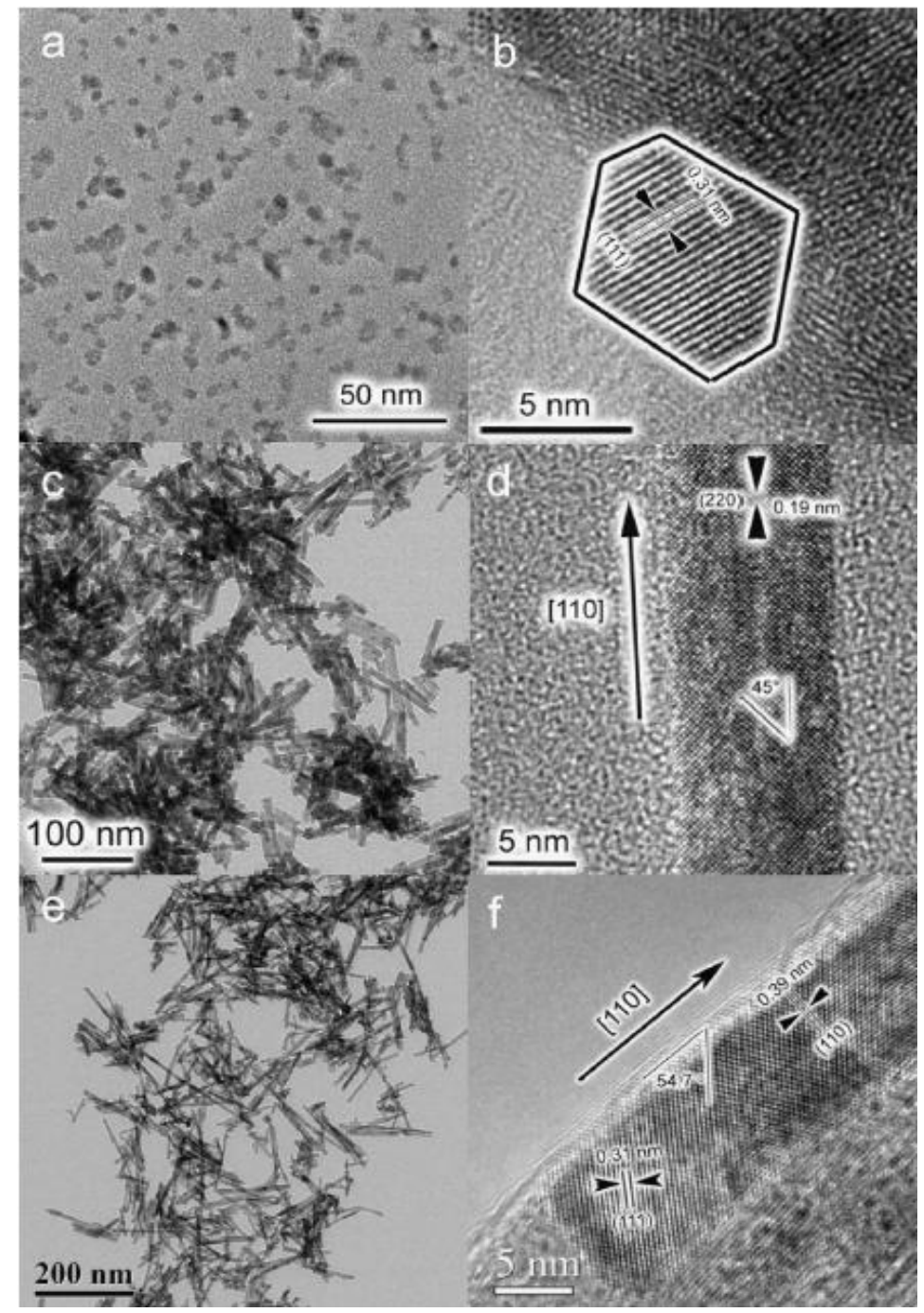

FIGURE 2.5 - TEM images of the $\mathrm{CeO} 2$ nanoparticles ( $\mathrm{a}$ and $\mathrm{b}$ ), nanorods ( $\mathrm{c}$ and d) and nanowires (e and f) (Tana, 2009). 
Other approaches or recent studies in $\mathrm{CeO}_{2}$ have focused on the size/shapecontrolled nanostructures. For example, Chen et al. (2004) fabricated polycrystalline $\mathrm{CeO}_{2}$ nanowires via a solution-phase route using sodium bis(2-ethylhexyl) sulfosuccinate as a structure-directing agent, and observed size-dependent effect on Raman spectra. Wu et al. (2004) obtained fluorite-type ceria nanowires with diameters of $70 \mathrm{~nm}$ by a sol-gel process within the nanochannels of porous anodic alumina (a "hard" template). Li et al. (2005) synthesized single-crystalline $\mathrm{CeO}_{2}$ nanorods by hydrothermal method, which showed an enhanced $\mathrm{CO}$ conversion activity. Yang et al. (2006) produced $\mathrm{CeO}_{2}$ nanocubes through a solvothermal approach using oleic acid as stabilizing agent while monodisperse $\mathrm{CeO}_{2}$ nanocubes have been fabricated via an acrylamide-assisted hydrothermal route by using $\left(\mathrm{NH}_{4}\right)_{2} \mathrm{Ce}\left(\mathrm{NO}_{3}\right)_{6}$ and $\mathrm{CeCl}_{3} \cdot 7 \mathrm{H}_{2} \mathrm{O}$ instead of $\mathrm{Ce}\left(\mathrm{NO}_{3}\right)_{3} \cdot 6 \mathrm{H}_{2} \mathrm{O}$ as the cerium source which resulted in uniform spherical particles shown in Figure 2.6 with an average diameter of $200 \mathrm{~nm}$.

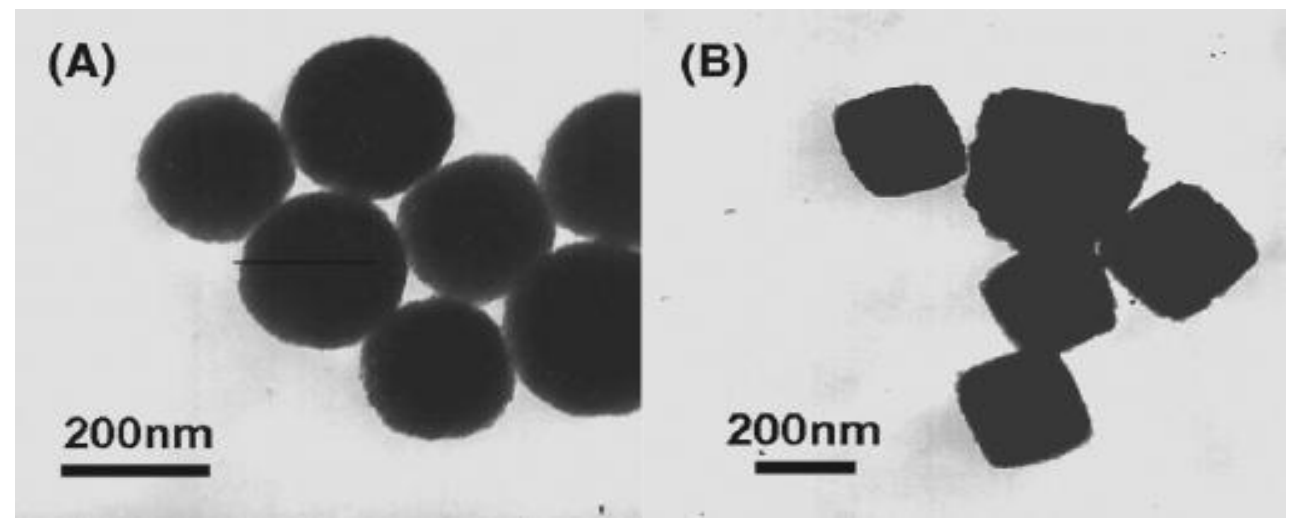

FIGURE 2.6 - TEM images of the products obtained by the utilization of varied cerium source: (A) $\left(\mathrm{NH}_{4}\right)_{2} \mathrm{Ce}\left(\mathrm{NO}_{3}\right)_{6}$; (B) $\mathrm{CeCl}_{3} \cdot 7 \mathrm{H}_{2} \mathrm{O}$ (Yang, 2009). 


\section{EXPERIMENTATION}

\section{A. Plan of Experimentation}

Three different synthesis methods were designed to investigate the properties of cerium oxide nanostructures synthesized with the three precursors $\mathrm{H}_{2} \mathrm{O}_{2}, \mathrm{NH}_{4} \mathrm{OH}$, and $\mathrm{NaOH}$. The synthesis was performed by hydrothermal reaction at temperatures 100,180 , and $220^{\circ} \mathrm{C}$. The experimental flow chart in Figure 3.1 illustrates the schematic procedure of the synthesis of $\mathrm{CeO}_{2}$ by hydrothermal method using $\mathrm{H}_{2} \mathrm{O}_{2}$. The details of the different parameters used to synthesize the different ceria nanostructures are presented in the Procedure Section of this chapter.

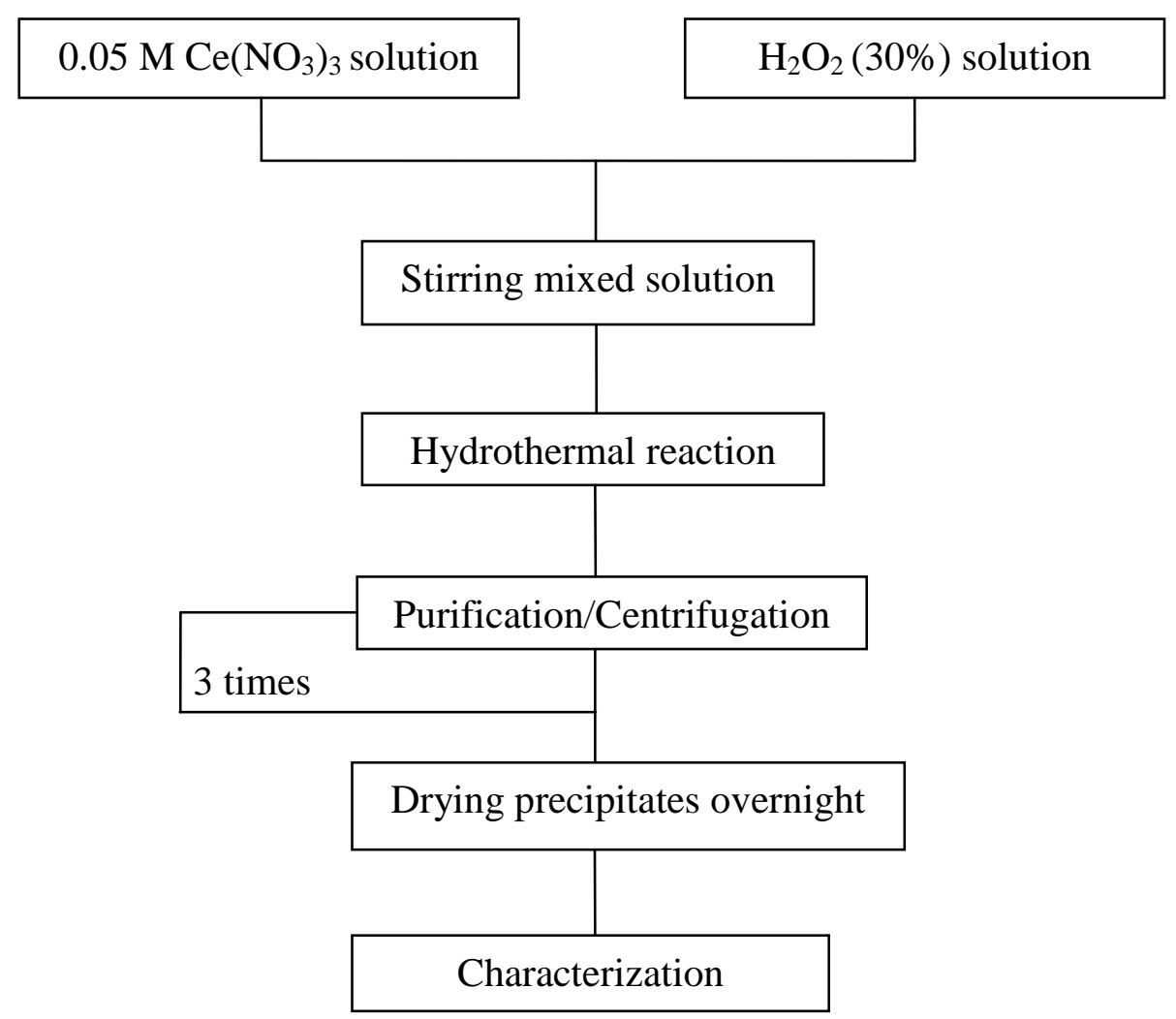

FIGURE 3.1 - Experimental flow chart of synthesis of $\mathrm{CeO}_{2}$ with $\mathrm{H}_{2} \mathrm{O}_{2}$. 
In order to identify the morphology of ceria, characterization was performed

through BET specific surface area, transmission electron microscopy (TEM), X-ray photoelectron spectroscopy (XPS), and X-ray diffraction (XRD). TEM, XPS and XRD equipments are illustrated in Figures 3.3 - 3.5. It was found that the synthesis of ceria produces nanoplates, nanorods, and nanocubes depending on the type of precursor used and other parameters such as reaction time and concentration.

Source:

\section{B. Materials}

Cerium (III) nitrate hexahydrate, $99 \%$ metal basis $\left(0.05 \mathrm{M} \mathrm{Ce}\left(\mathrm{NO}_{3}\right)_{3}\right)$

Sigma-Aldrich, Inc

St Louis, MO 63103 USA

Product of China

Cat. No.: 238538-100G

Precursors:

Perdrogen $® 30 \%$ by weight $\mathrm{H}_{2} \mathrm{O}_{2}$ puriss. p.a.

Reag. ISO, Reag. Ph. Eur. Stabilized, (Hydrogen Peroxide)

Sigma-Aldrich, Inc

St Louis, MO 63178 USA

Made in Germany

Cat. No.: 31642

Sodium Hydroxide, pellets, 99.99\% metals basis, semiconductor grade $\left(\mathrm{Na}_{2} \mathrm{CO}_{3}<1 \%\right)$

Sigma-Aldrich, Inc

St Louis, MO 63103 USA

Product of USA

Cat. No.: 306576-100G

Ammonium Hydroxide, A.C.S. reagent (28\%)

Sigma-Aldrich, Inc

St Louis, MO 63103 USA

Product of USA

Cat. No.: 306576-100G

Deionized water 


\section{Procedure}

The hydrothermal synthesis of cerium oxide was conducted in a $50 \mathrm{ml}$ Teflon autoclave shown in Figure 3.3 and then heated up to 100,180 , and $220^{\circ} \mathrm{C}$ in a furnace, Figure 3.3, for 24 hours. First, a $50 \mathrm{ml}$ solution of $0.05 \mathrm{M} \mathrm{Ce}\left(\mathrm{NO}_{3}\right)_{3}$ was prepared. The weight of $0.05 \mathrm{M} \mathrm{Ce}\left(\mathrm{NO}_{3}\right)_{3}$ for the $50 \mathrm{ml}$ solution was $1.085 \mathrm{~g}$. This solution was used to react with $\mathrm{H}_{2} \mathrm{O}_{2}$ or $\mathrm{NH}_{4} \mathrm{OH}$ to form ceria nanoplates.

Table III-I through table III-IV present the three methods of synthesis that were performed; they differ because of the precursors used for the formation. In this study, ceria nanoplates, nanorods, and nanocubes are produced by the following the synthesis recipes.

TABLE III-I

SYNTHESIS OF CERIA NANOPLATE WITH HYDROGEN PEROXIDE PRECURSOR (TANG, 2005)

\begin{tabular}{|c|c|}
\hline Vol. 30\% $\mathrm{H}_{2} \mathrm{O}_{2}$ & $8 \mathrm{ml}$ \\
\hline Solution $0.05 \mathrm{M} \mathrm{Ce}\left(\mathrm{NO}_{3}\right)_{3}$ & $8 \mathrm{ml}$ \\
\hline Stirring time & $10 \mathrm{~min}$ \\
\hline Temperature & $220^{\circ} \mathrm{C}$ \\
\hline Time & $24 \mathrm{~h}$ \\
\hline
\end{tabular}

TABLE III-II

SYNTHESIS OF CERIA NANOPLATE WITH AMMONIUM HYDROXIDE PRECURSOR

\begin{tabular}{|c|c|}
\hline Vol. $\mathrm{NH}_{4} \mathrm{OH}(28 \%)$ & $10 \mathrm{ml}$ \\
\hline Solution $0.05 \mathrm{M} \mathrm{Ce}\left(\mathrm{NO}_{3}\right)_{3}$ & $10 \mathrm{ml}$ \\
\hline Stirring time & $10 \mathrm{~min}$ \\
\hline Temperature & $100^{\circ} \mathrm{C}$ \\
\hline Time & $24 \mathrm{~h}$ \\
\hline
\end{tabular}


TABLE III-III

SYNTHESIS OF CERIA NANOROD $\left(\mathrm{C}_{\mathrm{NaOH}}=9 \mathrm{M}\right)$ WITH SODIUM HYDROXIDE PRECURSOR (MAI, 2005)

\begin{tabular}{|c|c|}
\hline Weight of $0.05 \mathrm{M} \mathrm{Ce}\left(\mathrm{NO}_{3}\right)_{3}$ & $0.86 \mathrm{~g}$ \\
\hline DI water & $5 \mathrm{ml}$ \\
\hline Weight of NaOH pellets & $\approx 12.68 \mathrm{~g}$ \\
\hline DI water & $35 \mathrm{ml}$ \\
\hline Total mixed solution & $40 \mathrm{ml}$ \\
\hline Stirring time & $30 \mathrm{~min}$ \\
\hline Temperature & $100^{\circ} \mathrm{C}$ \\
\hline Time & $24 \mathrm{~h}$ \\
\hline
\end{tabular}

TABLE III-IV

SYNTHESIS OF CERIA NANOCUBE $\left(\mathrm{C}_{\mathrm{NaOH}}=6 \mathrm{M}\right)$ WITH SODIUM HYDROXIDE PRECURSOR (MAI, 2005)

\begin{tabular}{|c|c|}
\hline Weight of $0.05 \mathrm{M} \mathrm{Ce}\left(\mathrm{NO}_{3}\right)_{3}$ & $0.86 \mathrm{~g}$ \\
\hline DI water & $5 \mathrm{ml}$ \\
\hline Weight of NaOH pellets & $\approx 8.46 \mathrm{~g}$ \\
\hline DI water & $35 \mathrm{ml}$ \\
\hline Total mixed solution & $40 \mathrm{ml}$ \\
\hline Stirring time & $30 \mathrm{~min}$ \\
\hline Temperature & $180^{\circ} \mathrm{C}$ \\
\hline Time & $24 \mathrm{~h}$ \\
\hline
\end{tabular}

After the hydrothermal synthesis, the precipitates were separated by centrifugation and washed with deionized water several times. In order to characterize, precipitates were dried overnight at $75^{\circ} \mathrm{C}$. The precipitates turned into yellow and white powders for $\mathrm{NaOH}$ precursor at $6 \mathrm{M}$ and $9 \mathrm{M}$, respectively, white for $\mathrm{H}_{2} \mathrm{O}_{2}$ and dark yellow for $\mathrm{NH}_{4} \mathrm{OH}$. For $\mathrm{XRD}, \mathrm{CeO}_{2}$ powders were calcined at $100^{\circ} \mathrm{C}, 400^{\circ} \mathrm{C}$, and $600^{\circ} \mathrm{C}$ for 12 hours. 


\section{D. $\underline{\text { Characterization of the Prepared } \mathrm{CeO}_{2}}$}

The crystallinity of final $\mathrm{CeO}_{2}$ nanostructures was recorded by XRD (D8 Dicover) shown in Figure 3.6 using $\mathrm{CuK} \alpha$ radiation $(\lambda=1.5406 \AA)$ in the $2 \theta$ range of 20 $90^{\circ}$ at $0.02^{\circ} 2 \theta / \mathrm{s}$. To estimate crystallite size and lattice parameter, the reflection from (111) plane was used for the analysis. Particle morphology, state of agglomeration and crystalline state were determined by transmission electron microscopy (TEM) shown in Figure 3.4. The Brunaure Emmett Teller (BET) specific surface area was measured by nitrogen-adsorption-desorption isotherms at $77.3 \mathrm{~K}$ with TriStar 3000. X-ray photoelectron spectra (XPS) shown in Figure 3.5 were measured by employing $\mathrm{Mg}-\mathrm{K} \alpha$ radiation $(\mathrm{BE}=1253.6 \mathrm{eV})$. The binding energy $(\mathrm{BE})$ was calibrated by setting the $\mathrm{BE}$ of Ce 3d, O 1S, and C 1S to 935-875, 545-525 and 295-275 eV, respectively.

\section{E. Equipment}

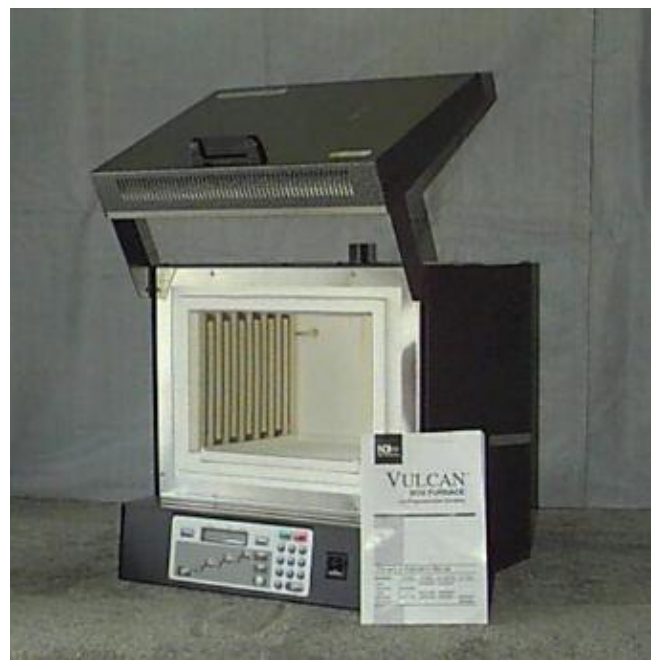

Ney® Vulcan 3-550 Furnace Dentsupply Ceramco International York, PA 17404 Mfg No.: AKW0917113 Serial No.: 9493308

FIGURE 3.2 - Vulcan Furnace 


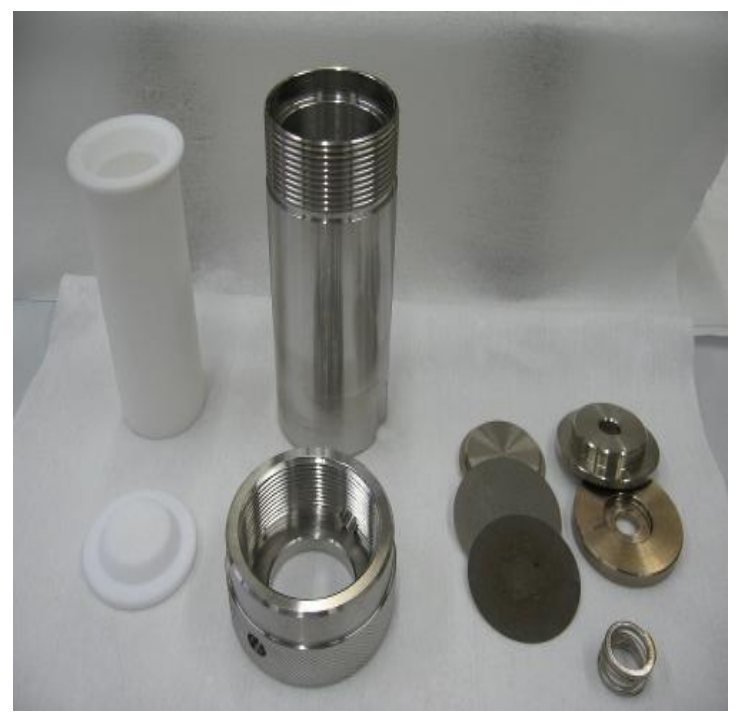

FIGURE 3.3 - Hydrothermal Autoclave

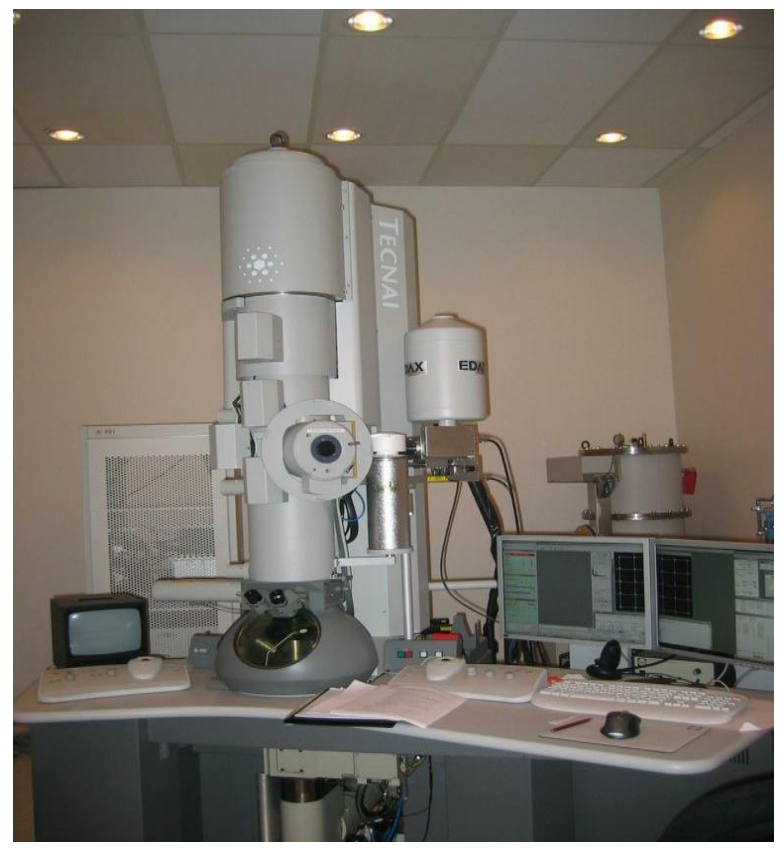

FIGURE 3.4 - Transmission Electron Microscopy

Teflon autoclave $(50 \mathrm{ml})$

Tecnai F20

FEI Company Made in USA 


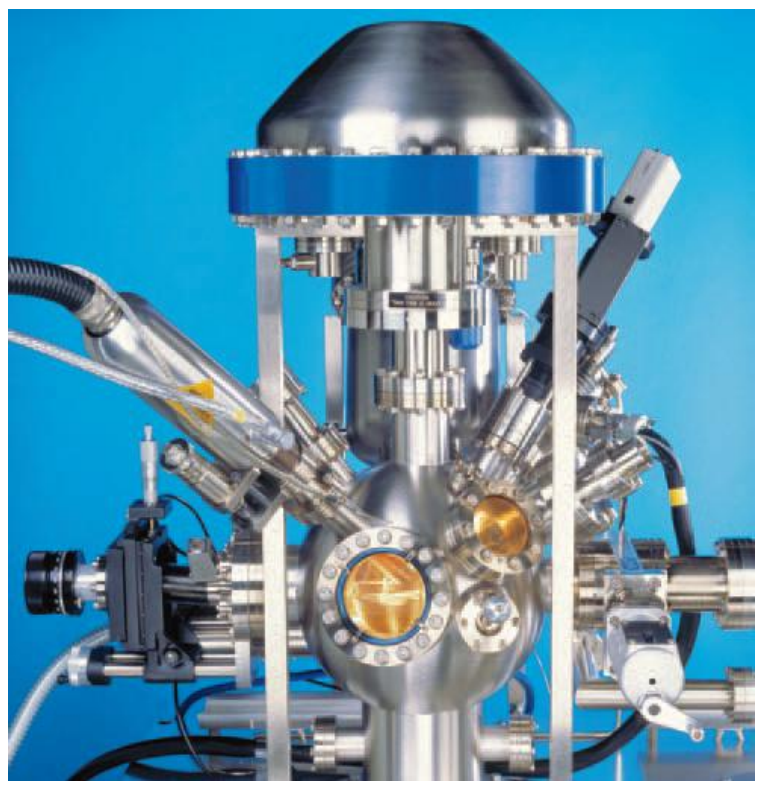

FIGURE 3.5 - X-ray Photoelectron Spectroscopy

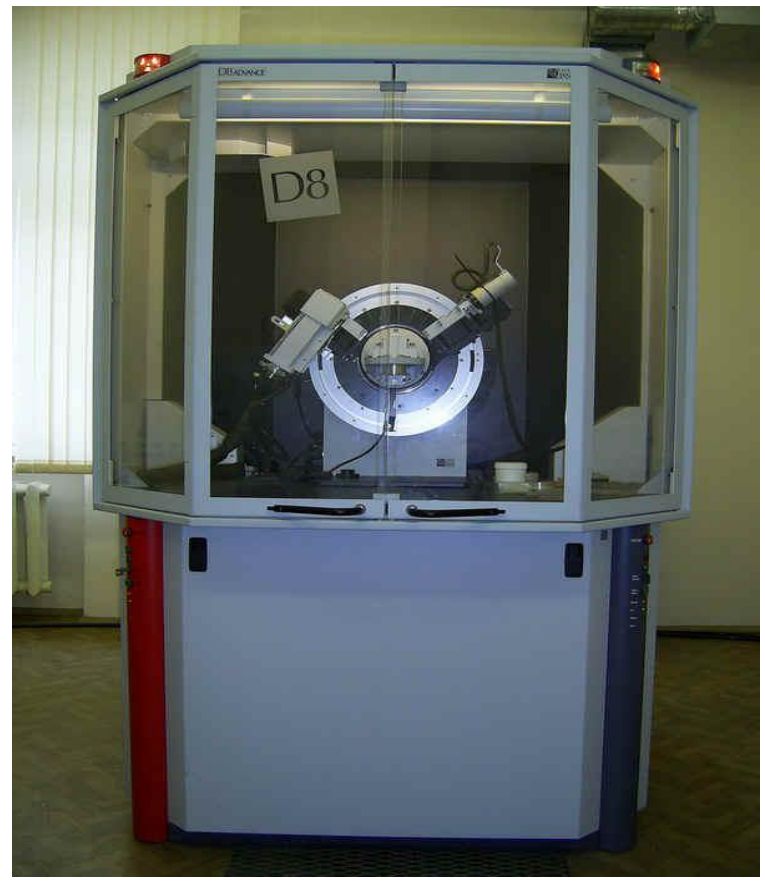

FIGURE 3.6 - X-ray diffraction
Thermo VG Scientific

Product Type: Multilab

Serial No.: A1126

The Birches Industrial Estate

West Sussex, United Kingdom RH91UB
Bruker AXS - Diffraktometer D8

Erz Nr.: 7KP2025 - 2LR15-0Z

Serial No.: 203407

Karlsruhe, Germany D76181 


\section{RESULTS AND DISCUSSION}

\section{A. Shape Selective Synthesis and Its Mechanism}

Previously, it was stated that ceria nanoplates, nanocubes and nanorods were fabricated by using three different precursors $\left(\mathrm{H}_{2} \mathrm{O}_{2}, \mathrm{NH}_{4} \mathrm{OH}\right.$, and $\left.\mathrm{NaOH}\right)$ and using $\mathrm{Ce}\left(\mathrm{NO}_{3}\right)_{3}$ as the cerium source. In this work, we found that $\mathrm{CeO}_{2}$ nanoplates using $\mathrm{H}_{2} \mathrm{O}_{2}$ and $\mathrm{NH}_{4} \mathrm{OH}$ are obtained in the investigated temperature range from $100^{\circ} \mathrm{C}$ to $250^{\circ} \mathrm{C}$. In the case of nanoplates using $\mathrm{H}_{2} \mathrm{O}_{2}$, increasing the hydrothermal temperature or decreasing the time does not affect the crystal structure. Furthermore, nanorods and nanocubes could be selectively fabricated by changing the base concentrations of $\mathrm{NaOH}$ and hydrothermal temperature. $\mathrm{CeO}_{2}$ nanocubes were synthesized at a hydrothermal temperature of $100^{\circ} \mathrm{C}$ with a base concentration $\left(\mathrm{C}_{\mathrm{NaOH}}=6 \mathrm{M}\right)$ whereas, the elevated concentration $\left(\mathrm{C}_{\mathrm{NaOH}}=9 \mathrm{M}\right)$ led to the formation of $\mathrm{CeO}_{2}$ nanorods. According to the results discussed later, the base concentration and hydrothermal temperature seem to be the two key factors in the selective formation of $\mathrm{CeO}_{2}$ nanocubes and nanorods.

In the following, a sequence of reaction condition-dependent experiments were conducted to understand the characteristics of the nucleation and crystal growth processes involved in the synthesis and further to uncover the underlying shape-selective mechanism. Details of ceria characterization and analysis of the different morphologies help to understand this phenomenon. 


\section{B. TEM analysis}

A TEM image of $\mathrm{CeO}_{2}$ nanoplates using $\mathrm{H}_{2} \mathrm{O}_{2}$ as oxidizing agent shown in Figure 4.1 has an average particle size of $25 \times 20 \times 20 \mathrm{~nm}$. The SAED (selected area electron diffraction) pattern shows that the nanoplates were composed of cubic fluoritetype $\mathrm{CeO}_{2}$ described later. Three kinds of lattice fringe directions attributed to (111), (200), and (220) were observed for these nanoplates, which have respective interplanar spacing of $0.31,0.27$, and $0.19 \mathrm{~nm}$ calculated using Bragg's Law discussed in the section E. XRD analysis.

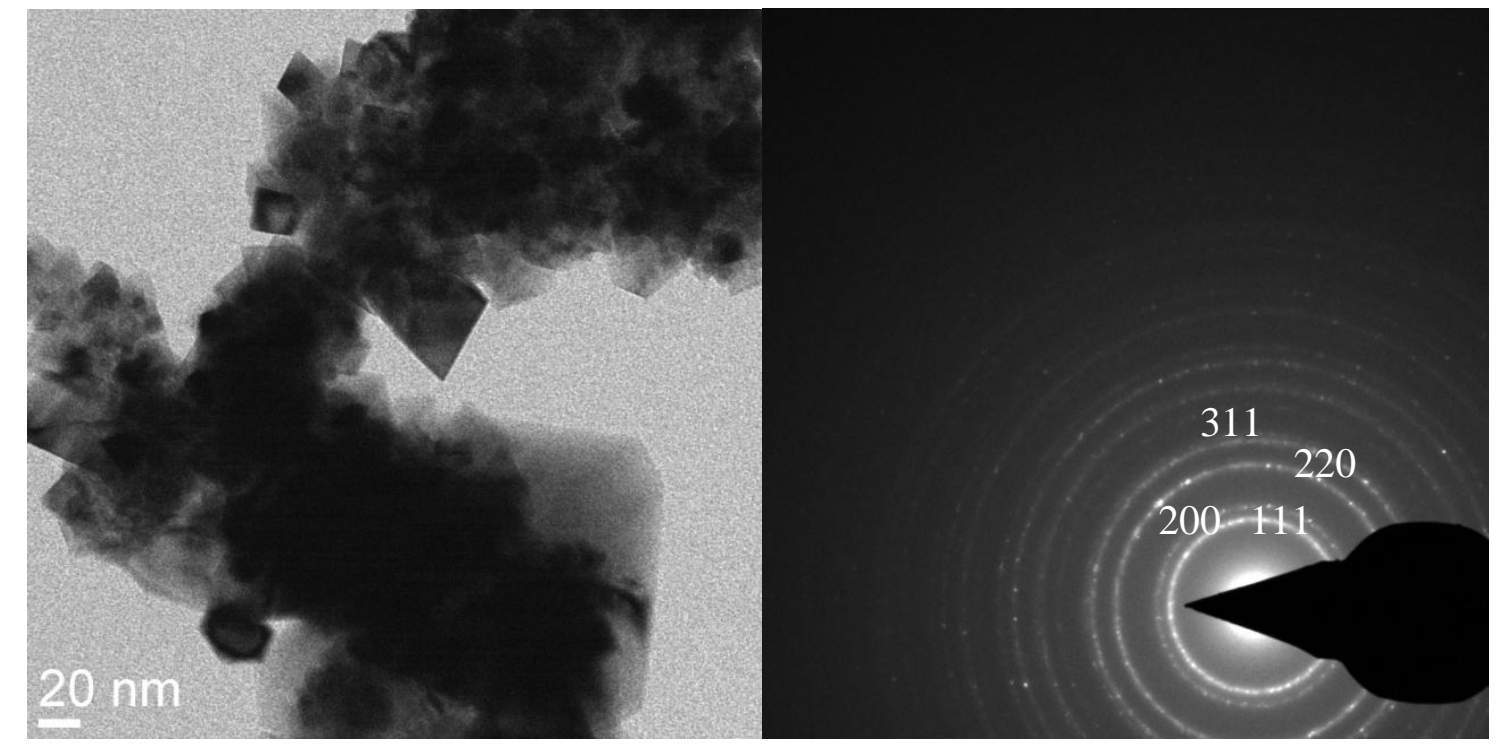

FIGURE 4.1 - TEM and SAED images of $\mathrm{CeO}_{2}$ nanoplates at $220^{\circ} \mathrm{C}$ by $\mathrm{H}_{2} \mathrm{O}_{2}$.

$\mathrm{CeO}_{2}$ nanoplates were formed using $\mathrm{H}_{2} \mathrm{O}_{2}$ at different temperatures but maintaining the same concentration to see if the synthesis temperature has an effect on ceria crystal structure. However, it did not show any difference by synthesizing at temperatures of $180^{\circ} \mathrm{C}$ and $200^{\circ} \mathrm{C}$, for 24 hours. Also, it did not show any effect at $250^{\circ} \mathrm{C}$ 
by changing the hydrothermal time to 3 hours as shown in Figure 4.2. They all present uniform nanoplate structure which indicate that temperature did not have an effect in the nanoceria structure using $\mathrm{H}_{2} \mathrm{O}_{2}$.
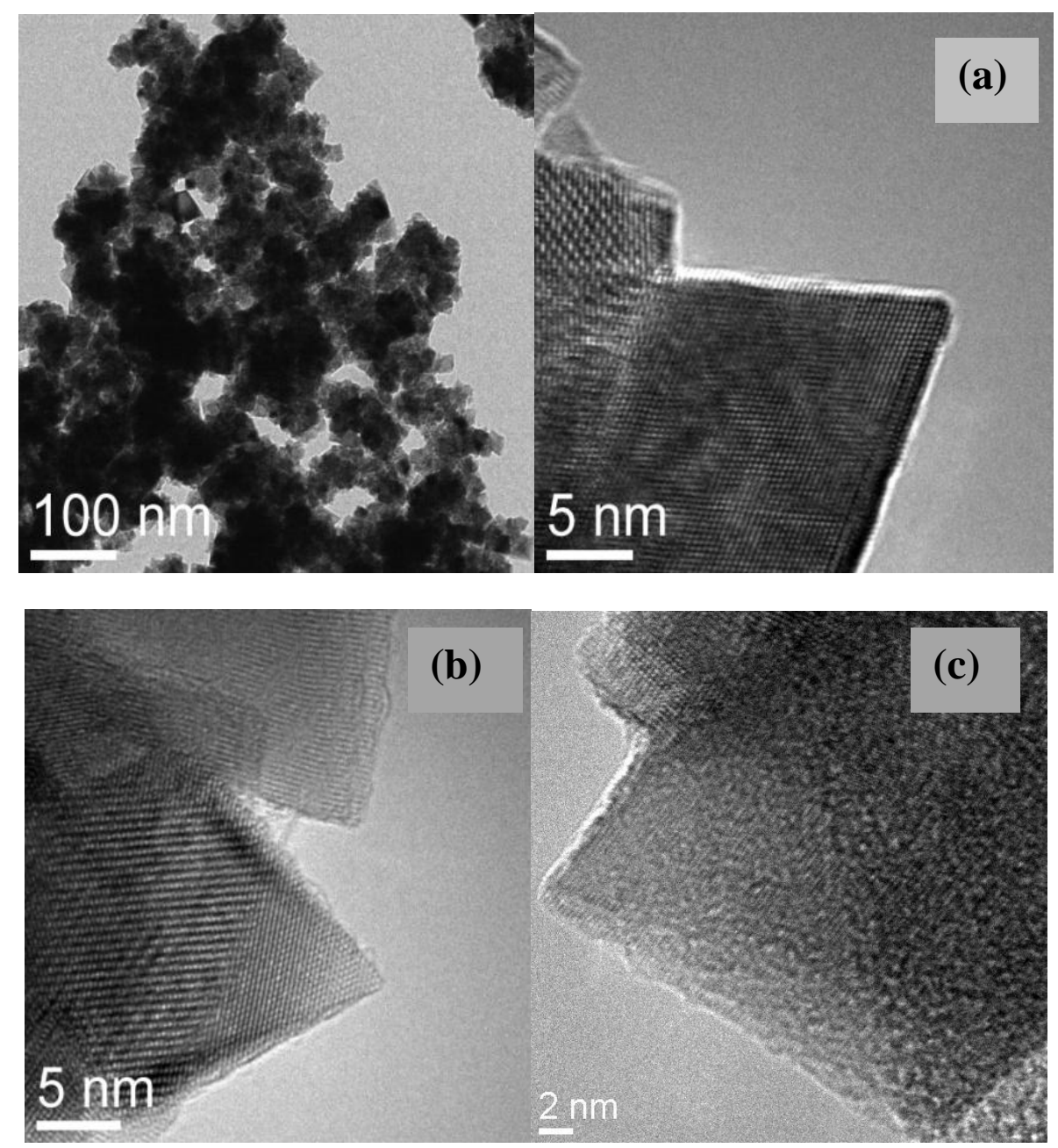

FIGURE 4.2 - TEM, HRTEM and SAED images of $\mathrm{CeO}_{2}$ nanoplates by $\mathrm{H}_{2} \mathrm{O}_{2}$ synthesized at different temperatures (a) $180^{\circ} \mathrm{C}$ for $24 \mathrm{hr}$, (b) $200^{\circ} \mathrm{C}$ for $24 \mathrm{hr}$, and (c) $250^{\circ} \mathrm{C}$ for $3 \mathrm{~h}$.

Ceria nanoplates were formed by using $\mathrm{NH}_{4} \mathrm{OH}$ as mentioned previously. Figure 4.3 shows ceria nanoplates synthesized at $100^{\circ} \mathrm{C}$ and agglomeration can be seen. Agglomeration usually increases with decrease in particle size due to higher surface energy (Tok, 2007). Nanoplates synthesized by $\mathrm{NH}_{4} \mathrm{OH}$ also exhibit the lattice planes 
(111), (200), and (220), same interplanar spacings and has a BET surface area of 62.01 $\mathrm{m}^{2} / \mathrm{g}$ which will be explained further.
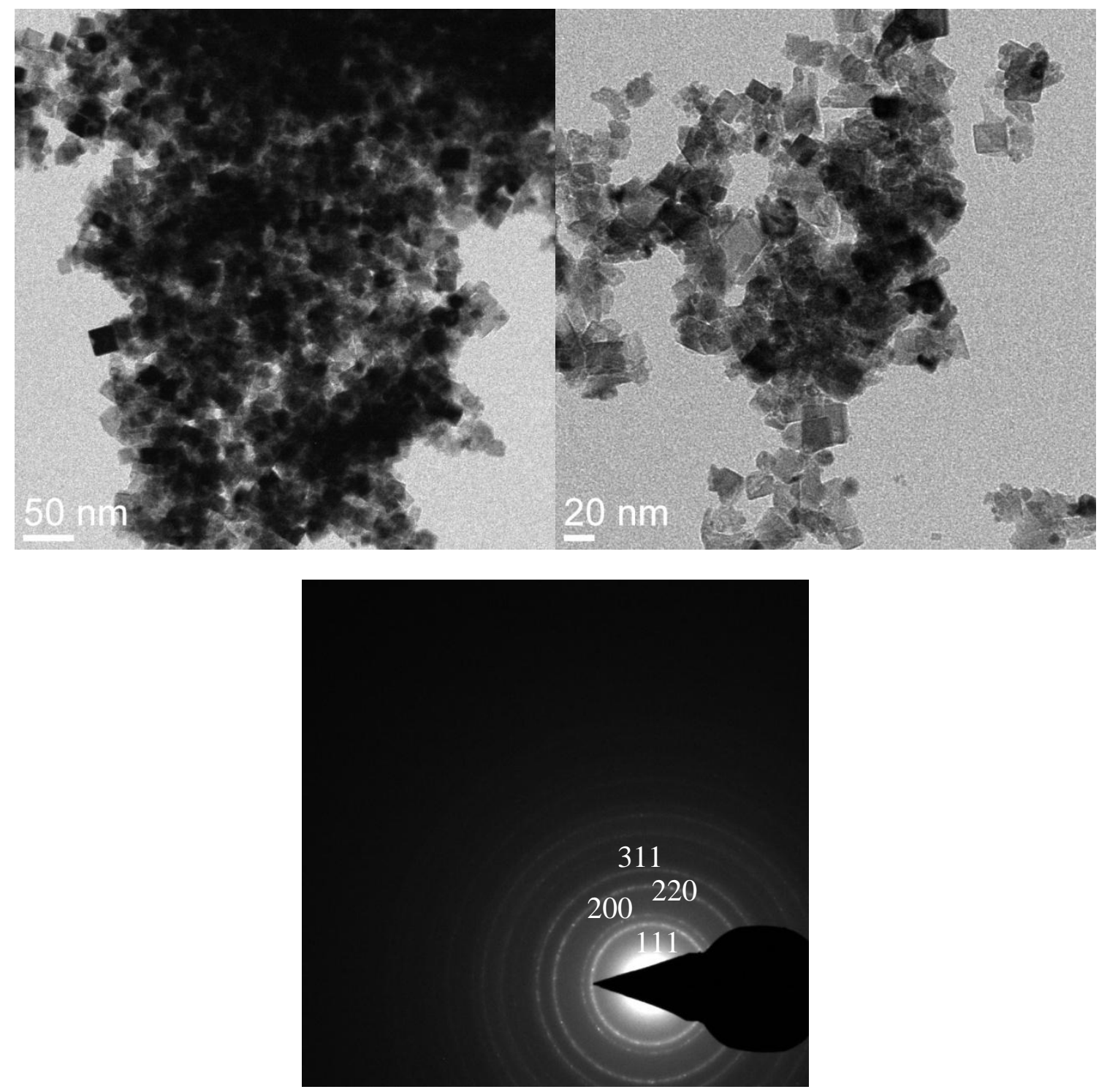

FIGURE 4.3 - TEM and SAED image of $\mathrm{CeO}_{2}$ nanoplates by $\mathrm{NH}_{4} \mathrm{OH}$ at $100^{\circ} \mathrm{C}$.

Figure 4.4 depicts the TEM and HRTEM images of $\mathrm{CeO}_{2}$ nanorods using $\mathrm{NaOH}$ as the precursor with a concentration of $9 \mathrm{M}$. Nanorods show a 1D growth structure with a preferred growth direction along [110], and are enclosed by (220) and 
(200) planes in other studies (Mai, 2005). In this study, nanorods are enclosed by the lattice planes (111), (200) and (220) according to FFT (fast Fourier transform) analysis, inset in Figure 4.4, with the direction along the [110]. Nanorods exposed the most the (111) plane with an interplanar spacing of $0.31 \mathrm{~nm}$. The nanorods have an average diameter $12-20 \mathrm{~nm}$ and a length from 100 to $200 \mathrm{~nm}$.

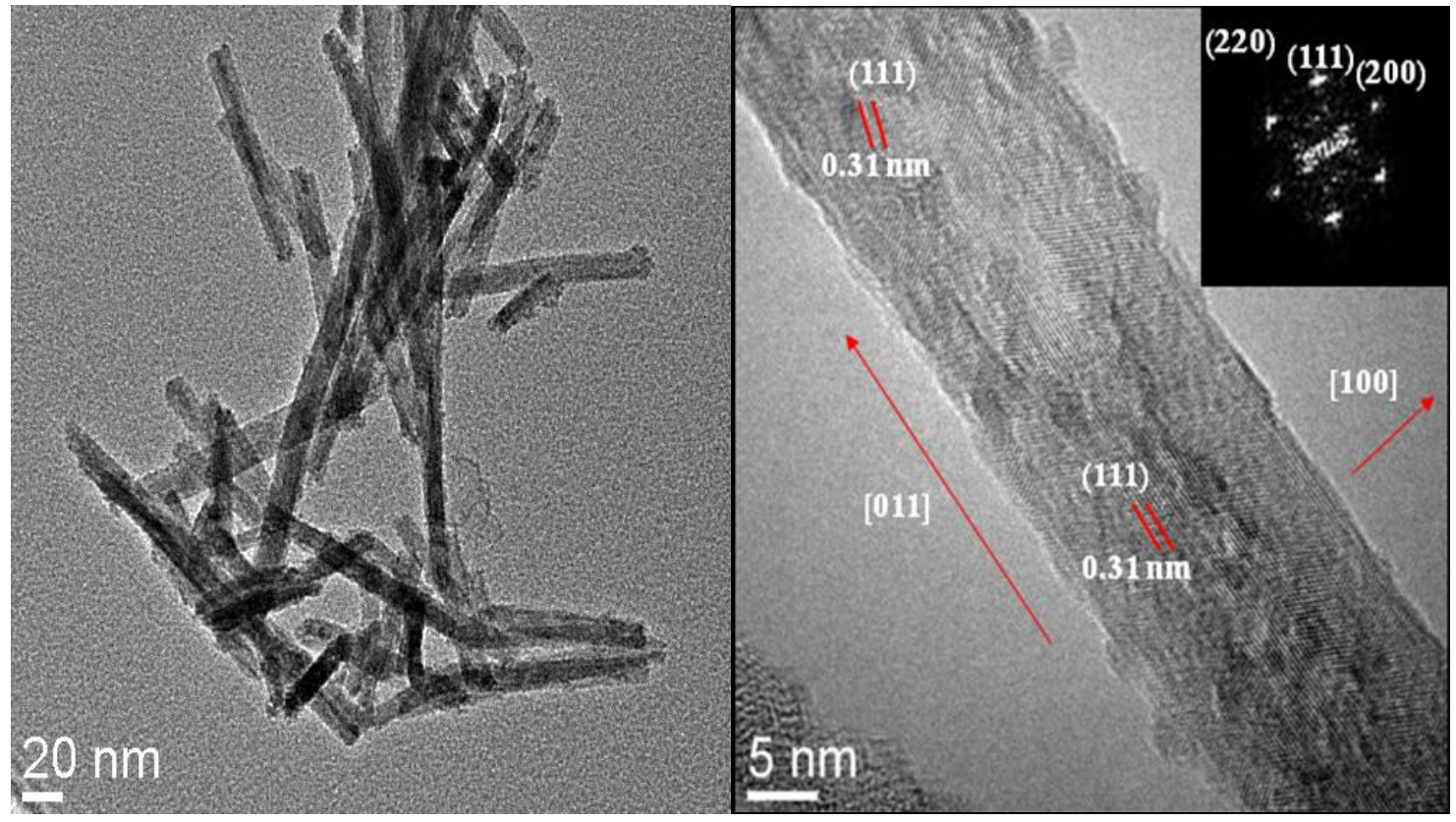

FIGURE 4.4- TEM and HRTEM images of $\mathrm{CeO}_{2}$ nanorods with a $\mathrm{C}_{\mathrm{NaOH}}=9 \mathrm{M}$ at $100^{\circ} \mathrm{C}$.

In addition, ceria was synthesized by keeping the same concentration of $\mathrm{NaOH}(9 \mathrm{M})$ and changing the hydrothermal temperature to $180^{\circ} \mathrm{C}$ instead of $100^{\circ} \mathrm{C}$. The crystal structure changes from nanorods to nanocubes. TEM and HRTEM images of ceria nanocubes are shown in Figure 4.5. This result indicates that temperature does have an effect on the crystal structure. The average size of nanocubes is about $40 \times 40 \times 30 \mathrm{~nm}$. We can see that ceria nanocubes can also be fabricated either using a $\mathrm{C}_{\mathrm{NaOH}}=9 \mathrm{M}$ at $180^{\circ} \mathrm{C}$ or $\mathrm{C}_{\mathrm{NaOH}}=6 \mathrm{M}$ at $100^{\circ} \mathrm{C}$. 


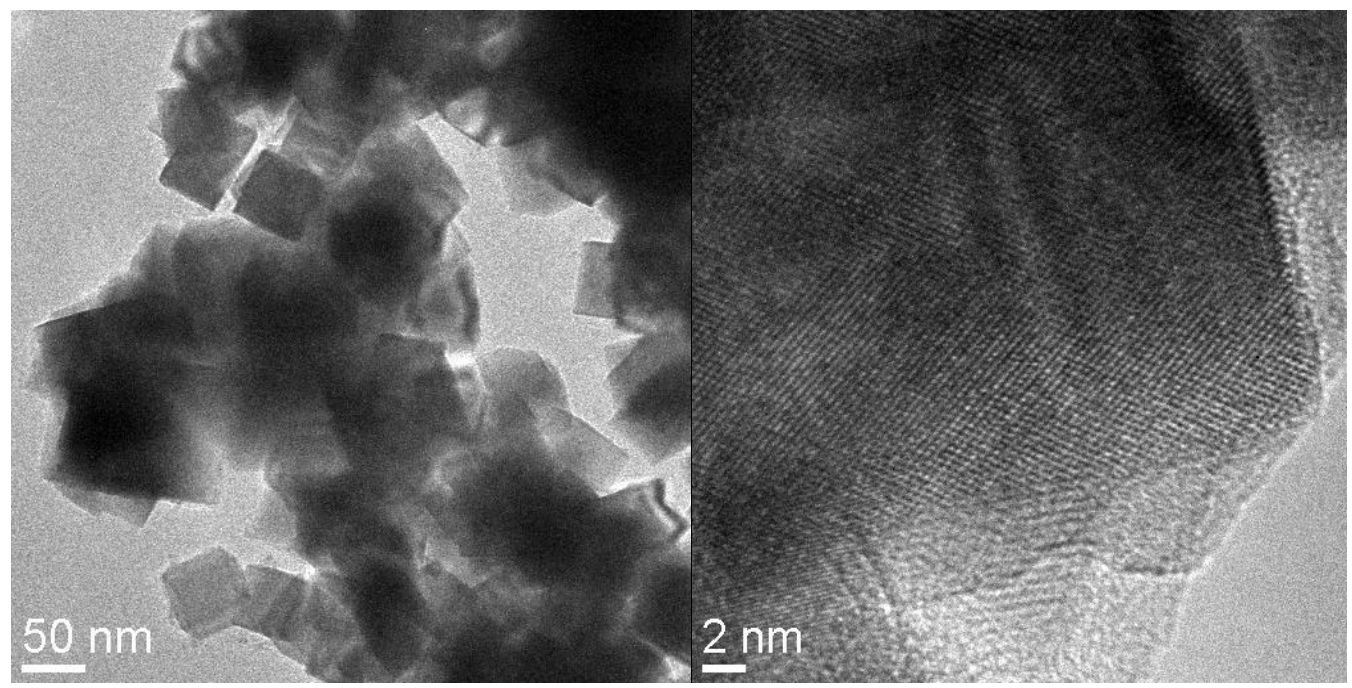

FIGURE 4.5 - TEM and HRTEM images of $\mathrm{CeO}_{2}$ nanocubes with a $\mathrm{C}_{\mathrm{NaOH}}=9 \mathrm{M}$ at $180^{\circ} \mathrm{C}$.

As mentioned earlier, ceria nanocubes are developed by using $\mathrm{NaOH}$ with a concentration of $6 \mathrm{M}$ at hydrothermal temperature at $100^{\circ} \mathrm{C}$. Figure 4.6 illustrates the TEM and HRTEM images of $\mathrm{CeO}_{2}$ nanocubes with an average size of $30 \times 30 \times 20 \mathrm{~nm}$. Through FFT analysis, nanocubes are enclosed by the (111), (200), and (220) planes. The HRTEM displays the clear (111) lattice fringe in the directions [100] and [011] with an interplanar spacing of $0.31 \mathrm{~nm}$. Other studies imply that $\mathrm{CeO}_{2}$ nanocubes are only enclosed by the (200) planes (Mai, 2005). The TEM and HRTEM images of $\mathrm{CeO}_{2}$ nanoplates, nanorods, and nanocubes in Figures 4.1 to 4.6 show that they are of single crystalline nature. 

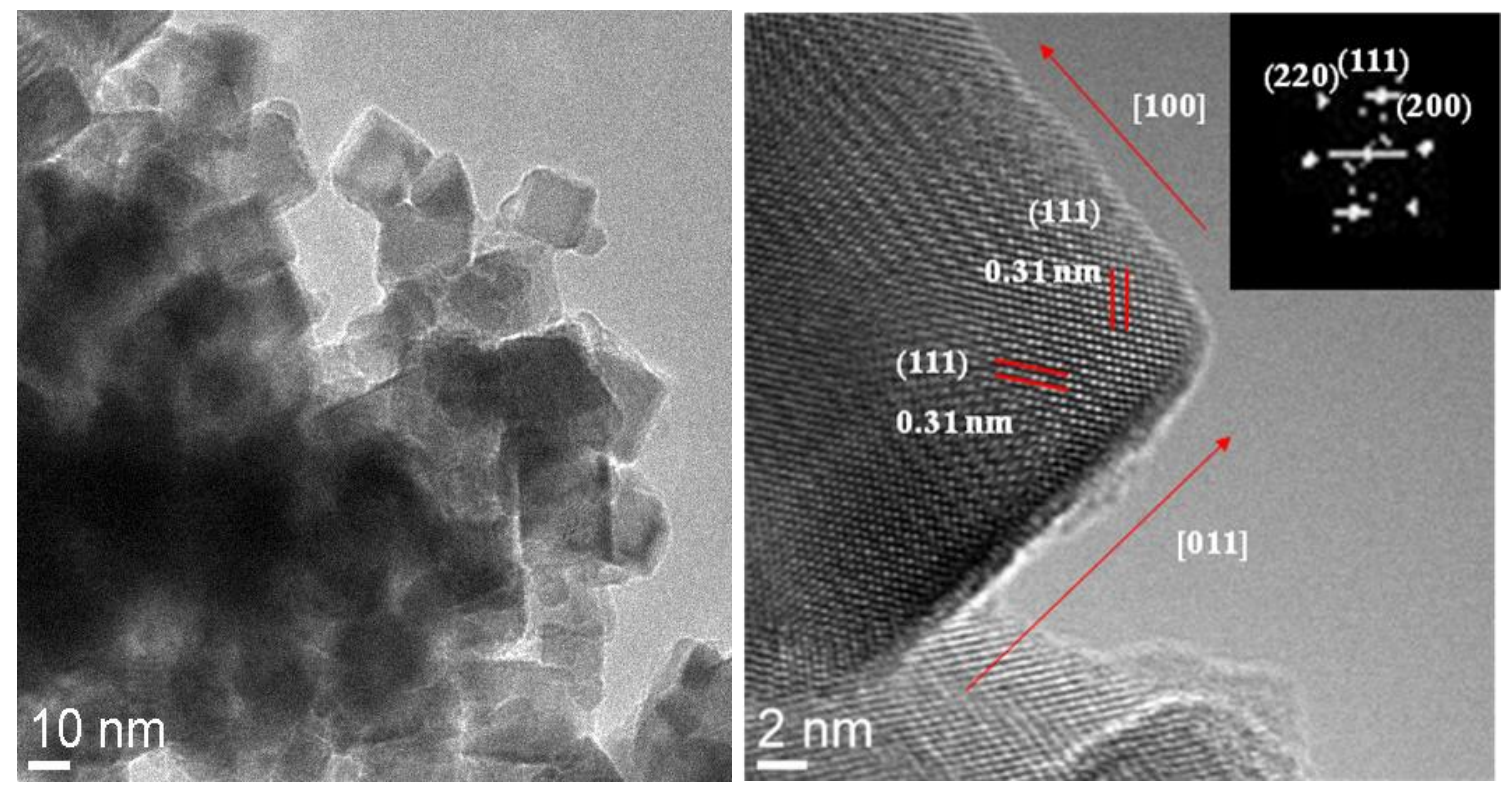

FIGURE 4.6 - TEM and HTERM images of $\mathrm{CeO}_{2}$ nanocubes with a $\mathrm{C}_{\mathrm{NaOH}}=6 \mathrm{M}$ at $180^{\circ} \mathrm{C}$.

\section{BET specific surface area analysis}

Brunaure Emmett Teller (BET) analysis was performed to measure the surface area of different $\mathrm{CeO}_{2}$ nanostructures. Table IV-I reports the BET specific surface area of ceria nanoplates, nanocubes and nanorods. Nanoplates show a higher surface area while nanorods and nanocubes have lower surface area. Ceria nanostructures need to have a high surface area because of their importance in industrial applications such as catalyst. In the present work, nanorods and nanocubes show a low surface area, and, as a result, $\mathrm{CeO}_{2}$ nanoplates could be better catalyst from surface area aspect. $\mathrm{CeO}_{2}$ nanoplates have high surface area than nanocubes and nanorods. Nanorods and nanocubes have compatible surface area even though they are of different morphology. 
TABLE IV-I

BET SPECIFIC SURFACE AREA OF DIFFERENT $\mathrm{CeO}_{2}$ SHAPES

\begin{tabular}{ccccc}
\hline \multirow{2}{*}{$\begin{array}{c}\text { Precursor } \\
\text { Shape }\end{array}$} & $\mathrm{H}_{2} \mathrm{O}_{2}$ & $\mathrm{NH}_{4} \mathrm{OH}$ & $\mathrm{NaOH}-6 \mathrm{M}$ & $\mathrm{NaOH}-9 \mathrm{M}$ \\
\cline { 2 - 5 } & Nanoplate & Nanoplate & Nanocube & Nanorod \\
BET surface area $\left(\mathrm{m}^{2} / \mathrm{g}\right)$ & 95.11 & 62.07 & 16.55 & 16.74 \\
\hline
\end{tabular}

The $\mathrm{N}_{2}$ adsorption-desorption isotherm plots are illustrated in Figure 4.7. The hysteresis loop at $\mathrm{P} / \mathrm{P}_{\mathrm{o}}$ 0.8-1.0 of Fig. $4.7 \mathrm{c}$ indicates that nanocubes elucidate the typical IUPAC type IV pattern (Pavasupree, 2006), revealing the presence of mesoporous material. The isotherm for nanorods in Fig. 4.7d exhibits also type IV pattern with variation of nitrogen adsorbed volume at $\mathrm{P} / \mathrm{P}_{\mathrm{o}}$ 0.4-0.9 indicating also the existence of mesopores. However, BET surface area does not correlate with the existence of mesoporous material for nanorods and nanocubes because they show small surface area. 

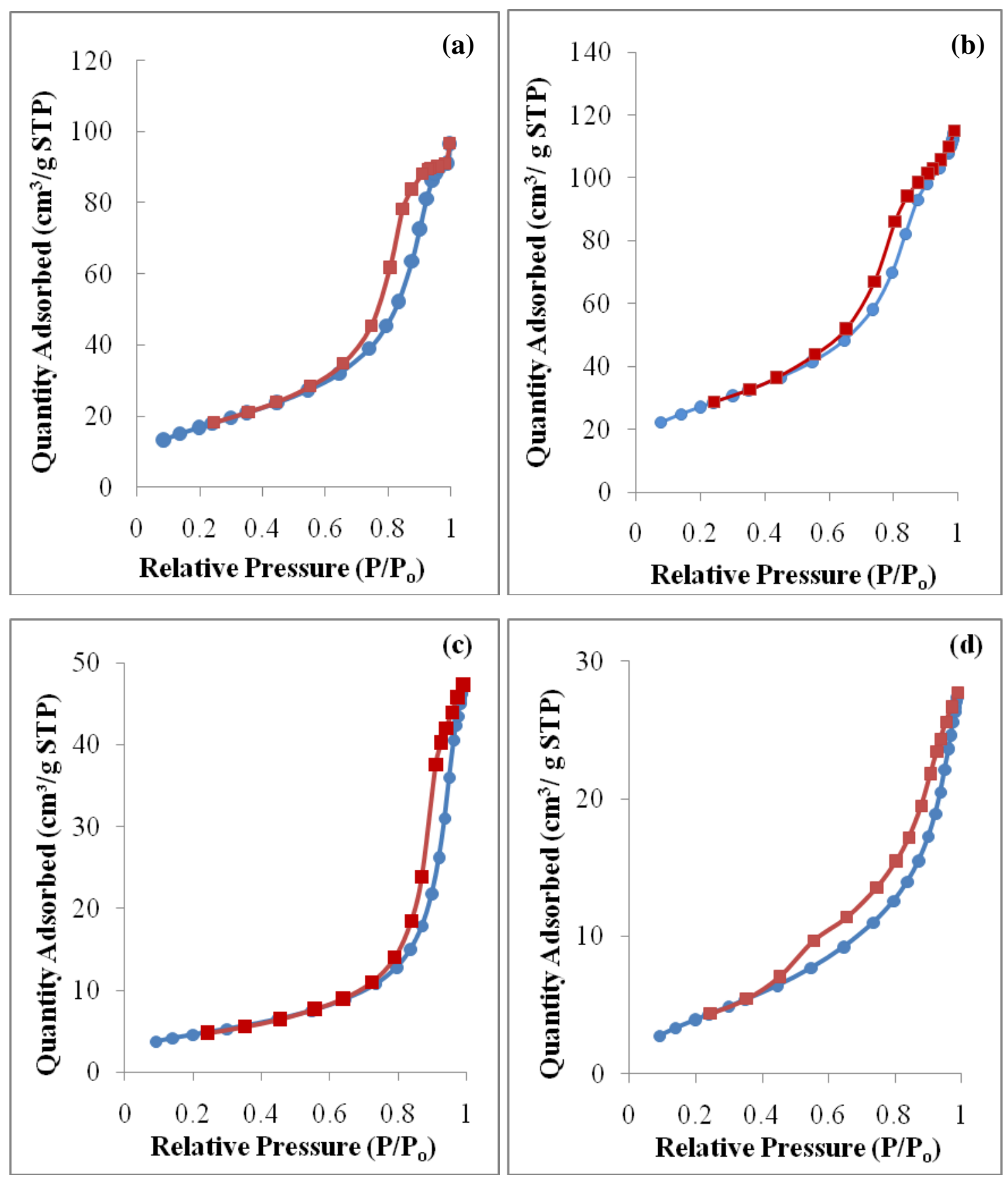

FIGURE 4.7 - Nitrogen adsorption-desorption isotherm pattern as synthesized of $\mathrm{CeO}_{2}$ nanoplates using $\mathrm{H}_{2} \mathrm{O}_{2}$ (a), nanoplates using $\mathrm{NH}_{4} \mathrm{OH}$ (b), nanocubes (c), and nanorods (d), (• adsorption, $\square$ desorption).

Nanoplates also present a typical type IV pattern with hysteresis loop as shown in Fig. 4.7a-b, which is characteristic of mesoporous material according to the classification of 
IUPAC. Characteristic features of the Type IV isotherm are its hysteresis loop, which is associated with capillary condensation taking place in mesopores. Type IV isotherms are given by many mesoporous industrial adsorbents (Sing, 1985). A sharp increase in adsorption volume of $\mathrm{N}_{2}$ was observed and located in the $\mathrm{P} / \mathrm{P}_{\mathrm{o}}$ range of $0.70-0.85$. This sharp increase can be attributed to the capillary condensation, indicating a good homogeneity of the sample and fairly small pore size since the $\mathrm{P} / \mathrm{P}_{\mathrm{o}}$ position of the inflection point is related to the pore dimension (Pavasupree, 2006). The pore size distribution based on Barret-Joyner-Halenda $(\mathrm{BJH})$ model of $\mathrm{CeO}_{2}$ at different shapes is shown in Figure 4.8.

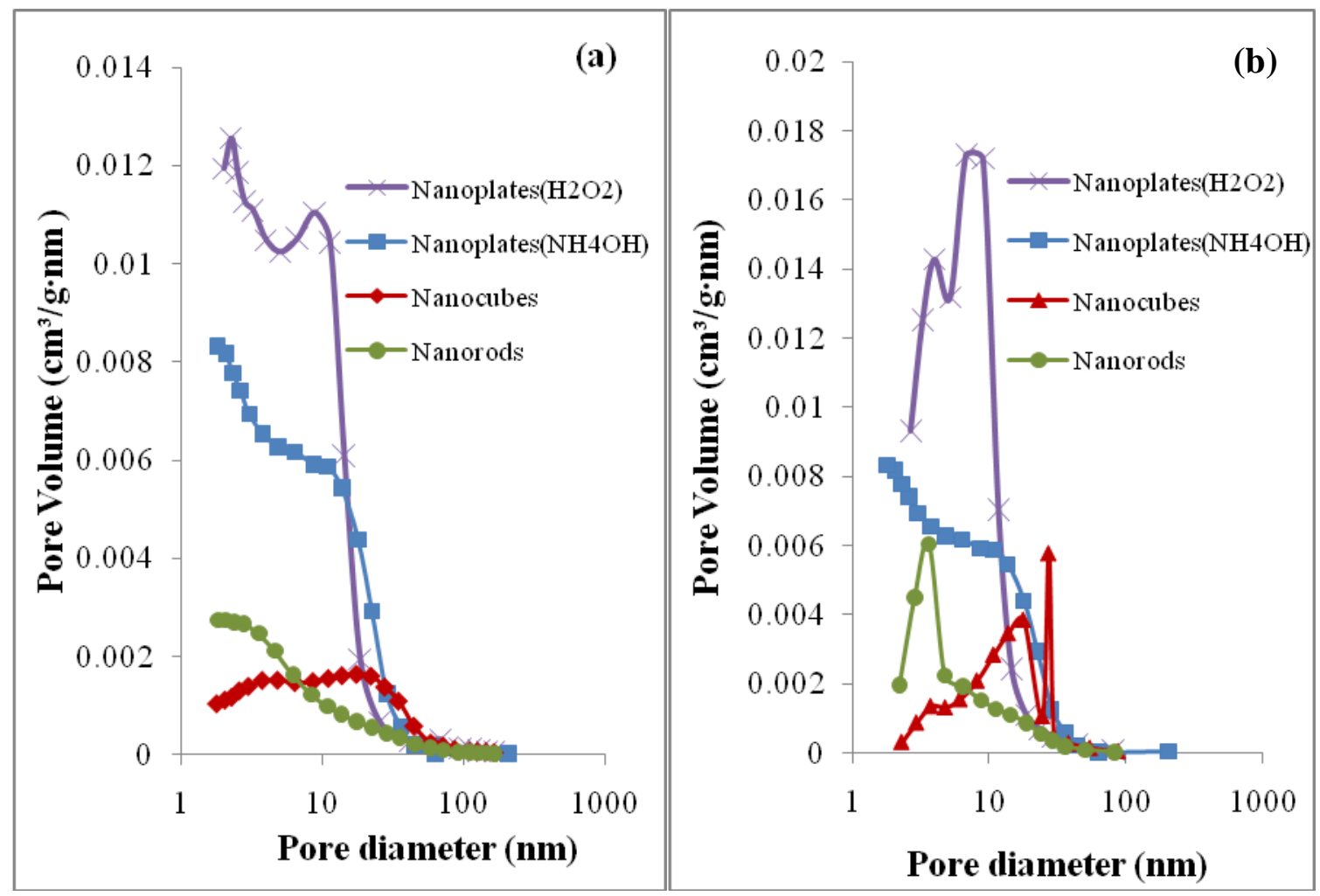

FIGURE 4.8 - Plot of the pore volume vs. pore diameter for $\mathrm{CeO}_{2}$ nanoplates by $\mathrm{H}_{2} \mathrm{O}_{2}$, nanoplates by $\mathrm{NH}_{4} \mathrm{OH}$, nanocubes, and nanorods in $\mathrm{BJH}$ adsorption (a) and desorption (b). 
We can see from Figure 4.8 of adsorption and desorption pore diameter distribution that the application of $\mathrm{BJH}$ model to desorption branch will give a completely different result compared to that of the adsorption branch. Similar phenomena have been observed by others (Groen, 2003). In desorption branch, nanocubes and nanorods isotherms have narrower pores centered on $13 \mathrm{~nm}$ and $7 \mathrm{~nm}$, respectively. However, in the adsorption branch, nanorods and nanocubes show a broad distribution centered approximately $17 \mathrm{~nm}$ and $9 \mathrm{~nm}$, respectively. Nanoplates by $\mathrm{NH}_{4} \mathrm{OH}$ derived from the adsorption branch indicates that the created mesopores show a semi-narrow distribution by having an average pore diameter of about 8-9 $\mathrm{nm}$ while nanoplates by $\mathrm{H}_{2} \mathrm{O}_{2}$ had about 7-8 nm. The pore sizes of the $\mathrm{CeO}_{2}$ nanomaterials are within the mesopores range 2-50 $\mathrm{nm}$ (Sing, 1985), which prove that they are of mesoporous material. Table IV-II summarizes the pore diameter and pore volume for the ceria structures studied by BJH adsorption.

TABLE IV-II

AVERAGE PORE SIZE AND PORE VOLUME OF THE PREPARED CERIA NANOMATERIALS

\begin{tabular}{cccc}
\hline Precursor & Shape & $\begin{array}{c}\text { Pore Volume by BJH } \\
\text { Adsorption }\left(\mathrm{cm}^{3} / \mathrm{g}\right)\end{array}$ & $\begin{array}{c}\text { Pore size by BJH } \\
\text { Adsorption }(\mathrm{nm})\end{array}$ \\
\hline $\mathrm{H}_{2} \mathrm{O}_{2}$ & Nanoplate & 0.179 & 7.33 \\
$\mathrm{NH}_{4} \mathrm{OH}$ & Nanoplate & 0.149 & 8.54 \\
$\mathrm{NaOH}-6 \mathrm{M}$ & Nanocube & 0.073 & 14.75 \\
$\mathrm{NaOH}-9 \mathrm{M}$ & Nanorod & 0.042 & 8.52 \\
\hline
\end{tabular}




\section{XPS analysis}

X-ray photoelectron spectroscopy (XPS) was conducted in the studied nanoceria structures. Figure 4.9 exhibits the XPS patterns of $\mathrm{CeO}_{2}$ nanoplates, nanocubes, and nanorods. Peaks of Ce 3d, O 1s, C 1s, and Ce 4d can be recognized. Also, there were no peaks observed attributable to $\mathrm{Na} 2 \mathrm{p}$ and ammonium which means that the $\mathrm{NaOH}$ and $\mathrm{NH}_{4} \mathrm{OH}$ impurities were not present.

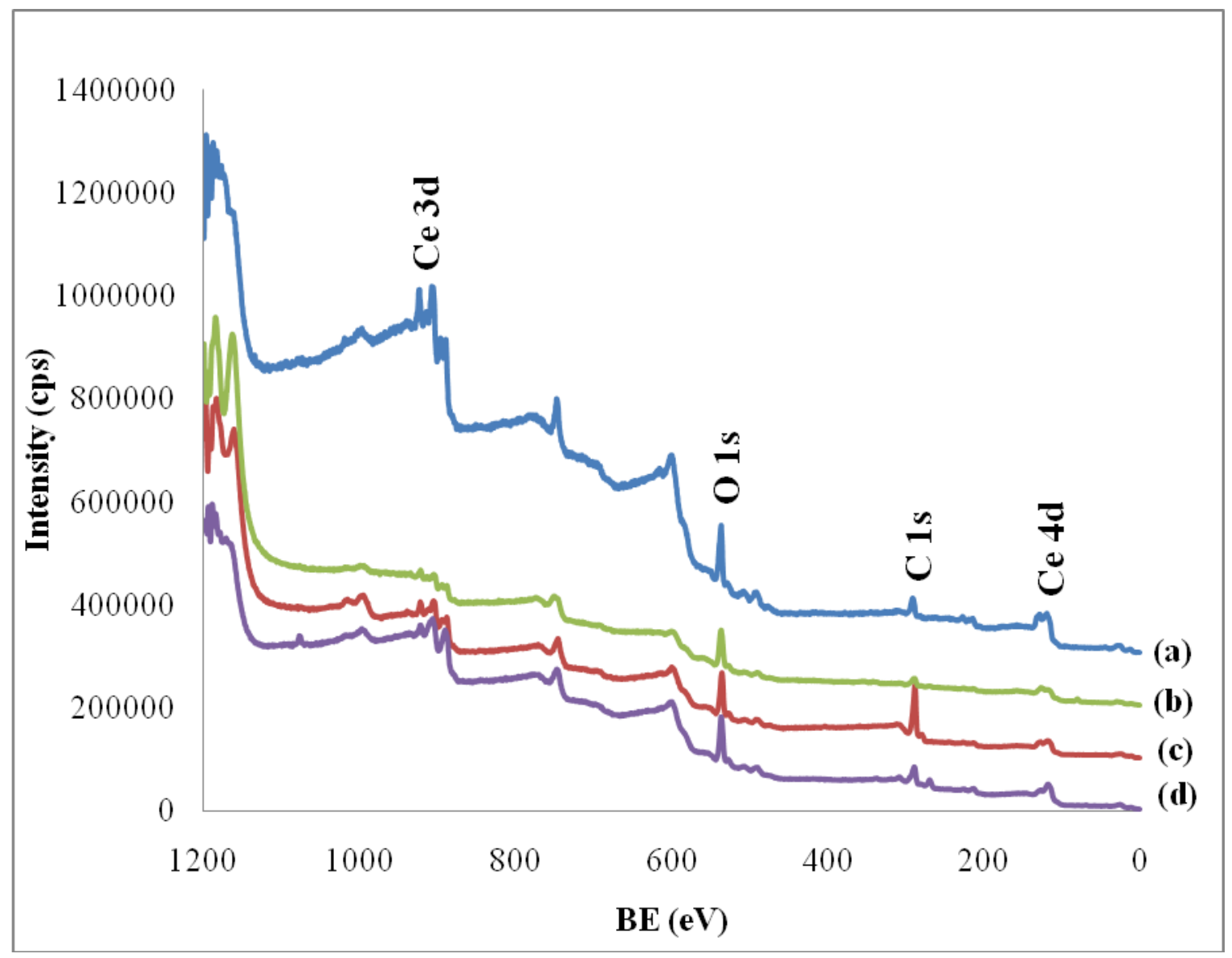

FIGURE 4.9 - XPS survey spectra of $\mathrm{CeO}_{2}$ nanoplates by $\mathrm{H}_{2} \mathrm{O}_{2}$ (a), nanocubes (b), nanoplates by $\mathrm{NH}_{4} \mathrm{OH}(\mathrm{c})$, and nanorods (d). 
Moreover, Figure 4.10 indicates that six Ce 3d binding energy (BE) peaks were steady with previous studies on $\mathrm{Ce}^{4+}$ indicating that the main cerium valence of cerium oxide in the nanoplates, nanocubes, and nanorods was $\mathrm{Ce}^{4+}$. Ceria nanoplates using $\mathrm{H}_{2} \mathrm{O}_{2}$ show a higher intensity than the rest while nanoplates using $\mathrm{NH}_{4} \mathrm{OH}$ and nanocubes have similar intensities.

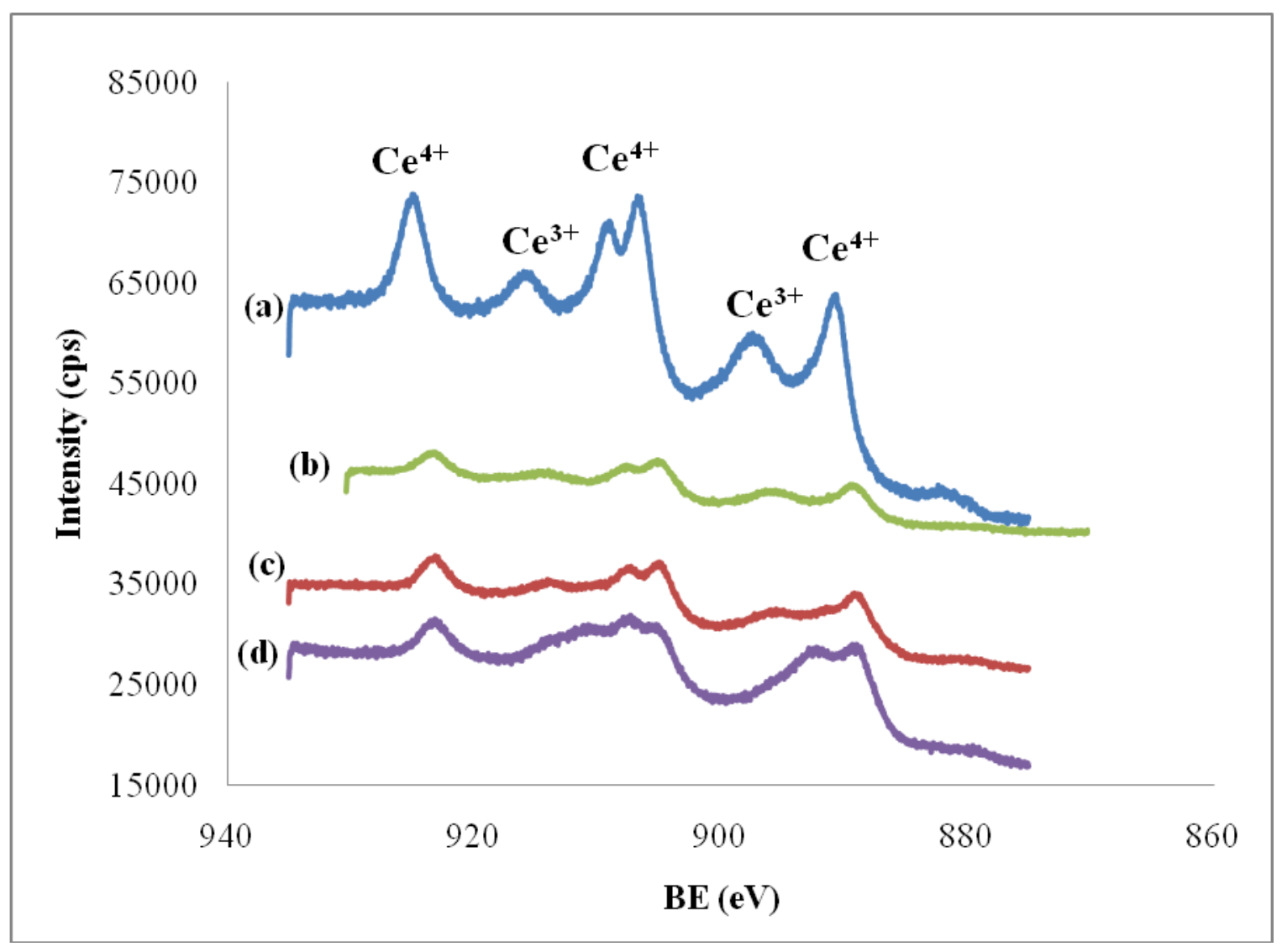

FIGURE 4.10 - XPS spectrum of the six peaks of Ce 3d for nanoplates by $\mathrm{H}_{2} \mathrm{O}_{2}$ (a), nanocubes (b), nanoplates by $\mathrm{NH}_{4} \mathrm{OH}$ (c), and nanorods (d).

The mixed valence state $\left(\mathrm{Ce}^{3+}\right.$ and $\left.\mathrm{Ce}^{4+}\right)$ is illustrated in Figure 4.11 for the synthesized cerium oxide nanoplates by $\mathrm{H}_{2} \mathrm{O}_{2}$. Ceria nanoplates, nanocubes and nanorods also show the same presence of a mixed valence state. $\mathrm{Ce}^{3+}$ ions are introduced in the nanoceria crystal lattice because of oxygen vacancies created by surface chemical 
reactions (Tarnuzzer, 2005). Also, Tarnuzzer suggested that nanoceria behaves as an antioxidant due to the presence of the mixed valence states of $\mathrm{Ce}^{3+}$ and $\mathrm{Ce}^{4+}$ on the surface.

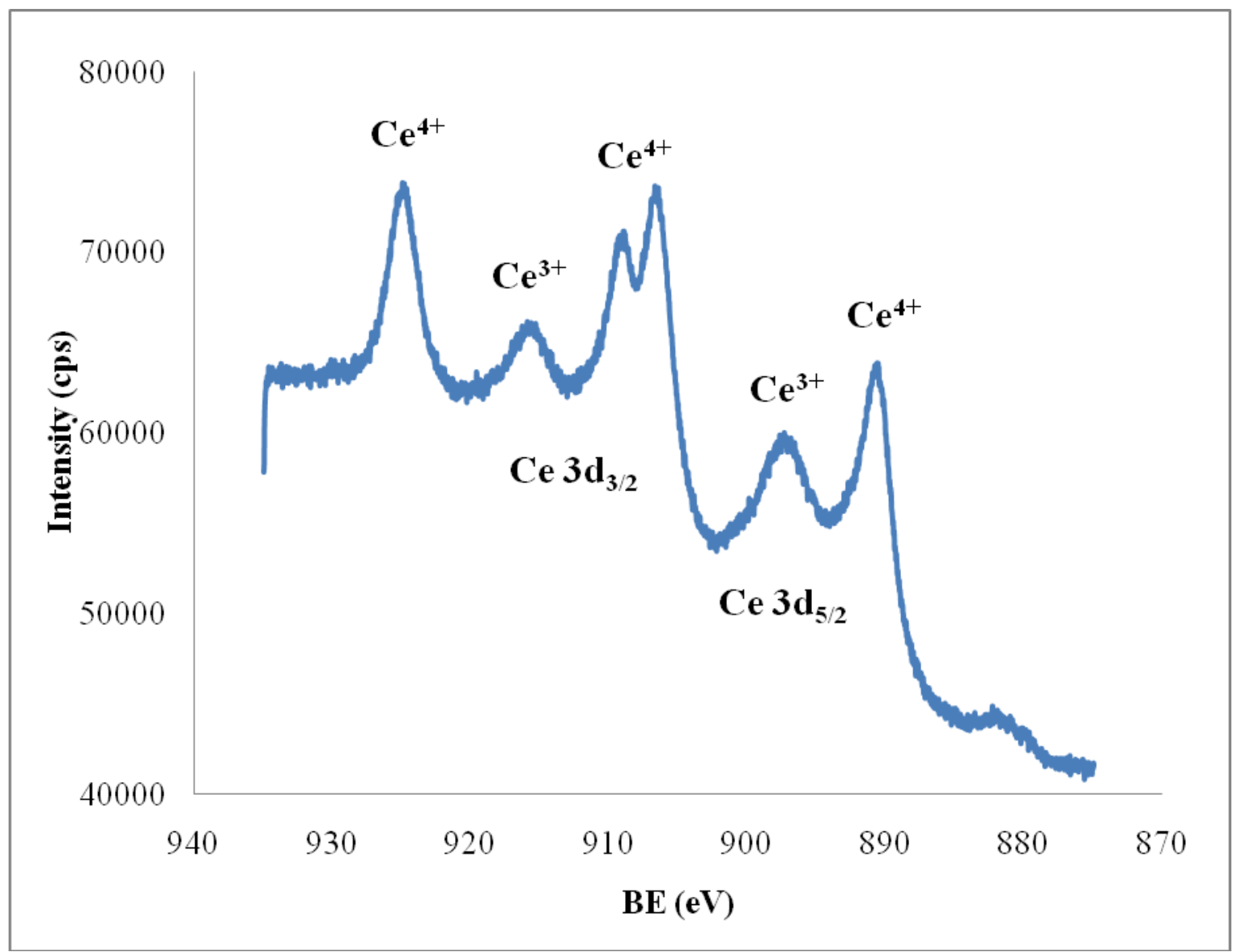

FIGURE 4.11 - XPS spectrum of the synthesized ceria nanoplates by $\mathrm{H}_{2} \mathrm{O}_{2}$ with the mixed valence state.

Deconvoluted XPS Ce (3d) spectra were performed in $\mathrm{CeO}_{2}$ nanoplates, nanocubes, and nanorods. An example image of deconvoluted peaks of ceria nanocubes is shown in Figure 4.12. Similar peak fitting for the XPS spectra of the other $\mathrm{CeO}_{2}$ nanomaterials are presented in Appendix 2. The peaks $v_{0}, v^{\prime}, u_{0}$, and $u^{\prime}$ are characteristic of $\mathrm{Ce}^{3+}$ while $v^{\prime \prime}, v^{\prime \prime},, u, u$ ', and $u^{\prime \prime}$ are attributed to $\mathrm{Ce}^{4+}$ (Seal, 2001). In the present 
deconvoluted spectrums, peak $v$ has a value of zero because it was not necessary to add another peak to fit it into the actual spectrum.

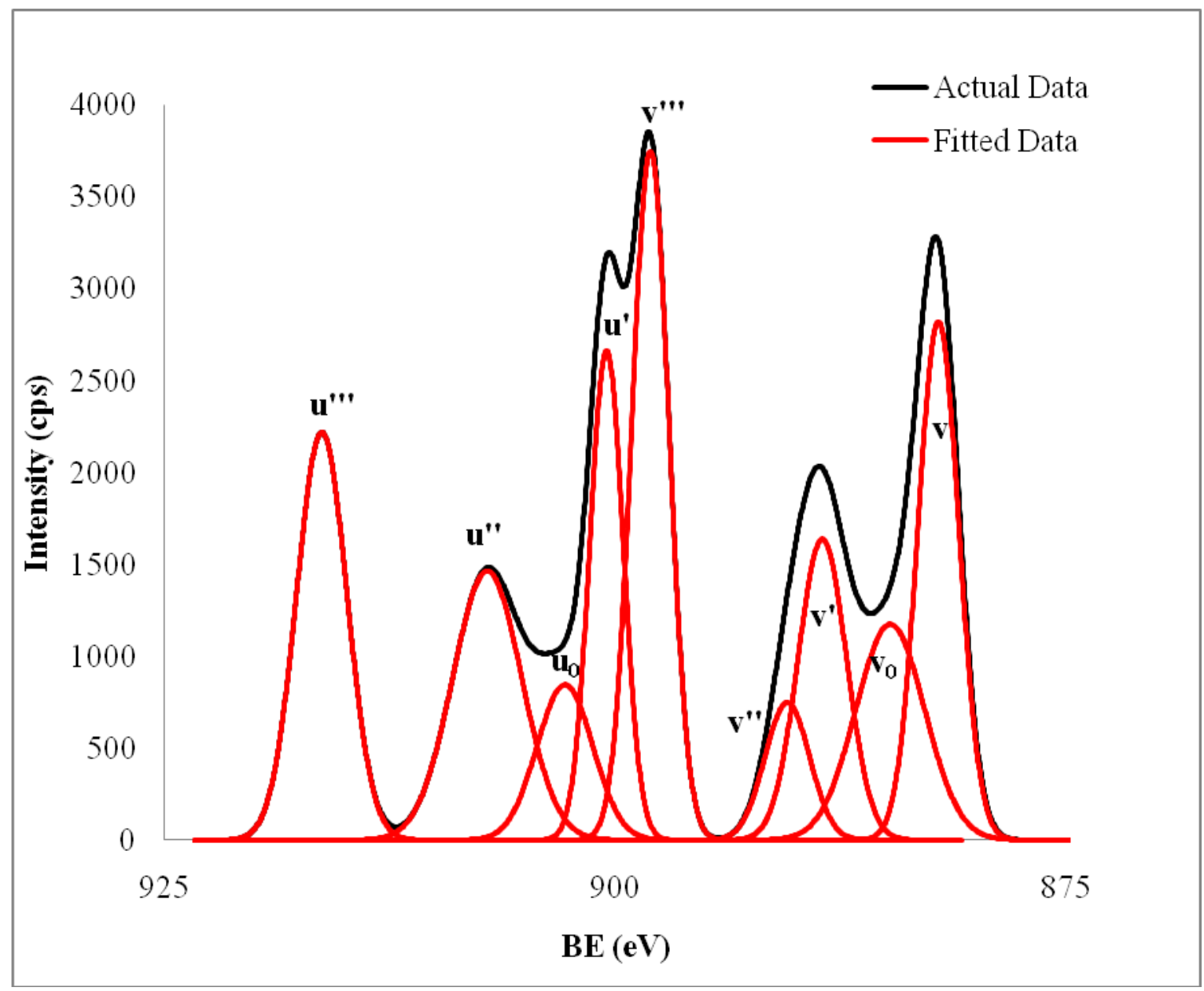

FIGURE 4.12 - Deconvoluted XPS Ce (3d) spectrum of ceria nanocubes.

The individual peak positions for all the studied nanoceria shapes are listed in Table IVIII. Notice that the values of the individual peaks are essentially identical between the different shapes of ceria which indicates that the fitted-peaks were introduced in similar positions in order to fit the actual Ce $3 \mathrm{~d}$ spectrum. 
TABLE IV-III

XPS BINDING ENERGIES OF INDIVIDUAL PEAKS OF THE CE (3D) SPECTRUM FOR DIFFERENT $\mathrm{CeO}_{2}$ SHAPES

\begin{tabular}{|c|c|c|c|c|c|c|c|c|c|}
\hline \hline \multirow{2}{*}{ Shape } & \multicolumn{4}{|c|}{ Ce (3d $\mathbf{d}_{5 / 2}$ ) } & \multicolumn{5}{c|}{ Ce (3d $\left.\mathbf{d}_{3 / 2}\right)$} \\
\cline { 2 - 10 } & $v_{0}$ & $v^{\prime}$ & $v^{\prime \prime}$ & $v^{\prime \prime \prime}$ & $u_{0}$ & $u$ & $u^{\prime}$ & $u^{\prime \prime}$ & $u^{\prime \prime \prime}$ \\
\hline Nanoplate $\left(\mathrm{H}_{2} \mathrm{O}_{2}\right)$ & 882.32 & 885.17 & 888.39 & 891.00 & 898.40 & 901.07 & 903.61 & 907.07 & 916.72 \\
\hline Nanoplate $\left(\mathrm{NH}_{4} \mathrm{OH}\right)$ & 882.14 & 884.26 & 888.27 & 890.81 & 898.28 & 900.88 & 903.55 & 907.56 & 916.62 \\
\hline Nanocube & 881.78 & 884.99 & 887.72 & 890.27 & 898.03 & 900.70 & 903.37 & 907.31 & 916.23 \\
\hline Nanorod & 882.08 & 885.29 & 887.78 & 890.33 & 897.97 & 900.70 & 903.07 & 906.77 & 916.05 \\
\hline
\end{tabular}

A partial quantitative analysis of the integrated peak area can provide the concentration of $\mathrm{Ce}^{3+}$ ions in the synthesized ceria. Equation 1 calculates the fraction of $\mathrm{Ce}^{3+}($ Seal, 2001):

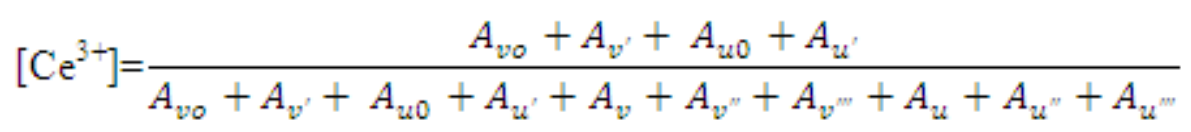

where $A_{i}$ is the integrated area of peak " $i$." Table IV-IV and IV-V present the integrated areas obtained from each peak and the concentration of $\mathrm{Ce}^{3+}$ of ceria nanoplates, nanocubes and nanorods, respectively. 
TABLE IV-IV

INTEGRATED AREAS OF INDIVIDUAL PEAKS

\begin{tabular}{|c|c|c|c|c|c|c|c|c|c|}
\hline \hline \multirow{2}{*}{ Shape } & \multicolumn{7}{|c|}{ Area of Peak } \\
\cline { 2 - 10 } & $A_{v 0}$ & $A_{v^{\prime}}$ & $A_{v^{\prime \prime}}$ & $A_{v^{\prime \prime \prime}}$ & $A_{u 0}$ & $A_{u}$ & $A_{u^{\prime}}$ & $A_{u^{\prime \prime}}$ & $A_{u^{\prime \prime \prime}}$ \\
\hline $\begin{array}{c}\text { Nanoplate } \\
\left(\mathrm{H}_{2} \mathrm{O}_{2}\right)\end{array}$ & 14680 & 11040 & 8354.20 & 15220 & 10500 & 6139.87 & 9474.21 & 8199.96 & 4743.22 \\
\hline $\begin{array}{c}\text { Nanoplate } \\
(\mathrm{NH}+\mathrm{OH})\end{array}$ & 34770 & 30830 & 45370 & 32740 & 23230 & 27170 & 27840 & 15450 & 17990 \\
\hline & 24920 & 25780 & 10360 & 8266.41 & 25640 & 10910 & 25630 & 16880 & 13150 \\
\hline Nanocube & 30890 & 20140 & 8610.84 & 12070 & 25920 & 11800 & 18890 & 20980 & 14730 \\
\hline Nanowire
\end{tabular}

Using Equation 1, we can calculate the concentration of $\mathrm{Ce}^{3+}$. It has been reported that the concentration of $\mathrm{Ce}^{3+}$ increases with a decrease in particle size of nanoceria (Deshpande, 2005). In the current study, we found that nanocubes and nanorods have high concentration of $\mathrm{Ce}^{3+}$ and smaller particle sizes. It can be attributed to higher oxygen vacancies in the smaller particles.

TABLE IV-V

CONCENTRATION OF $\mathrm{Ce}^{3+}$ FOR DIFFERENT SHAPES OF CERIA CALCULATED USING EQ. (1).

\begin{tabular}{ccccc}
\hline Precursor & $\mathrm{H}_{2} \mathrm{O}_{2}$ & $\mathrm{NH}_{4} \mathrm{OH}$ & $\mathrm{NaOH}-6 \mathrm{M}$ & NaOH-9M \\
\hline Shape & Nanoplate & Nanoplate & Nanocube & Nanorod \\
\hline Concentration of $\mathrm{Ce}^{3+}$ & 0.52 & 0.46 & 0.63 & 0.58 \\
\hline
\end{tabular}




\section{E. XRD analysis}

The crystallite size and crystal structure of the $\mathrm{CeO}_{2}$ nanoplates, nanocubes and nanorods are obtained by examining the XRD patterns. Figure 4.13 exhibits the XRD patterns of the $\mathrm{CeO}_{2}$ nanomaterials after calcined at $100^{\circ} \mathrm{C}$. The exposing XRD peaks correspond to the (111), (200), (220), (311), (400), (3310, (420), and (422) planes of a ceria cubic fluorite structure (space group Fm3m (225)) with an average lattice parameter $a=5.407 \AA$. The XRD peaks for nanorods (c) and nanoplates using $\left(\mathrm{NH}_{4} \mathrm{OH}\right)(\mathrm{d})$ are very broad which indicates that these two morphologies have low crystallinity or contain a large portion of amorphous phase (Sujama, 2008).

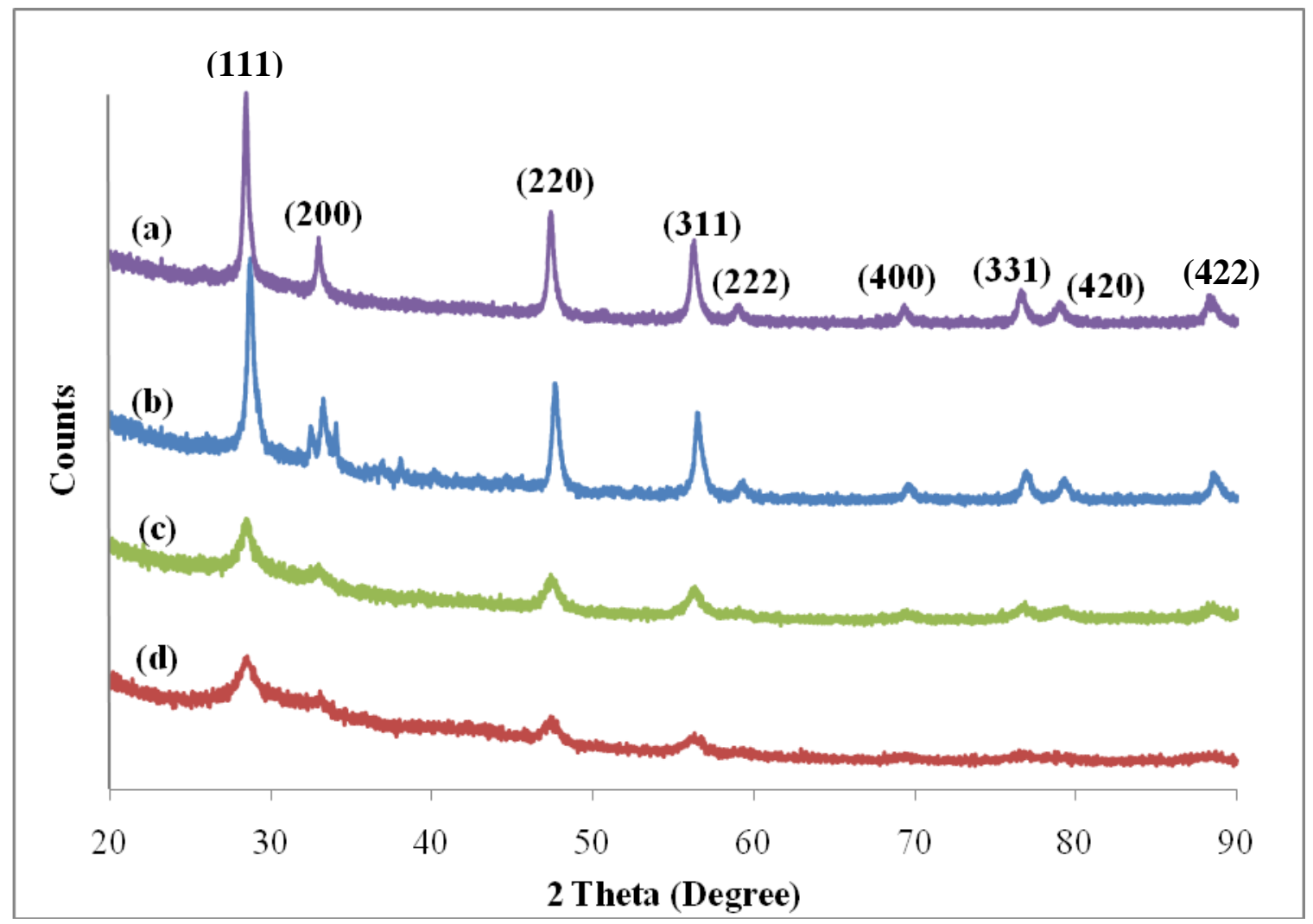

FIGURE 4.13 - XRD of $\mathrm{CeO}_{2}$ nanoplates by $\mathrm{H}_{2} \mathrm{O}_{2}$ (a), nanocubes (b), nanoplates by $\mathrm{NH}_{4} \mathrm{OH}(\mathrm{c})$, and nanorods (d). 
The XRD patterns for $\mathrm{CeO}_{2}$ nanoplates, nanocubes and nanorods calcined at $400^{\circ} \mathrm{C}$ and $600^{\circ} \mathrm{C}$ are illustrated in Figures 4.14 to 4.17 . The nanoplates exhibit in Figure 4.14 using $\mathrm{H}_{2} \mathrm{O}_{2}$ show a higher intensity at $100^{\circ} \mathrm{C}$ than at $400^{\circ} \mathrm{C}$ while nanoplates using $\mathrm{NH}_{4} \mathrm{OH}$ shown in Figure 4.15 do not present any difference between $100^{\circ} \mathrm{C}$ and $600^{\circ} \mathrm{C}$. XRD patterns for nanocubes $\left(\mathrm{C}_{\mathrm{NaOH}}=6 \mathrm{M}\right)$ shown in Figure 4.16 at $100^{\circ} \mathrm{C}$ shows small peaks in between the (200) plane, either another crystal structure is present or some $\mathrm{NaOH}$ impurities. However, at $400^{\circ} \mathrm{C}$, the (200) plane shows a uniform peak which denies the fact of another crystal structure leaving the possibility of some residues of $\mathrm{NaOH}$ impurities in the sample. For nanorods, $\mathrm{XRD}$ spectrum is wider at $100^{\circ} \mathrm{C}$ and has lower intensity than at $600^{\circ} \mathrm{C}$ as shown in Figure 4.17. Narrow peaks show high crystallinity while wide peaks, low crystallinity.

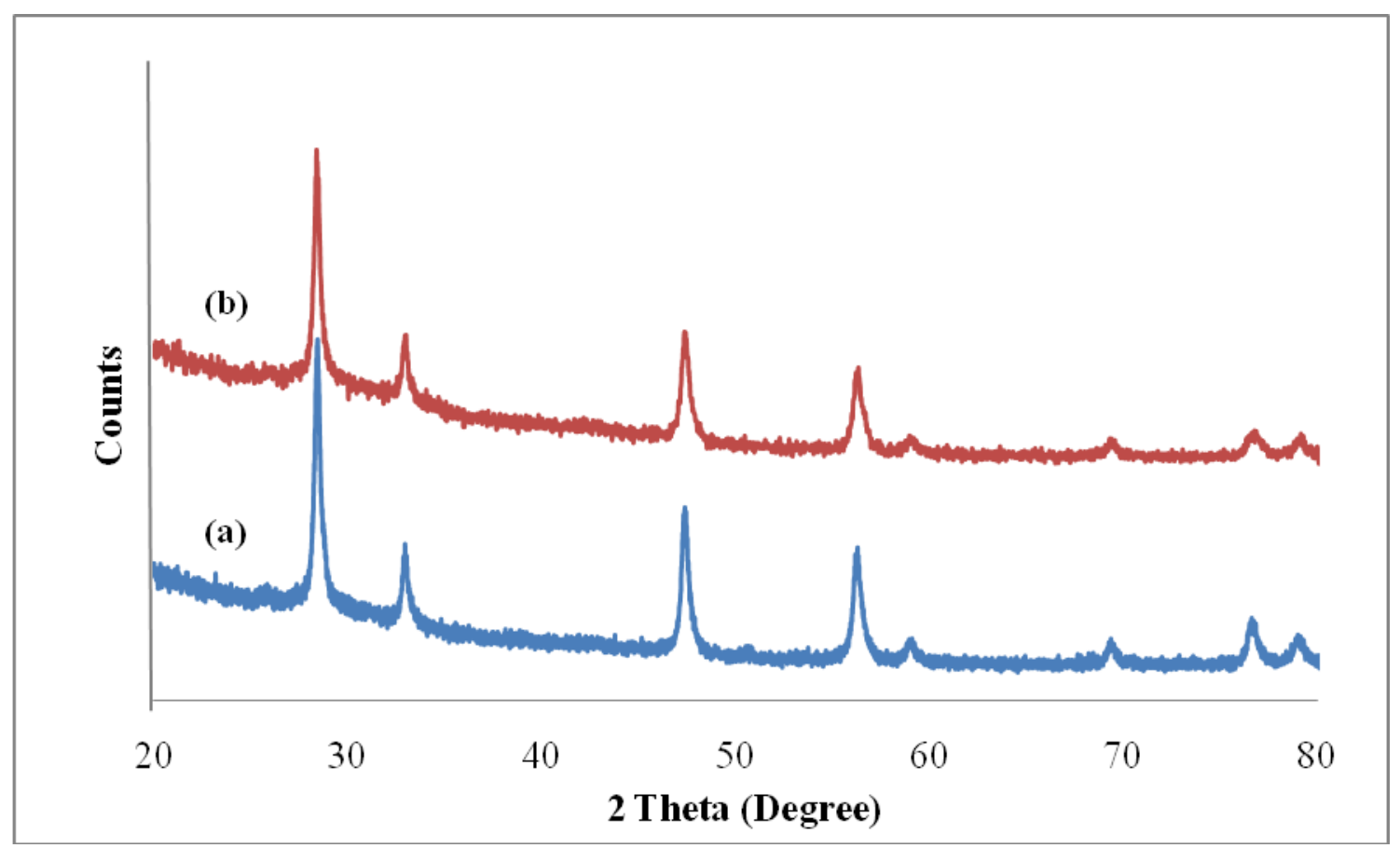

FIGURE 4.14 - XRD patterns of $\mathrm{CeO}_{2}$ nanoplates by $\mathrm{H}_{2} \mathrm{O}_{2}$ calcined at $100^{\circ} \mathrm{C}$ (a) and $400^{\circ} \mathrm{C}$ (b). 


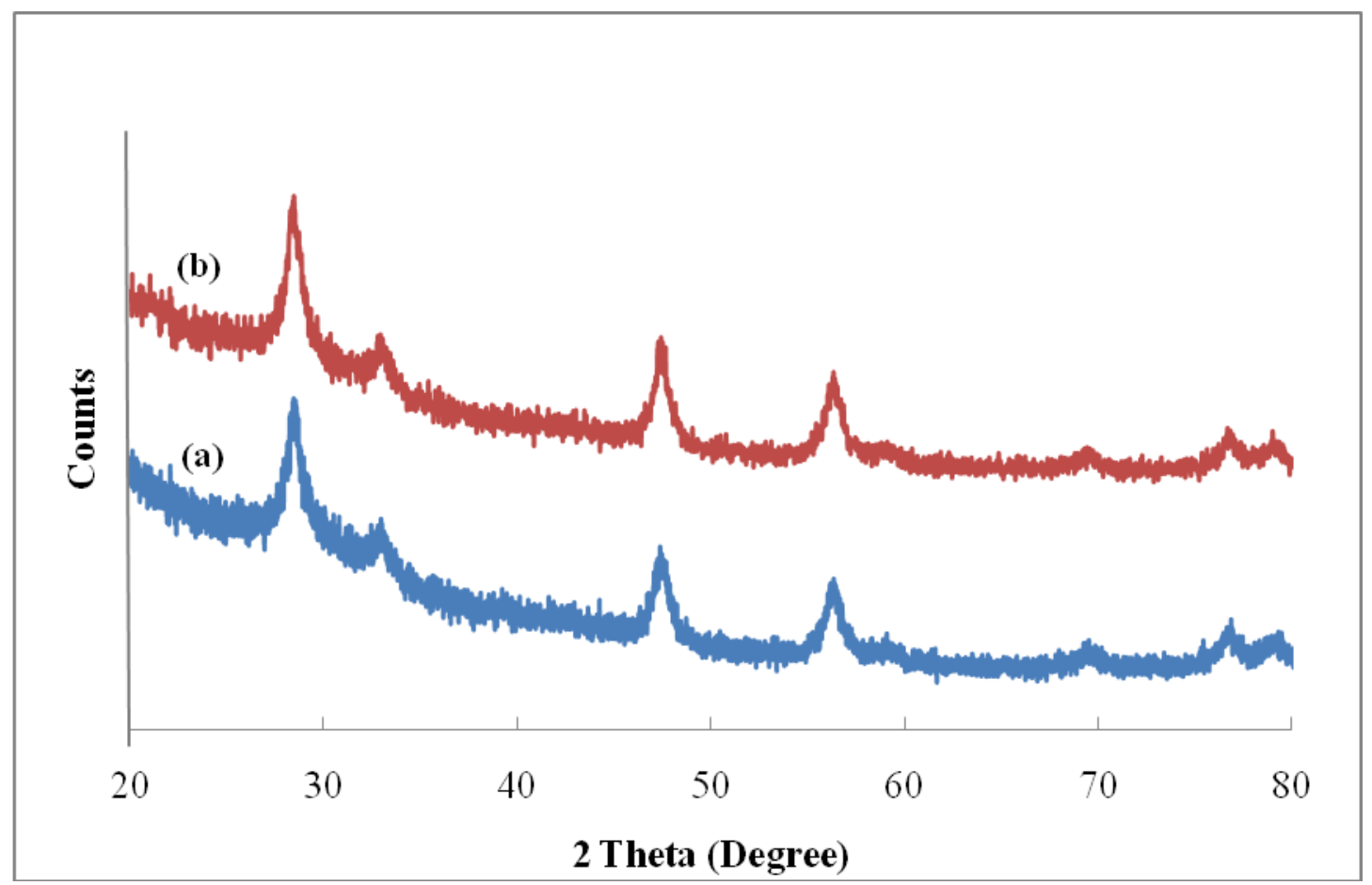

FIGURE 4.15 - XRD patterns of $\mathrm{CeO}_{2}$ nanoplates by $\mathrm{NH}_{4} \mathrm{OH}$ calcined at $100^{\circ} \mathrm{C}$ (a) and $600^{\circ} \mathrm{C}(\mathrm{b})$.

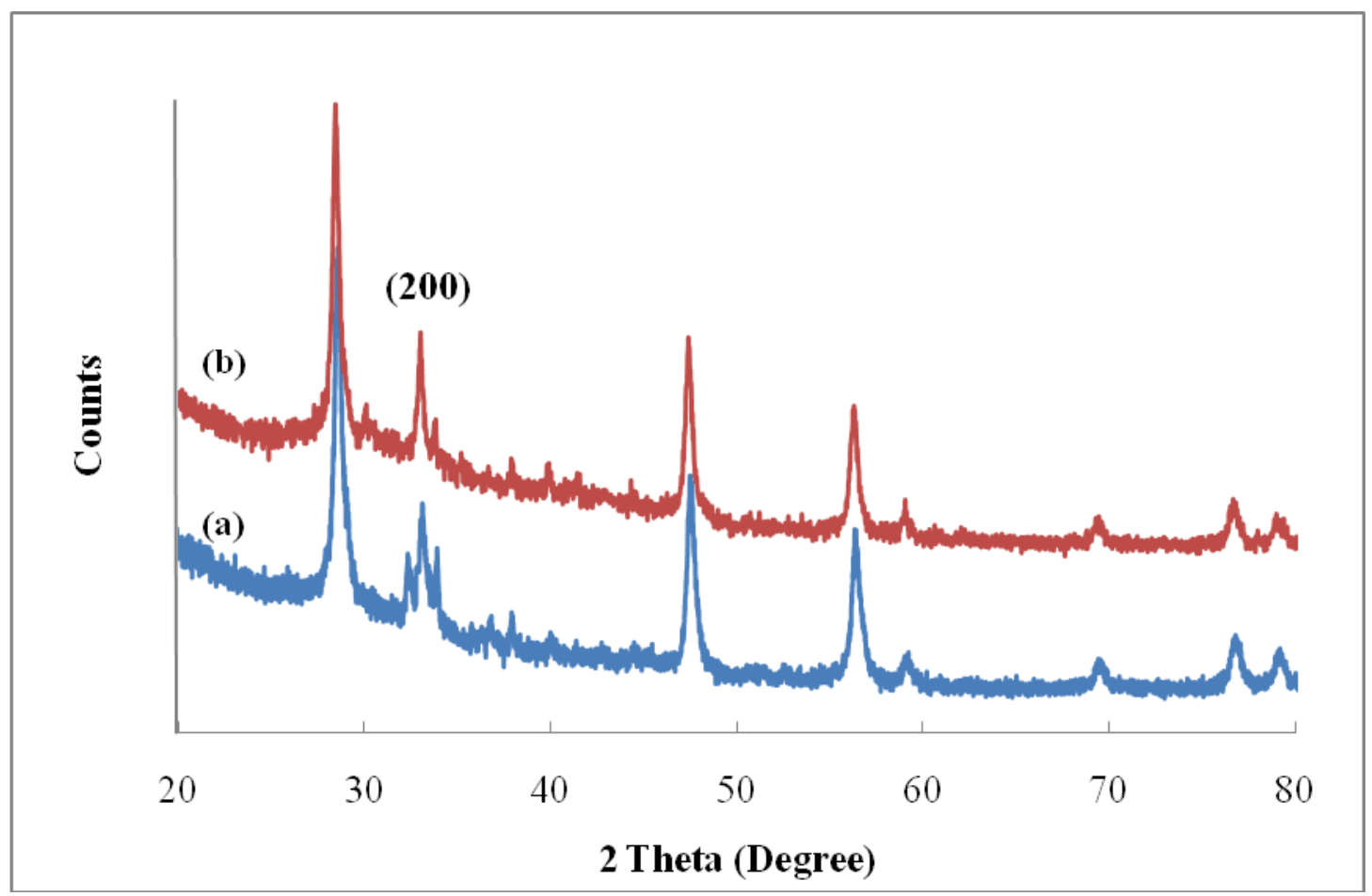

FIGURE 4.16 - XRD patterns of $\mathrm{CeO}_{2}$ nanocubes $\left(\mathrm{C}_{\mathrm{NaOH}}=6 \mathrm{M}\right)$ calcined at $100^{\circ} \mathrm{C}$ (a) and $400^{\circ} \mathrm{C}(\mathrm{b})$. 


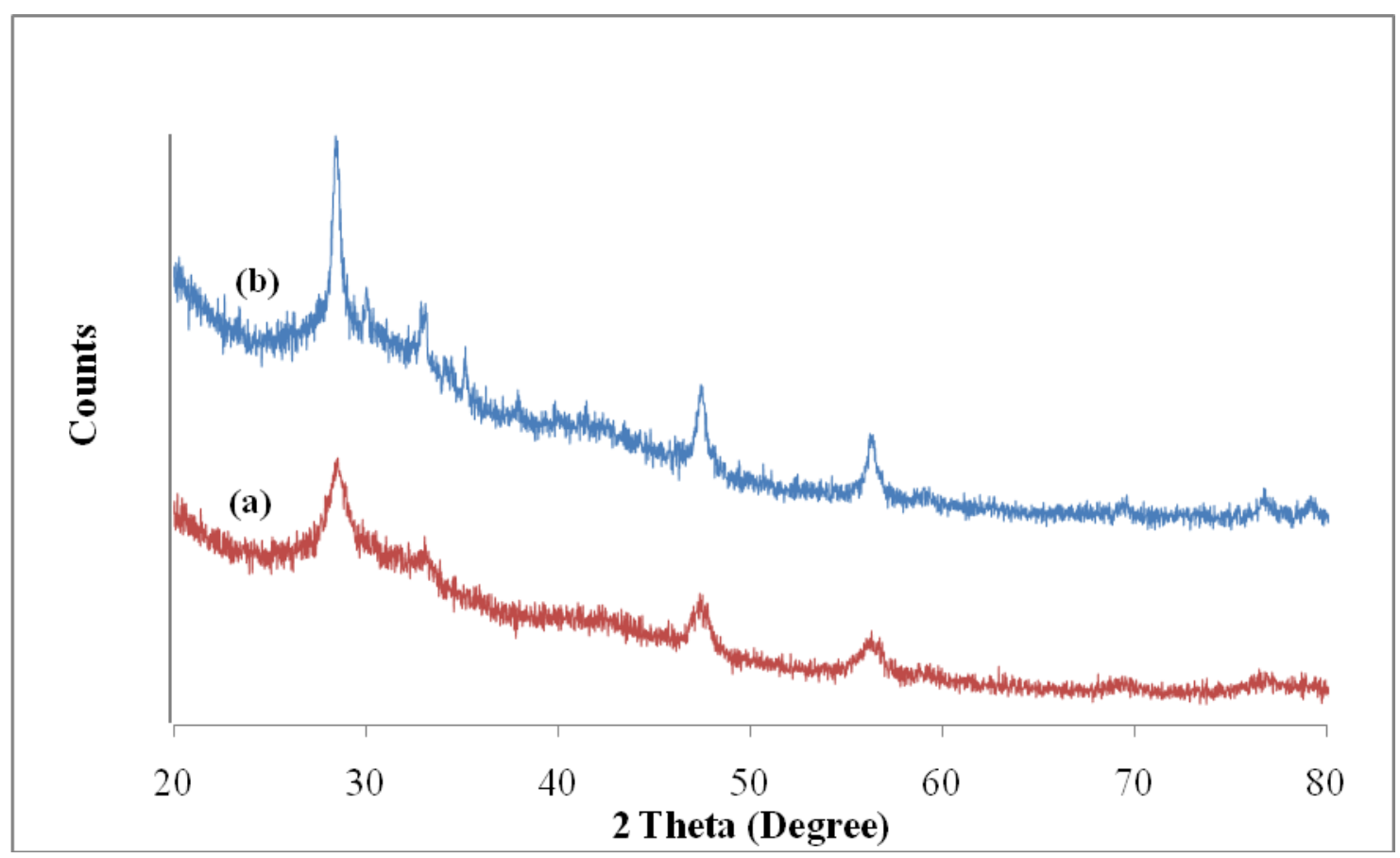

FIGURE 4.17 - XRD patterns of $\mathrm{CeO}_{2}$ nanorods calcined at $100^{\circ} \mathrm{C}$ (a) and $600^{\circ} \mathrm{C}$ (b).

Table IV-VI shows the calculated lattice parameters, $a$, using Equation 2 versus the theoretical XRD values at different calcinations temperatures.

$$
a=d_{h k l} \sqrt{h^{2}+k^{2}+l^{2}}
$$

The experimental lattice parameters are similar to the theoretical ones proving that the diffraction peaks correspond only to $\mathrm{CeO}_{2}$. The different lattice parameters values are due to the different precursors used to synthesize $\mathrm{CeO}_{2}$. It was necessary to find the right ceria pattern that belongs to ceria with its respective precursor. It is noted that some values of the lattice parameter for $\mathrm{CeO}_{2}$ nanostructures are lower or higher than that reported for the bulk of $\mathrm{CeO}_{2}$ which is $a=5.411 \AA$ provided in other studies (Zhou, 
$2005)$. The lattice parameter only varied within the average range $(\Delta a / a \approx 0.25 \%)$. In addition, the (111) plane is the most exposing plane in the XRD spectra.

TABLE IV-VI

COMPARISON OF LATTICE PARAMETERS AT DIFFERENT CALCINATION TEMPERATURES

\begin{tabular}{cccc|cc|cc}
\hline & & \multicolumn{2}{c|}{$100^{\circ} \mathrm{C}$} & \multicolumn{2}{c|}{$400^{\circ} \mathrm{C}$} & \multicolumn{2}{c}{$600^{\circ} \mathrm{C}$} \\
\cline { 3 - 8 } Precursor & Shape & $\begin{array}{c}a, \\
\text { calculated }\end{array}$ & $\begin{array}{c}a, \\
\text { from } \\
\text { XRD }\end{array}$ & $\begin{array}{c}a, \\
\text { calculated }\end{array}$ & $\begin{array}{c}a, \\
\text { from } \\
\text { XRD }\end{array}$ & $\begin{array}{c}a, \\
\text { calculated }\end{array}$ & $\begin{array}{c}a \text {, from } \\
\text { XRD }\end{array}$ \\
\cline { 3 - 8 } $\mathrm{H}_{2} \mathrm{O}_{2}$ & Nanoplate & 5.4291 & 5.4124 & 5.4382 & 5.4124 & - & - \\
$\mathrm{NaOH}$ & Nanocube & 5.4035 & 5.4037 & 5.4344 & 5.4124 & - & - \\
$\mathrm{NaOH}$ & Nanorod & 5.4157 & 5.4037 & - & - & 5.4157 & 5.411 \\
$\mathrm{NH}_{4} \mathrm{OH}$ & Nanoplate & 5.4291 & 5.4037 & - & - & 5.4269 & 5.4037 \\
\hline
\end{tabular}

In order to calculate the crystallite size $\left(\mathrm{D}_{\mathrm{hk}}\right)$, the following equations were needed:

$$
\begin{gathered}
\mathrm{n} \lambda=2 \mathrm{~d}_{\mathrm{hkl}} \sin \theta \\
\mathrm{D}_{\mathrm{hkl}}=\frac{0.89 \times \lambda}{\mathrm{B}_{\mathrm{hkl}} \times \cos \theta_{\mathrm{B}}}
\end{gathered}
$$

Equation 3 expresses Bragg's Law where $n=1, \lambda=1.5406 \AA$ and $\theta$ is obtained from XRD spectra. The $a$ refers to the $\mathrm{CeO}_{2} \mathrm{FCC}$ (face-centered-cubic) lattice parameter, and $h, k, l$ are the crystallite size indices while $d$ is the crystalline face space. On the other hand, Equation 4 is the Scherrer equation which is used to calculate the crystallite size ( $\left.D_{\mathrm{hkl}}\right)$ (Tennyson, 2007). The $B_{\mathrm{hkl}}$ corresponds to the measured half-width at maximum peak height. Table IV-VII summarizes the lattice type, lattice parameter and crystallite 
size values of $\mathrm{CeO}_{2}$ nanostructures by using the equations mentioned earlier. The crystallite sizes for nanoplates, nanocubes and nanorods were estimated from X-ray line broadening of the reflections of (111) plane.

\section{TABLE IV-VII}

LATTICE TYPE AND CRYSTALLITE SIZE OF $\mathrm{CeO}_{2} \mathrm{NANOSTRUCTURES}$

\begin{tabular}{cccc|ccc|ccc}
\hline & \multicolumn{3}{c|}{ As synthesized } & \multicolumn{2}{c|}{ Calcined at $400^{\circ} \mathrm{C}$} & \multicolumn{3}{c}{ Calcined at $600^{\circ} \mathrm{C}$} \\
\cline { 2 - 11 } Shape & \multicolumn{2}{c|}{$\begin{array}{c}\text { Lattice } \\
\text { Type }\end{array}$} & $a(\AA)$ & $\begin{array}{c}D_{h k l} \\
(\mathrm{~nm})\end{array}$ & $\begin{array}{c}\text { Lattice } \\
\text { Type }\end{array}$ & $a(\AA)$ & $\begin{array}{c}D_{h k l} \\
(\mathrm{~nm})\end{array}$ & $\begin{array}{c}\text { Lattice } \\
\text { Type }\end{array}$ & $\begin{array}{c}D_{h k l} \\
(\mathrm{~nm})\end{array}$ \\
\hline $\begin{array}{c}\text { Nanoplate } \\
\left(\mathrm{H}_{2} \mathrm{O}_{2}\right)\end{array}$ & Cubic & 5.4291 & 24.92 & Cubic & 5.4382 & 22.90 & - & - & - \\
Nanocube & Cubic & 5.4035 & 19.65 & Cubic & 5.4344 & 17.99 & - & - & - \\
$\begin{array}{c}\text { Nanorod } \\
\text { Nanoplate } \\
\left(\mathrm{NH}_{4} \mathrm{OH}\right)\end{array}$ & Cubic & 5.4157 & 5.97 & - & - & - & Cubic & 5.4382 & 11.40 \\
\hline
\end{tabular}

The lattice type is cubic for the different morphologies of ceria. Lattice parameters values are slightly different to each other except for nanoplates by $\mathrm{NH}_{4} \mathrm{OH}$ which are the same regardless of the calcination temperatures. Figure 4.18 illustrates the effect of calcination temperature and lattice parameter on the crystallite size. We can see that crystallite size in nanoplates using $\mathrm{H}_{2} \mathrm{O}_{2}$ shown in Fig. 4.18a increases at high calcination temperature and lattice parameter while nanoplates using $\mathrm{NH}_{4} \mathrm{OH}$ in Fig $4.18 \mathrm{c}$ remain unchanged or steady, indicating that temperature and lattice parameter do not affect the size. Nanocube's crystallite size in Fig $4.18 \mathrm{~b}$ decreases at high calcination temperature and lattice parameter while the crystallite size of nanorods in Fig 4.18d is proportional to temperature and lattice parameter. 

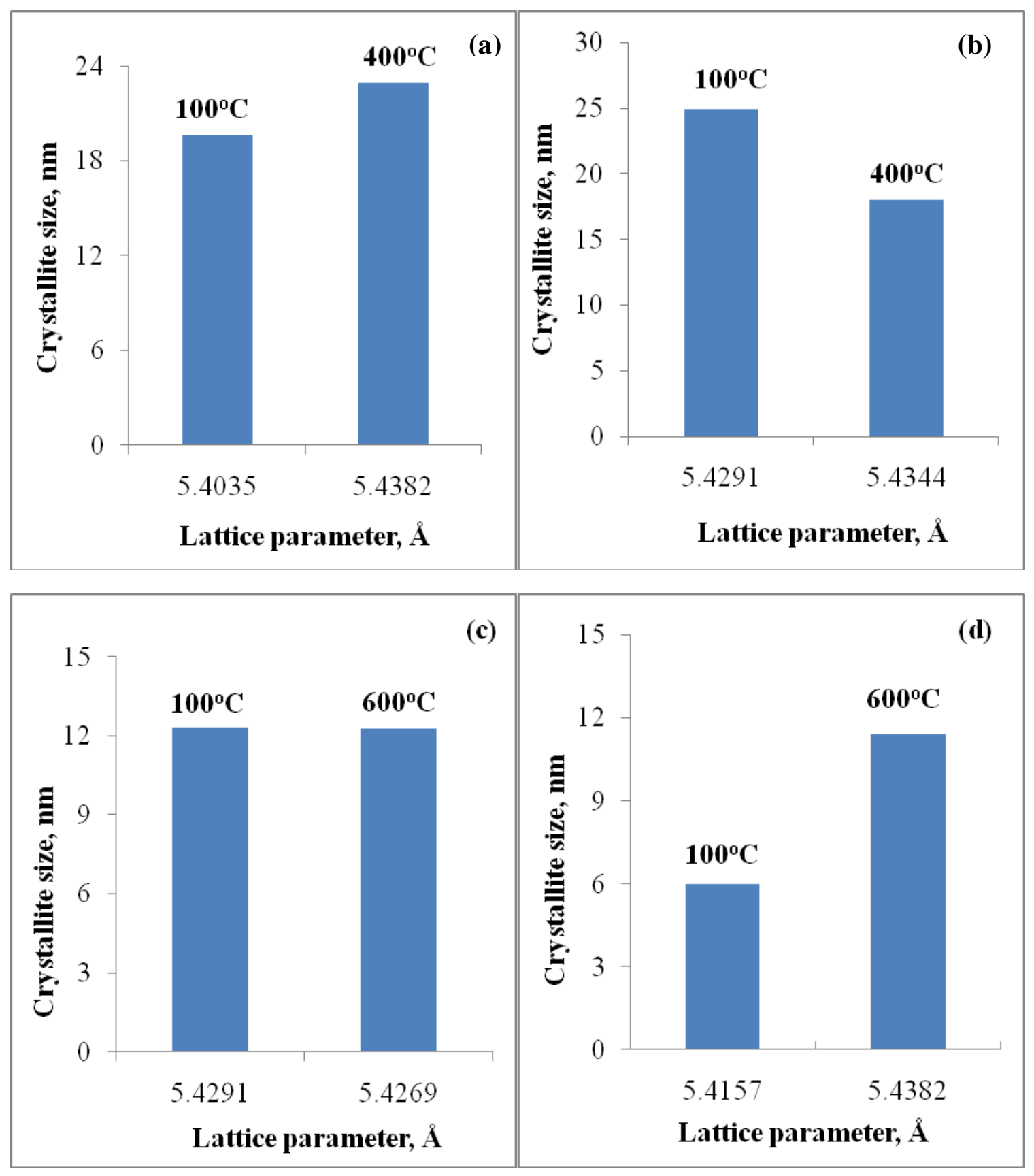

Figure 4.18- Crystallite size as a function of calcination temperatures for nanoplates by $\mathrm{H}_{2} \mathrm{O}_{2}(\mathrm{a})$, nanocubes (b), nanoplates by $\mathrm{NH}_{4} \mathrm{OH}(\mathrm{c})$, and nanorods (d).

By comparing the crystallite size and surface area of ceria nanorods, nanoplates, and nanocubes: nanoplates have high surface area with respect to their crystallite size while nanocubes exhibit high crystallite size at low surface area. 
Theoretically, BET specific surface area should increase with the decrease in crystallite size (Tok, 2007). However, this theory only applies to nanorods and nanoplates. In the case of nanocubes, low BET surface area can be accounted for the effect of agglomeration. The agglomerations of these morphologies can be observed in the TEM images described earlier. Table IV-VIII presents the comparison of the surface area with the crystallite size. On the other hand, Figure 4.19 illustrates the concentration of $\mathrm{Ce}^{3+}$ as a function of lattice parameter. Higher values of $\mathrm{Ce}^{3+}$ ions lead to a larger lattice strain and, consequently, an increase in the lattice parameter of the particles (Deshpande, 2005). Though, in this study, high concentration of $\mathrm{Ce}^{3+}$ shows low lattice parameter. This is due to high oxygen vacancies which can induce the lattice parameter to change.

TABLE IV-VIII

BET SPECIFIC SURFACE AREA AND CYRSTALLITE SIZE OF DIFFERENT $\mathrm{CeO}_{2}$ SHAPES

\begin{tabular}{ccccc}
\hline \multirow{2}{*}{$\begin{array}{c}\text { Precursor } \\
\text { Shape }\end{array}$} & $\mathrm{H}_{2} \mathrm{O}_{2}$ & $\mathrm{NH}_{4} \mathrm{OH}$ & $\mathrm{NaOH}-6 \mathrm{M}$ & NaOH-9M \\
\cline { 2 - 5 } & Nanoplate & Nanoplate & Nanocube & Nanorod \\
\cline { 2 - 5 } BET surface area $\left(\mathrm{m}^{2} / \mathrm{g}\right)$ & 95.11 & 62.07 & 16.55 & 16.74 \\
\cline { 2 - 5 } Crystallite size $(\mathrm{nm})$ & 24.92 & 12.30 & 19.65 & 5.97 \\
\hline
\end{tabular}




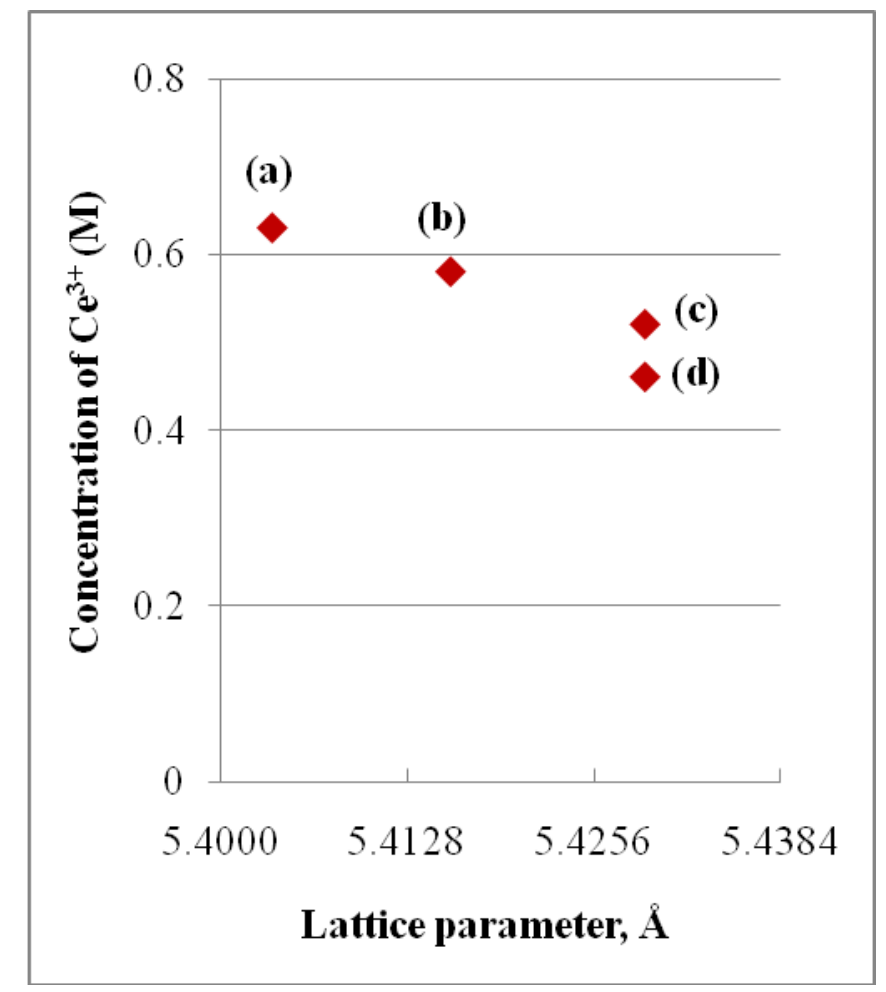

FIGURE 4.19 - Concentration of $\mathrm{Ce}^{3+}$ as a function of lattice parameter for $\mathrm{CeO}_{2}$ nanocubes (a), nanorods (b), nanoplates by $\mathrm{NH}_{4} \mathrm{OH}$ (c), and nanoplates by $\mathrm{H}_{2} \mathrm{O}_{2}$.

In summary, from all the characterizations performed to the synthesized $\mathrm{CeO}_{2}$ nanomaterials, we can conclude that the precursors and reaction parameters have a significant effect on the morphology of ceria. Nanoplates, nanorods and nanocubes presented different and unique properties. To enhance catalytic performance, $\mathrm{CO}$ oxidation is an important process in the three-way catalysis. In order to design and synthesize $\mathrm{CeO}_{2}$ nanostructured catalyst, decrease in the less reactive crystal planes and increase in the more reactive ones is needed to optimize the desired structure of the active sites. However, it has been a very difficult task for most of the practical catalysts (Kung, 2003). In general, high-surface area nanocatalytic materials exhibiting numerous crystal faces, edges, and corners, which are conventionally considered active sites for the 
adsorption of reactants (Terribile, 1997; Daturi, 2000 and Stoimenov, 2003), should generate better catalytic performance.

Thus, it is reasonable to consider that the different catalytic properties of various $\mathrm{CeO}_{2}$ nanomaterials may occur from their morphologies and sizes. The $\mathrm{CO}$ oxidation activity of $\mathrm{CeO}_{2}$ is strongly influenced by the crystal planes due to their different ability of creating oxygen vacancies which are the key point for the $\mathrm{CO}$ oxidation. In the present study, the frequently exposed crystal plane in $\mathrm{CeO}_{2}$ nanoplates, nanorods and nanocubes is (111) plane. The (111) is the most stable surface which has the lowest surface energy (Lundberg, 2004), followed by (110), (100), and (211). Sayle et al. (2002) found that (100) is more reactive and important catalytically as compared with either (110) or the (111) plane. Previous computer modeling demonstrates that less energy is required to form vacancies on (100) than that on (110) and (111). This results suggest that the exposure of more reactive (100) surfaces should facilitate the formation of oxygen vacancies and enhance the $\mathrm{OSC}$ (oxygen storage capacity) of $\mathrm{CeO}_{2}$ (Mai, 2005). Lundberg et al. (2004) found that the more exposure of (100) surfaces in ceria can greatly enhance its $\mathrm{CO}$ activity.

This research shows that ceria nanoplates synthesized with $\mathrm{H}_{2} \mathrm{O}_{2}$ and $\mathrm{NH}_{4} \mathrm{OH}$ are mesoporous and have higher surface area than nanocubes and nanorods. Nanorods have compatible surface area as nanocubes synthesized with $\mathrm{NaOH}$, however, they have more exposed crystalline planes (111), (200), and (220) than nanocubes and nanoplates. To provide active sites for catalytic reactions, it is necessary that the exposed planes with higher surface energy could be generated and stabilized (Zhou, 2005). We found that nanorods have also higher concentration of $\mathrm{Ce}^{3+}$ than nanoplates which is 
important for OSC and redox reactions. Nanorods also have smaller crystallite size. The XPS, BET and XRD results in this thesis elucidate that nanorods are better catalyst for CO oxidation and OSC (Mai 2005, Zhou 2005, Tana 2009). 


\section{CONCLUSIONS}

The selection of precursors $\left(\mathrm{H}_{2} \mathrm{O}_{2}, \mathrm{NaOH}\right.$ and $\left.\mathrm{NH}_{4} \mathrm{OH}\right)$ in the synthesis of ceria has yielded different results in terms of crystallite size, crystallinity, particle size, and specific surface area and oxygen vacancy. $\mathrm{CeO}_{2}$ nanoplates, nanocubes, and nanorods were studied by TEM, BET specific surface area, XPS and XRD. Nanoplates $\left(\mathrm{H}_{2} \mathrm{O}_{2}\right)$ and nanorods had a crystallite size range of $22-25 \mathrm{~nm}$ and 5-11 nm, respectively. The crystallite size was proportional to the calcination temperature and lattice parameter. Nanocubes' crystallite size decreased with the increase of calcination temperature and lattice parameter while nanoplates $\left(\mathrm{NH}_{4} \mathrm{OH}\right)$ remained constant in the size of $12.3 \mathrm{~nm}$ regardless of temperature and lattice parameter. From TEM, agglomeration is observed in nanoplates. Mesoporous material was found in nanoplates by $\mathrm{H}_{2} \mathrm{O}_{2}$ and $\mathrm{NH}_{4} \mathrm{OH}$, nanorods and nanocubes due to their adsorption-desorption isotherm and pore size distribution. Their pore size was in the range of 7-15 $\mathrm{nm}$ according to BJH adsorption model. $\mathrm{CeO}_{2}$ structures share the same exposing plane (111) and same interplanar dspacings although their lattice parameters were slightly different from each other. Nanoplates with $\mathrm{H}_{2} \mathrm{O}_{2}$ have larger particle size than nanoplates with $\mathrm{NH}_{4} \mathrm{OH}$; nanorods have smaller particle size than nanocubes. After the characterization and analysis, nanorods are considered better catalyst for $\mathrm{CO}$ oxidation and oxygen storage capacity (OSC). 


\section{RECOMMENDATIONS}

It was found that high temperature did not affect the crystal structure of ceria nanoplates synthesized using $\mathrm{H}_{2} \mathrm{O}_{2}$, so it is necessary to conduct synthesis of nanoplates at different concentrations of $\mathrm{H}_{2} \mathrm{O}_{2}$ and observe any significant differences in size and crystal structure. Ceria nanoplates using $\mathrm{NH}_{4} \mathrm{OH}$ need to be studied at higher synthesis temperatures and concentrations of $\mathrm{NH}_{4} \mathrm{OH}$ since is uncertain the effect of higher temperature and concentration on the shape and size of nanoplates. For nanorods and nanocubes, decrease the hydrothermal time to see if the crystal size and structure change. Also, it will be helpful if the precipitates are stored longer before characterization and note if time has a significant effect on the crystal structure of ceria.

As mentioned in other studies, other types of characterizations such as particle size analyzer, FT-IR, and TG-DTA will be helpful to better understand the morphology and particle size of ceria nanostructures. Finally, it is necessary to perform $\mathrm{CO}$ oxidation to find out the catalytic evaluation and oxygen storage capacity by $\mathrm{H}_{2}-\mathrm{TPR}$ in order to understand this behavior. TEM images of ceria nanomaterials after calcination are needed to evaluate their exposing planes. 


\section{APPENDIX 1-RAW DATA}

TABLE A1 - 1

EXPERIMENTAL DATA FOR CERIA NANOPLATES USING H2O2

\begin{tabular}{|c|c|c|c|c|c|}
\hline $\begin{array}{c}\text { Conc. }(\mathbf{m l}) \\
{[\mathbf{0 . 0 5} \mathbf{M}} \\
\mathbf{C e}\left(\mathbf{N O}_{\mathbf{3}} \mathbf{3}_{\mathbf{3}}\right]\end{array}$ & $\begin{array}{c}\text { Conc. } \\
\mathbf{3 0 \%} \\
\mathbf{H}_{\mathbf{2}} \mathbf{O}_{\mathbf{2}}(\mathbf{m l})\end{array}$ & $\begin{array}{c}\text { Color } \\
(\text { Before) }\end{array}$ & $\begin{array}{c}\text { Temperature } \\
\mathbf{(} \mathbf{C})\end{array}$ & $\begin{array}{c}\text { Time } \\
(\mathbf{h r})\end{array}$ & Color (After) \\
\hline 8 & 8 & orangish & 220 & 24 & white \\
\hline 8 & 8 & orangish & 180 & 24 & $\begin{array}{c}\text { milky color } \\
\text { (white) }\end{array}$ \\
\hline 8 & 10 & orangish & 100 & 24 & $\begin{array}{c}\text { white } \\
\text { transparent }\end{array}$ \\
\hline 8 & 8 & orangish & 200 & 3 & $\begin{array}{c}\text { milky color } \\
\text { (white) }\end{array}$ \\
\hline 8 & 8 & orangish & 100 & 24 & white \\
\hline 8 & 8 & orangish & 220 & 24 & white \\
\hline 8 & 8 & orangish & 220 & 24 & white \\
\hline 8 & 10 & orangish & 220 & 24 & white \\
\hline 8 & 8 & orangish & 220 & 24 & white \\
\hline 8 & 8 & orangish & 250 & 3 & white \\
\hline 8 & 8 & orangish & 250 & 12 & white \\
\hline 8 & 10 & orangish & 200 & 24 & white \\
\hline 8 & 8 & orangish & 220 & 24 & white \\
\hline
\end{tabular}

TABLE A1 - 2

EXPERIMENTAL DATA FOR CERIA NANOPLATES USING NH4OH

\begin{tabular}{|c|c|c|c|c|c|}
\hline $\begin{array}{c}\text { Solution }[0.05 \mathrm{M} \\
\left.\mathrm{Ce}\left(\mathrm{NO}_{3}\right)_{3}\right](\mathrm{ml})\end{array}$ & $\begin{array}{c}\mathrm{NH}_{4} \mathrm{OH} \\
(\mathrm{ml}) \\
\end{array}$ & $\begin{array}{c}\text { Color } \\
\text { (Before) }\end{array}$ & $\begin{array}{c}\text { Temperature } \\
\left({ }^{\circ} \mathrm{C}\right)\end{array}$ & $\begin{array}{l}\text { Time } \\
\text { (hr) }\end{array}$ & $\begin{array}{c}\text { Color } \\
\text { (After) }\end{array}$ \\
\hline 10 & 10 & dark orange & 100 & 24 & white \\
\hline 10 & 10 & dark orange & 150 & 24 & white \\
\hline 10 & 10 & dark orange & 150 & 24 & white \\
\hline 10 & 10 & dark orange & 100 & 24 & white \\
\hline 10 & 10 & dark orange & 100 & 24 & white \\
\hline
\end{tabular}


TABLE A1 - 3

EXPERIMENTAL DATA FOR CERIA NANORODS AND NANOCUBES

\begin{tabular}{|c|c|c|c|c|c|c|c|c|c|}
\hline $\begin{array}{c}\text { Weight (g) } \\
{[0.05 \mathrm{M}} \\
\left.\mathrm{Ce}\left(\mathrm{NO}_{3}\right)_{3}\right]\end{array}$ & $\begin{array}{c}\text { DI } \\
\text { Water } \\
(\mathbf{m l})\end{array}$ & $\begin{array}{c}\text { Weight } \\
\text { NaOH } \\
(\mathrm{g})\end{array}$ & $\begin{array}{c}\text { DI } \\
\text { Water } \\
(\mathbf{m l})\end{array}$ & $\begin{array}{c}\text { Conc. } \\
\left.\mathrm{Ce}\left(\mathrm{NO}_{3}\right)_{3}\right] \\
(\mathrm{mol} / \mathrm{L})\end{array}$ & $\begin{array}{c}\mathrm{C}_{\mathrm{NaOH}} \\
(\mathrm{M})\end{array}$ & $\begin{array}{c}\text { Color } \\
\text { (Before) }\end{array}$ & $\begin{array}{c}\mathbf{T} \\
\left({ }^{\circ} \mathbf{C}\right)\end{array}$ & $\begin{array}{l}\text { Time } \\
\text { (hr) }\end{array}$ & $\begin{array}{l}\text { Color } \\
\text { (After) }\end{array}$ \\
\hline 0.8682 & 5 & 0.0123 & 35 & 0.40 & 0.01 & milky & 100 & 24 & white \\
\hline 0.8684 & 5 & 12.6389 & 35 & 0.40 & 9.03 & milky & 100 & 24 & milky \\
\hline 0.8686 & 5 & 5.6823 & 35 & 0.40 & 4.06 & milky & 100 & 24 & $\begin{array}{l}\text { purple } \\
\text { slurry }\end{array}$ \\
\hline 0.8684 & 5 & 2.4543 & 35 & 0.40 & 1.75 & milky & 100 & 24 & $\begin{array}{l}\text { purple } \\
\text { slurry }\end{array}$ \\
\hline 0.868 & 5 & 0.0906 & 35 & 0.40 & 0.06 & $\begin{array}{l}\text { milky } \\
\text { white }\end{array}$ & 100 & 24 & white \\
\hline 0.8688 & 5 & 12.5983 & 35 & 0.40 & 9.00 & milky & 100 & 24 & cloudy \\
\hline 0.868 & 5 & 0.0143 & 35 & 0.40 & 0.01 & white & 100 & 24 & white \\
\hline 0.868 & 5 & 8.4255 & 35 & 0.40 & 6.02 & milky & 100 & 24 & cloudy \\
\hline 0.8683 & 5 & 2.8075 & 35 & 0.40 & 2.01 & milky & 100 & 24 & $\begin{array}{l}\text { purple } \\
\text { slurry }\end{array}$ \\
\hline 0.8701 & 5 & 12.6852 & 35 & 0.40 & 9.06 & milky & 100 & 24 & cloudy \\
\hline 0.8686 & 5 & 12.6855 & 35 & 0.40 & 9.06 & milky & 180 & 24 & white \\
\hline 0.8685 & 5 & 5.6822 & 35 & 0.40 & 4.06 & milky & 100 & 24 & white \\
\hline 0.8689 & 5 & 8.4586 & 35 & 0.40 & 6.04 & milky & 180 & 24 & white \\
\hline 0.8686 & 5 & 12.6842 & 35 & 0.40 & 9.06 & milky & 100 & 24 & white \\
\hline
\end{tabular}




\section{APPENDIX 2 - DECONVOLUTED XPS SPECTRUMS}

Peak and integrated area values are presented in Tables IV-III and IV-IV.

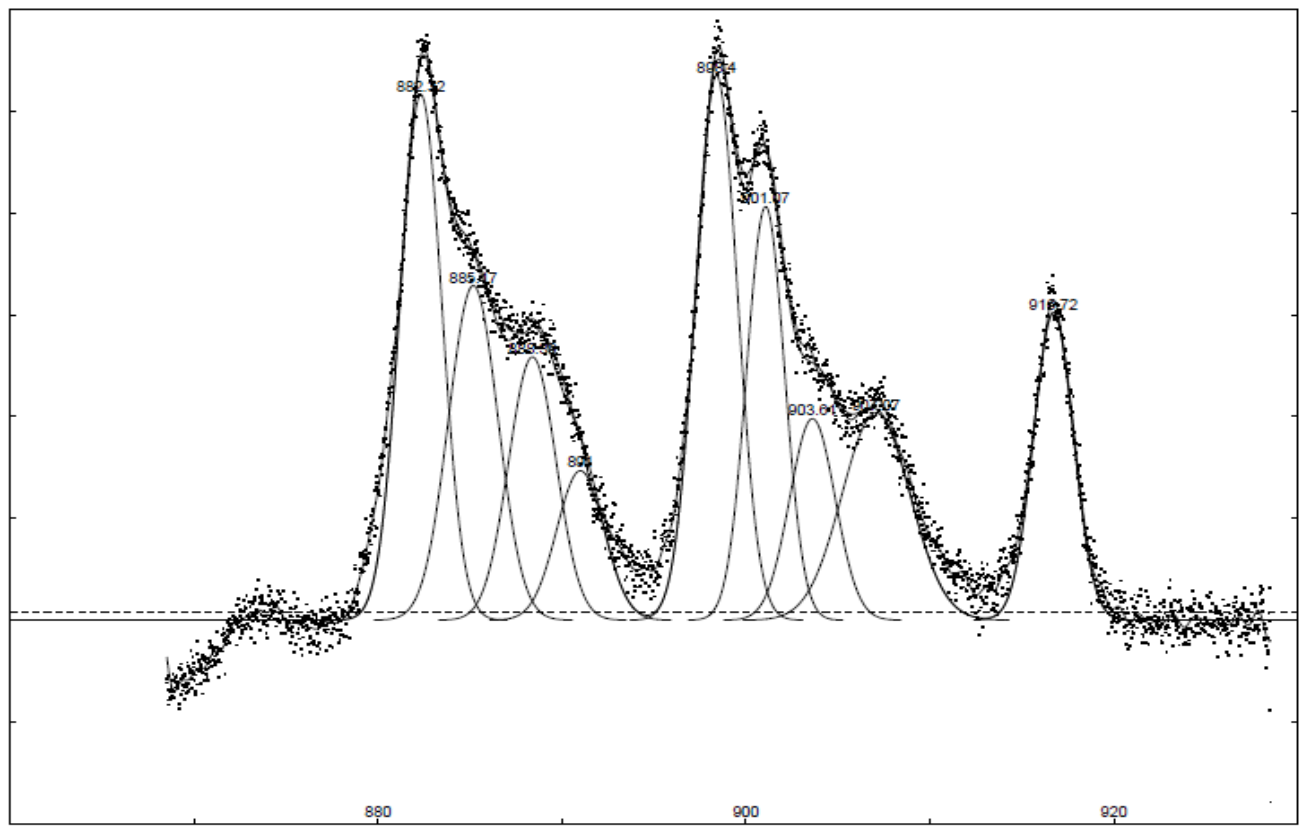

FIGURE A2-1 - $\mathrm{CeO}_{2}$ nanoplates by $\mathrm{H}_{2} \mathrm{O}_{2}$ deconvoluted XPS spectrum

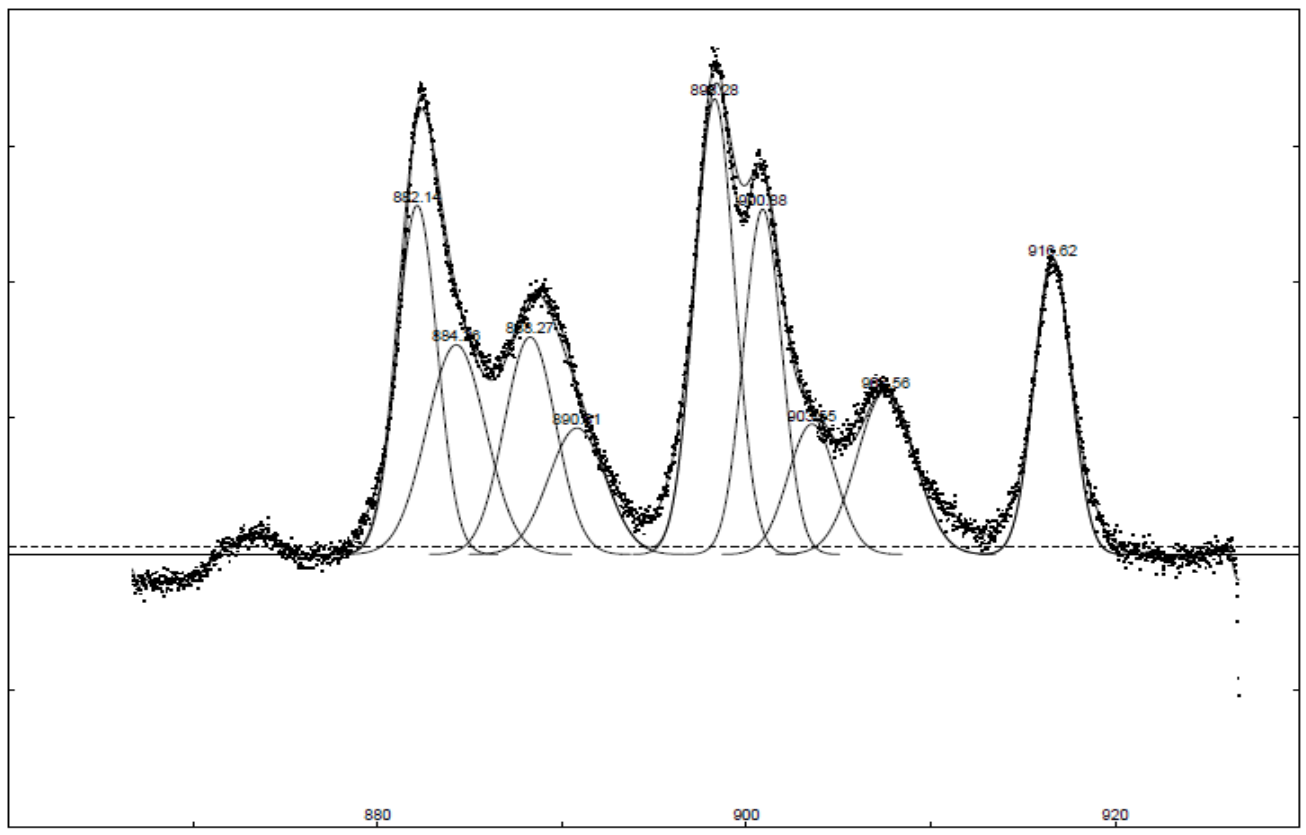

FIGURE A2-2 - $\mathrm{CeO}_{2}$ nanoplates by $\mathrm{NH}_{4} \mathrm{OH}$ deconvoluted XPS spectrum 


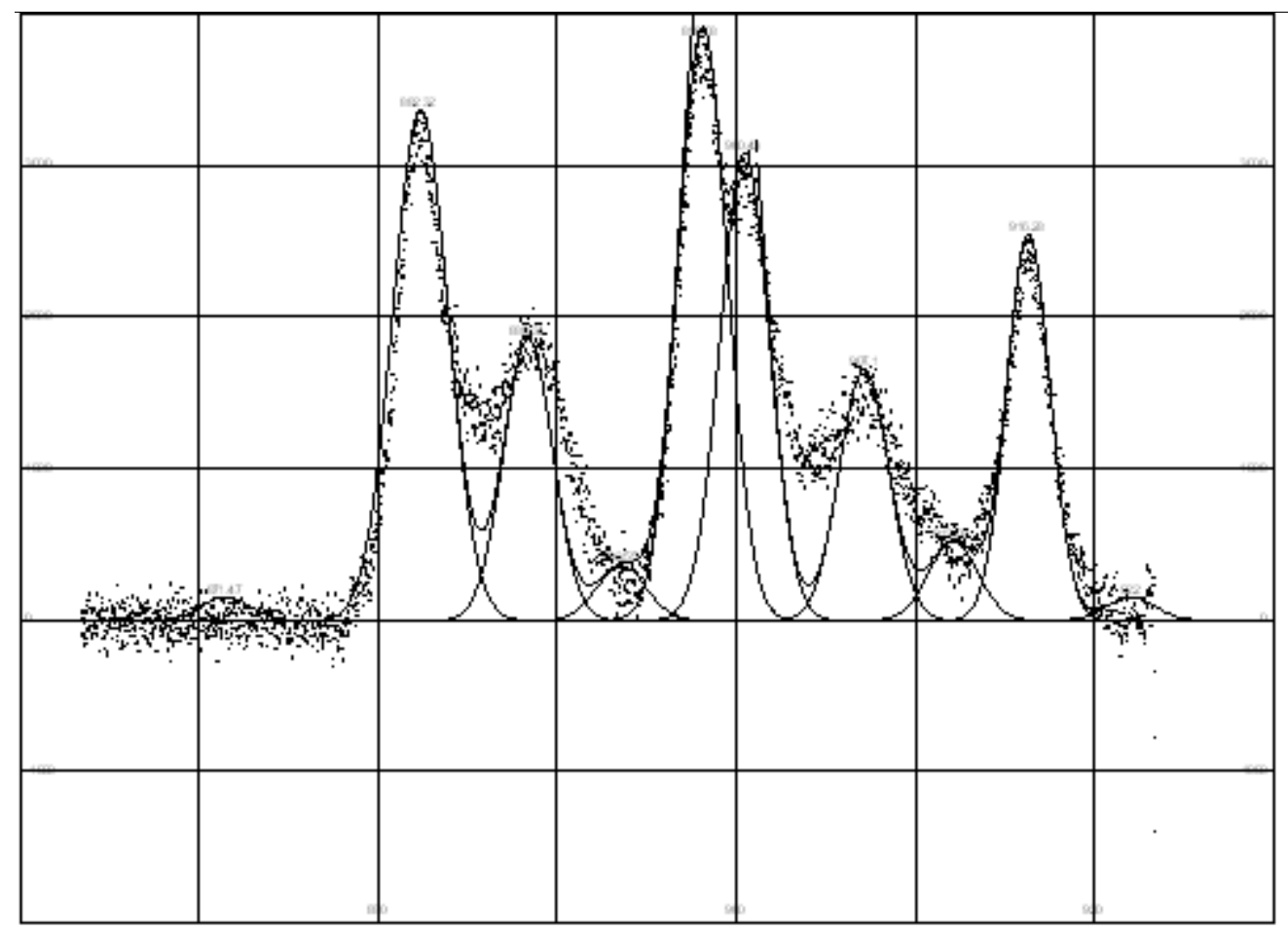

FIGURE A2-3 - $\mathrm{CeO}_{2}$ nanorods deconvoluted XPS spectrum

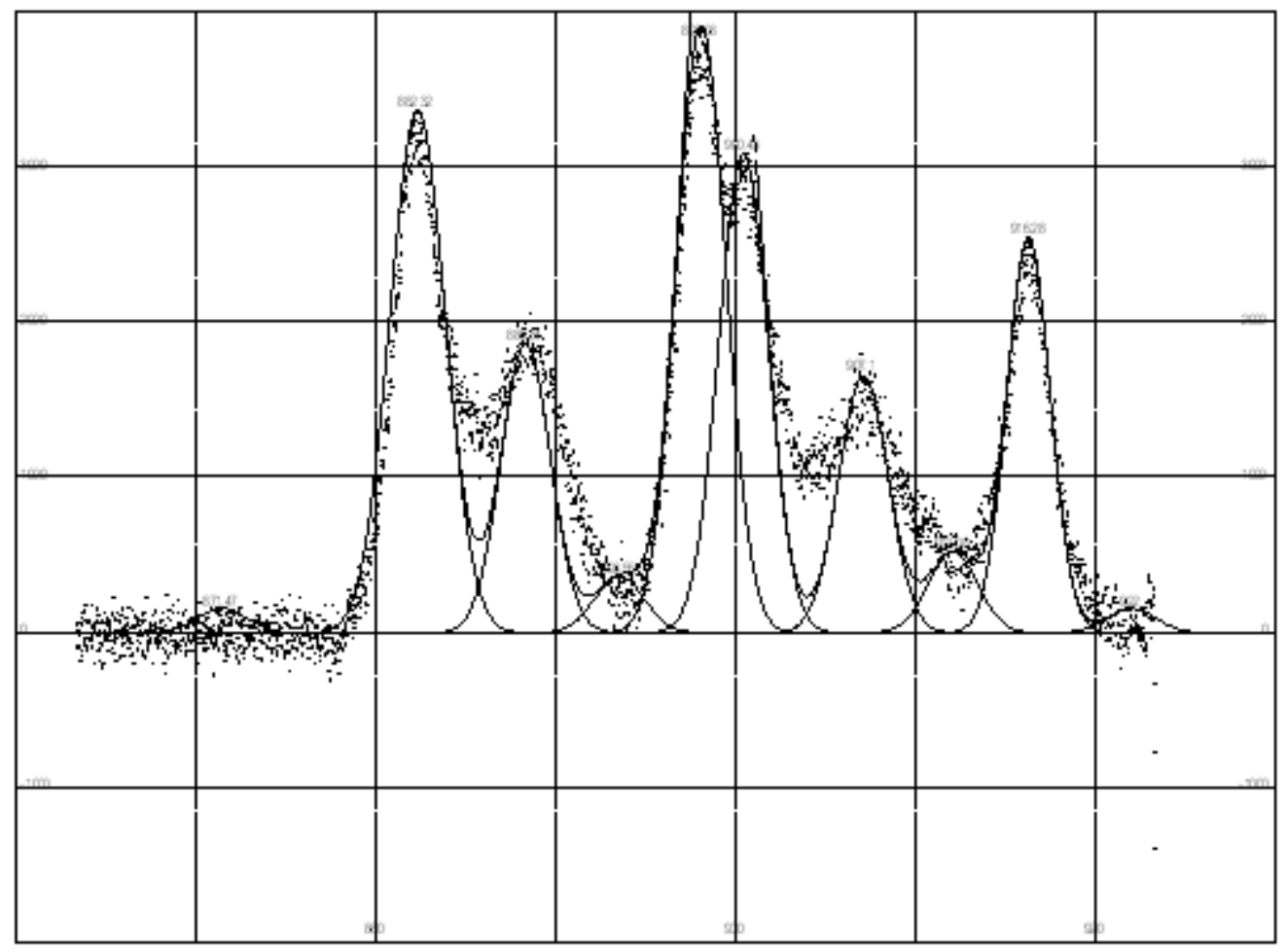

FIGURE A2-4 - $\mathrm{CeO}_{2}$ nanocubes deconvoluted XPS spectrum 


\section{APPENDIX 3: SAMPLE CALCULATION}

The following sample calculation is for determining the concentration of $\mathrm{Ce}^{3+}$ in a nanoplate. The integrated peak area values are presented in Table IV-IV.

$$
\begin{aligned}
& {\left[\mathrm{Ce}^{3+}\right]=\frac{14680+11040+10500+9474.21}{14680+11040+8354.20+15220+10500+6139.87+9474.21+8199.964743 .22}} \\
& {\left[\mathrm{Ce}^{3+}\right]=0.52 \mathrm{M}}
\end{aligned}
$$

Another sample calculation is for determining the crystallite size and lattice parameter in nanoplates using $\mathrm{H}_{2} \mathrm{O}_{2}$ at $100^{\circ} \mathrm{C}$. Figure 4.14 will be needed for the calculation

\section{$\underline{\text { Data Needed }}$}

$$
\begin{array}{ll}
\lambda=1.5406 \AA=0.15406 \mathrm{~nm} & 2 \theta \text { High }=28.61 \\
\mathrm{~K}=0.89 & 2 \theta \text { Low }=28.28 \\
(\mathrm{~h}, \mathrm{k}, \mathrm{l})=(111) & 2 \theta_{\mathrm{B}}=28.45
\end{array}
$$

\section{$\underline{\text { Calculate B }}$}

$\mathrm{B}=(2 \theta$ High $-2 \theta \mathrm{Low}) * \Pi / 180=(28.61-28.28) * \Pi / 180=0.00568$ degree

\section{$\underline{\text { Calculate } \theta_{\mathrm{B}}} \underline{\text { (degree) }}$}

$\theta_{\mathrm{B}}=28.45 * \Pi / 180=0.25($ degree $)$

\section{$\underline{\text { Calculate }} \mathrm{d}_{\underline{h k}}$}

$$
\mathrm{d}_{\mathrm{hkl}}=\frac{1.5406}{2 \times \sin 0.25}=3.31 \AA=0.31 \mathrm{~nm}
$$

\section{$\underline{\text { Calculate } \mathrm{D}_{\underline{h k}}}$}

$D_{h k l}=\frac{0.89 \times 0.15406}{0.00568 \times \cos 0.25}=24.92 \mathrm{~nm}$

\section{Calculate $a$}

$$
a=3.13 \times \sqrt{1^{2}+1^{2}+1^{2}}=5.4291 \AA
$$




\section{REFERENCES}

Carrettin, S, Concepción, P, Corma, A, Nieto, J.M, Puntes, V.F. 2004. Nanocrystalline $\mathrm{CeO}_{2}$ Increases the Activity of $\mathrm{Au}$ for $\mathrm{CO}$ Oxidation by Two Orders of Magnitude. Angewandte Chemie International Edition 43, 2538.

Chen, H.-I, Chang, H.-Y. 2004. Homogeneous precipitation of cerium dioxide nanoparticles in alcohol/water mixed solvents. Colloids and Surfaces. A: Physicochem. Eng. Aspects 242, 61-69.

Daturi, M,. Finocchio, E, Binet, C., Lavalley, J.-C., Fally, F., Perrichon, V., Vidal, H., Hickey, N., Kašpar, J. 2000. Reduction of High Surface Area $\mathrm{CeO}_{2}-\mathrm{ZrO}_{2}$ Mixed Oxides. Journal of Physical Chemistry B 104, 9186-9194.

Deshpande, Sameer, Patil, Swanand, VNT Kuchibhatla, Satyanarayana, Seal, Sudipta. 2005. Size Dependendy Variation in Lattice Parameter and Valency States in Nanocrystalline Cerium Oxide. Applied Physics Letters 87, 133113.

Djuricic, B, Pickering, S. 1999. Nanostructured Cerium Oxide: Preparation and Properties of Weakly-agglomerated Powders. Journal of the European Ceramic Society 19, 1925-1934

Gao, Feng, Lu, Qingyi, Komarneni, Sridhar. 2006. Fast synthesis of Cerium Oxide Nanoparticles and Nanorods. Journal of Nanoscience and Nanotechnology 6, 38123819.

Groe Johan C., Peffer, Louk A.A., Perez-Ramiırez, Javier. 2003. Pore size determination in modified micro- and mesoporous materials. Pitfalls and limitations in gas adsorption data analysis. Microporous and Mesoporous Materials 60, 1-17.

Han, Wei-Qiang, Wu, Lijun, Zhu, Yimei. 2005. Formation and Oxidation State of CeO2x Nanotubes. Journal American Chemical Soc. 127 (37), 12814- 12815.

Hirano, M, Fukuda, Y, Itawa, H, Hotta, Y, Inagaki, M. 2000. Preparation and Spherical Agglomeration of Crystalline Cerium (IV) Oxide Nanoparticles by Thermal Hydrolysis. Journal of American Ceramic Society 83, 1287-1289.

Kung, Harold H., Kung, Mayfair C. 2003. Heterogeneous catalysis: what lies ahead in nanotechnology. Applied Catalysis 246, 193-196 
Lundberg, M., Skårman, B., Wallenberg, L. R. 2004. Crystallography and porosity effects of $\mathrm{CO}$ conversion on mesoporous $\mathrm{CeO}_{2}$. Microporous and Mesoporous Materials 69, 187-195

Mai, H.X, Sun, L.D, Zhang, Y.W., W, Feng, Si, Rui, Zhang, H.P, Liu, H.C., Yan, C.H, 2005. Shape-Selective Synthesis and Oxygen Storage Behavior of Ceria Nanopolyhedra, Nanorods, and Nanocubes. Journal Physics Chemistry, B 109, 24380 .

Madier, Y., Descorme, C., Le Govic, A. M., Duprez, D. 1999. Oxygen Mobility in $\mathrm{CeO}_{2}$ and $\mathrm{Ce}_{\mathrm{x}} \mathrm{Zr}_{(1-\mathrm{x})} \mathrm{O}_{2}$ Compounds: Study by CO Transient Oxidation and ${ }^{18} \mathrm{O} /{ }^{16} \mathrm{O}$ Isotopic Exchange. Journal of Phyical Chemistry B 103 (50), 10999-11006.

Masui,Toshiyuki, Fujiwara, Kazuyasu, Machida, Ken-ichi, Adachi,Gin-ya. 1997. Characterization of Cerium (IV) Oxide Ultrafine Particles Prepared Using Reversed Micelles. Chemistry of Materials 9, 2197-2204.

Moulder, John F., Stickle, William F., Sobol, Peter E., Bomben, Kenneth D. Handbook of $X$-Ray Photoelectron Spectroscopy, edited by Jil Chastain and Roger C. King Jr. (Physical Electronics, Inc, Minnesota 1995), pp. 142-143.

Pan, Chengsi, Zhanga, Dengsong, Shia, Liyi. 2008. CTAB assisted hydrothermal synthesis, controlled conversion and COoxidation properties of $\mathrm{CeO} 2$ nanoplates, nanotubes, and nanorods. Journal of Solid State Chemistry 181, 1298-1306.

Pavasupree, S., Jitputti, J., Ngamsinlapasathian, S., Suzuki, Y., Yoshikawa, Susumu. 2006. Structural, Photocatalytic Activity and Photovoltaic Properties of Mesoporous Anatase Titania Nanopowders Prepared by Hydrothermal Method. Proceedings of the 2nd Joint International Conference on "Sustainable Energy and Environment (Bangkok, Thailand), A-010 (P):1-6

Pavasupree, S., Jitputti, J., Ngamsinlapasathian, S., Suzuki, Y., Yoshikawa, Susumu. 2006. Application of High Surface Area $\mathrm{TiO}_{2}$ Nanosheet in Dye-sensitized Solar Cells. Proceedings of the 2nd Joint International Conference on "Sustainable Energy and Environment (Bangkok, Thailand), A-008(P): 1-6.

Pavasupreea,S., Suzukia, Y., Pivsa-Artb, Sommai, Yoshikawaa, Susumu. 2005. Synthesis and characterization of nanoporous, nanorods, nanowires metal oxides. Science and Technology of Advanced Materials 6, 224-229

Sayle, D. C., Maicaneanu, S. A., Watson, G. W. 2002. Atomistic Models for $\mathrm{CeO}_{2}$ (111), (110), and (100) Nanoparticles, Supported on Yttrium-Stabilized Zirconia. Journal of the American Chemical Society 124 (38), 11429-11439

Seal, S, Barr, T. Experimental Methods in the Physical Sciences, edited by H. Singh Nalwa (Academic, New York, 2001), Chap. 2, pp. 111-190. 
Si,Rui, Zhang, Ya-Wen, You,Li-Ping, Chun-Hua Yan. 2005. Rare-Earth Oxide Nanopolyhedra, Nanoplates, and Nanodisks. Angewandte Chemie International Edition 44, 3256-3260

Sing, K.S.W, Everett, D. H., Haul, R.A.W., Pierotti, R.A., Rouquerol, J.,Siemieniewska, T. 1985. Reporting Physisorption Data for Gas/Solid Systems with Special Reference to the Determination of Surface Area and Porosity. Pure and Applied Chemistry 57 (4), 603-619.

Sun, C. W., Li, H., Wang, Z. X., Chen, L. Q., Huang, X. 2004. Synthesis and Characterization of Polycrystalline $\mathrm{CeO}_{2}$ Nanowires. Chemistry Letters 33, 662.

Tana, Zhang, Milin, Li, Juan, Li, Huaju, Li, Yong, Shen, Wenjie.2009. Morphologydependent redox and catalytic properties of $\mathrm{CeO} 2$ nanostructures: Nanowires, nanorods and nanoparticles. Catalysis Today 148, 179-183.

Tang, Bo, Zhuo, Linhai, Ge, Jiechao, Wang, Guangli, Shi, Zhiqiang, Niu, Jinye. 2005. A surfactant-free route to single-crystalline $\mathrm{CeO}_{2}$ nanowires. Chem. Communications, 3565-3567.

Tarnuzzer, Roy W, Colon, Jimmie, Patil,Swanand, Seal, Sudipta. 2005. Vacandy Engineered Ceria Nanostructures for Protection from Radiation-Induced Cellular Damage. Nano Letters 5, 2573-2577.

Tennyson, Wesley. "X-ray Diffraction: The basics followed by a few examples of data analysis". Internet source, 18 May 2007, available from http://www.nhn.ou.edu/ bumm/NanoLab; accessed 18 May 2007.

Terribile, D., Trovarelli, A., de Leitenburg, C., Dolcetti, G. 1997.Unusual Oxygen Storage/Redox Behavior of High-Surface-Area Ceria Prepared by a SurfactantAssisted Route. Chemistry of Materials 9, 2676-2678

Tian, Zhengrong R., Voigt, James A., Liu, Jun , McKenzie, Bonnie, McDermott, Matthew J. 2002. Biomimetic Arrays of Oriented Helical ZnO Nanorods and Columns. Journal American Chemical Soc. 124 (44), 12954-12955.

Tok, A.I.Y., Du, S.W., Boey, F.Y.C., Chong, W.K. 2007. Hydrothermal synthesis and characterization of rare earth doped ceria nanoparticles. Materials Science and Engineering A 466, 223-229

Trovarelli, A. 1996. Catalytic Properties of Ceria and $\mathrm{CeO}_{2}-$ Containing Materials. Catalysis. Reviews Science Eng. 38, 439. 
Wu, G.S., Xie, T., Yuana, X.Y., Cheng, B.C., Zhang, L.D. 2004. An improved sol-gel template synthetic route to large-scale $\mathrm{CeO}_{2}$ nanowires. Materials Research Bulletin 39, $1023-1028$

Yahiro, H, Baba, Y, Eguchi, K, Arai, H. 1988. High Temperature Fuel Cell with CeriaYttria Solid Electrolyte. Journal of the Electrochemical Society 135, 2077- 2080.

Yang, S.W, Gao, L. 2006. Controlled Synthesis and Self-Assembly of $\mathrm{CeO}_{2}$ Nanocubes. Journal of the American Chemical Society 128 (29), 9330-9331.

Yang, Zhijie, Yang, Yanzhao, Liang, Hui, Liu, Ling. 2009. Hydrothermal synthesis of monodisperse $\mathrm{CeO} 2$ nanocubes. Materials Letters 63, 1774-1777.

Zhang ,Ya-Wen, Sun, Xiao, Si, Rui, You, Li-Ping, Yan, Chun-Hua. 2005. SingleCrystalline and Monodisperse $\mathrm{LaF}_{3}$ Triangular Nanoplates from a Single- Source Precursor. Journal American Chemical Soc. 127 (10), 3260-3261.

Zhou, K.B, Wang, X, Sun, X.M, Peng, Q, Li, Y.D. 2005. Enhanced catalytic activity of ceria nanorods from well-defined reactive crystal planes. Journal of Catalysis 229, 206.

Zhou, X.D, Huebner, W, Anderson, H.U. 2002. Room-temperature homogeneous nucleation synthesis and thermal stability of nanometer single crystal $\mathrm{CeO}_{2}$. Applied Physics Letters 80 (20), 3814-3816.

Zhou, X.D, Huebner, W, Anderson, H.U. 2003. Processing of Nanometer-Scale $\mathrm{CeO}_{2}$ Particles. Chemistry of Materials. 15 (2), 378-382. 
VITA

\section{NITZIA CHEONG NG}

Chemical Engineering Department

J. B. Speed School of Engineering

University of Louisville

Louisville, KY 40292
4103 Blossomwood Dr.

Louisville, KY 40220

n0cheo01@louisville.edu

\section{EDUCATION}

Master of Engineering in Chemical Engineering with Environmental Engineering

Certificate, University of Louisville, Louisville, KY, 2010

Bachelor of Science in Chemical Engineering, University of Louisville, Louisville, KY, 2009

High School Diploma, Instituto Panamericano, Panama City, Panama, 2003

\section{HONORS AND AWARDS}

Awarded international student scholarship from International Center at University of Louisville for Bachelor of Science degree, 2008

Awarded student section award from Society of Women Engineers, University of Louisville, 2009 